University of Louisville

ThinkIR: The University of Louisville's Institutional Repository

Electronic Theses and Dissertations

$12-2010$

\title{
'Complementary' immune evasion by oral pathogen Porphyromonas gingivalis.
}

Jennifer Lynn Krauss

University of Louisville

Follow this and additional works at: https://ir.library.louisville.edu/etd

\section{Recommended Citation}

Krauss, Jennifer Lynn, "'Complementary' immune evasion by oral pathogen Porphyromonas gingivalis." (2010). Electronic Theses and Dissertations. Paper 776.

https://doi.org/10.18297/etd/776

This Doctoral Dissertation is brought to you for free and open access by ThinkIR: The University of Louisville's Institutional Repository. It has been accepted for inclusion in Electronic Theses and Dissertations by an authorized administrator of ThinkIR: The University of Louisville's Institutional Repository. This title appears here courtesy of the author, who has retained all other copyrights. For more information, please contact thinkir@louisville.edu. 


\title{
'COMPLEMENTARY' IMMUNE EVASION BY ORAL PATHOGEN PORPHYROMONAS GINGIVALIS
}

\author{
Jennifer Lynn Krauss
}

A dissertation submitted to the graduate faculty of the University of Louisville School of Medicine in partial fulfillment of the requirement for the degree of

\author{
Doctor of Philosophy
}

University of Louisville, School of Medicine Department of Microbiology and Immunology

December 2010 


\title{
'COMPLEMENTARY' IMMUNE EVASION BY ORAL PATHOGEN PORPHYROMONAS GINGIVALIS
}

\author{
By \\ Jennifer Lynn Krauss \\ B.A. University of Louisville, \\ M.S. University of Louisville, \\ A Dissertation Approved on
}

November 18, 2010

By the following Dissertation Committee

\begin{tabular}{c}
\hline George Hajishengallis (Dissertation Director) \\
\hline Pill Suttles (Co-Mentor) \\
\hline Don Demuth \\
\hline Venkatakrishna Jala
\end{tabular}

Venkatakrishna Jala 
“ No need to hurry.

No need to sparkle.

No need to be anybody

but oneself."

-Virginia Woolf 


\section{DEDICATION}

With admiration and reverence, I'd like to dedicate this work to Henrietta Lacks.

Henrietta, you will always be immortal.

Without your contribution, there would be a huge scientific gap.....

roughly the size of the Milky Way. 


\section{ACKNOWLEDGMENTS}

Mom, this is a work of non-fiction. No names have been changed, no characters invented, no events fabricated. I would like to thank you for your boundless patience, suspension of disbelief and willingness to ask questions about my seeming weird "scientific world", all the while secretly fretting that you'd lost your daughter to fiendish blood letters.

I would like to send out many hugs and kisses to the 'Blair Boys', my four nephews, who keep trying to convince me that I' $m$ in desperate need of a stunt double at work. This would facilitate the time required to fend off evil storm troopers, erect elaborate Lego ${ }^{\circledR}$ structures and god-willing, become the fifth teenage-mutant ninja turtle.

I have no desire to get mushy or sentimental about extending my gratitude towards my mentor; however, some things are just beyond your control. I can't thank you enough, Dr. George Hajishengallis, for guiding me through this process with unwavering dedication and professional integrity. You always cheer for the underdog, and I, was no exception. Despite my speckled scientific past and broken spirit, you took me under your wing and chiseled me into worthy academic contender. I hope I will always make you proud.

I could extend a generic acknowledgement to my committee members, but toss in

the night I won't. I am deeply honored that Pascale Alard and Jill Suttles accepted the 
invitation to be on my committee....for the second time. Both women have held their own in this male-dominated academic arena and paved the way for other female investigators through their mentorship. What's your secret? Indeed, I was also like to extend a Y-chromosome friendly acknowledgement and show appreciation for the contributions made to my project by Don Demuth and Venkatakrishna Jala.

To the power team of the Hajishengallis lab, I will be forever indebted to you for your humble graciousness. Meg, you've rescued me so many times from the conspiring and often, unforgiving universe. From temperamental refrigerators to collapsing roof gutters to flaky and unreliable lawnmowers, you always came to my aid. You even secured my smashed trunk with cables after my car was regrettably pulverized by a lady with shady insurance who thought there would be no harm in running that red light. Ravi, you are truly one of the most sincere and kindest human beings I've ever known. I'd like to thank you for fronting the ransom money when my car was being held hostage by the City of Louisville. Shuang, thanks for always being the voice of reason and calm logic. Last but certainly not least, I'd like to thank Fenge Li for taking such loving and nurturing care of my experimental mice. 


\section{ABSTRACT \\ 'COMPLEMENTARY' IMMUNE EVASION BY ORAL PATHOGEN PORPHYROMONAS GINGIVALIS}

\section{Jennifer Lynn Krauss}

\section{November 18, 2010}

Complement, an early recognition system of innate immunity that senses local tissue damage and infection, cross-talks with and regulates other signaling systems, including Toll-like receptor (TLR) pathways. In the context of periodontitis, destructive inflammation and disease promotion are associated with extensive and synergistic activation of TLRs and complement within the chronically inflamed periodontium. The virulence of the periodontal pathogen Porphyromonas gingivalis is dependent, at least in part, upon its ability to use sophisticated stealth and sabotage tactics to undermine innate immunity. Intriguingly, although this pathogen can modulate TLR2 signaling and suppress specific aspects of complement activation (126), it proactively generates an active complement fragment (C5a) through limited degradation of the fifth complement component (C5) by virtue of its $\mathrm{C} 5$ convertase-like activity. We hypothesized that this seemingly counterproductive action may provide a survival advantage; permitting $P$. gingivalis to instigate a subversive crosstalk between TLR2 and C5aR. Our work supports this hypothesis by demonstrating that $\mathrm{C} 5 \mathrm{a}$ exposure promoted a synergistic rise of intracellular cAMP and impaired the ability of macrophages to destroy $P$. gingivalis. The cAMP synergy strictly required TLR2 signaling and a pertussis toxin- and 
thapsigargin-sensitive C5a receptor pathway, whereas protein kinase A and glycogen synthase kinase-3 $\beta$ acted as downstream effectors. Antagonistic blockade of the C5a receptor abrogated this evasive strategy and may thus have important therapeutic implications in treating periodontal disease. This first demonstration of complementTLR crosstalk for immunosuppressive cAMP signaling indicates that pathogens may not simply undermine complement and/or TLRs as separate entities, but may also exploit their crosstalk pathways. 


\section{TABLE OF CONTENTS}

\section{PAGE}

DEDICATION ...................................................... iv

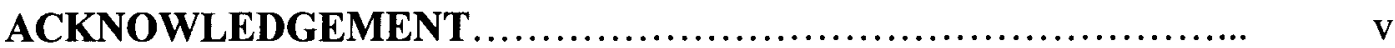

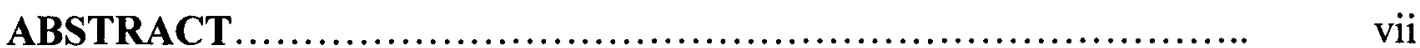

LIST OF FIGURES................................................. xii

\section{CHAPTER 1: INTRODUCTION}

Innate immunity: its role in periodontal disease .................. 1

Complement and TLRs: a potential for crosstalk .................. 3

Periodontitis, associated bacteria, and complement/TLR immunity

Porphyromonas gingivalis: master of subversion................... 12

Neutralization of complement action........................... 13

Evasion and subversion of TLRs...................................... 15

Exploitation of crosstalk interactions between TLRs

and complement.

\section{CHAPTER 2: MATERIALS AND METHODS}

Materials and reagents........................................ 25

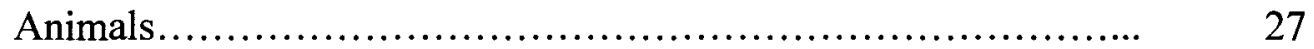

Culturing of bacterial strains ................................. 27

Oral gavage model............................................... 27

Subcutaneous chamber model.................................. $\quad 28$

Intracellular survival assay in murine macrophages................. $\quad 28$ 
Cell signaling and activation assays...................................... $\quad 29$

Intraperitoneal infection.................................... $\quad 29$

Quantitative real-time PCR............................................................ 30

Confocal microscopy...................................... $\quad 30$

Fluorescence resonance energy transfer (FRET) ................. 30

Statistical analysis............................................ 31

\section{CHAPTER 3: MOUSE MODELS OF PERIODONTAL HOST-PATHOGEN INTERACTION AND INFLAMMATION}

Introduction.................................................... $\quad 32$

Inflammatory periodontal bone loss:

the oral gavage model.................................... 33

Host cell-periodontal bacteria interactions:

the subcutaneous chamber model.......................... $\quad 35$

Results................................................. 37

Oral gavage model................................... $\quad 37$

Subcutaneous chamber model............................... $\quad 37$

Discussion........................................................ $\quad 40$

\section{CHAPTER 4: MICROBIAL HIJACKING OF COMPLEMENT-TOLL-LIKE RECEPTOR CROSSTALK}

Introduction................................................ 42

Results...................................................... 43

C5a and subversion of macrophage function............... 43

C5a immunosubversive effects are strictly dependent on cAMP-PKA signaling.....................................

In vivo exploitation of $\mathrm{C} 5 \mathrm{aR}$ signaling for inhibition of nitric oxide and promotion of microbial survival. 
Synergistic activation of the cAMP-PKA pathways

requires C5aR-TLR2 crosstalk........................... 51

Discussion........................................................... 58

\section{CHAPTER 5: THE C5A RECEPTOR IMPAIRS IL-12 DEPENDENT CLEARANCE OF PORPYROMONAS GINGIVALIS AND IS REQUIRED FOR THE INDUCTION OF PERIODONTAL DISEASE}

Introduction............................................... $\quad 62$

Results.................................................... 64

$P$. gingivalis proactively and selectively inhibits

IL-12p70 production via C5aR-TLR2 crosstalk.

C5aR signaling in vivo differentially regulates

$P$. gingivalis-induced cytokine responses.............................

C5aR-mediated inhibition of IL-12p70 promotes

$P$. gingivalis survival in vivo.

Comparison of $\mathrm{C} 5 \mathrm{a}$ and $\mathrm{C} 5 \mathrm{a}^{\mathrm{desArg}}$ in regulating

IL-12p70 and other macrophage activities....

C5aR mediates periodontal bone loss

Discussion

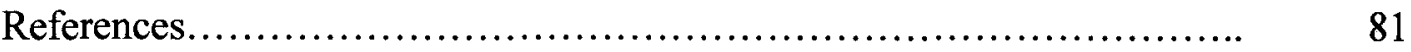

Curriculum vitae ...................................................... 98 


\section{LIST OF FIGURES}

\section{FIGURE}

1. Activation pathways of complement.................................. 6

2. Microbial ligand specificities of human Toll-like receptors.............. 8

3. Evasion or subversion of Toll-like receptor activation by Porphyromonas gingivalis...................................................

4. Crosstalk pathways between Toll-like receptors and complement in $P$. gingivalis activated macrophages..................................

5. Oral gavage model of Porphyromonas gingivalis-induced mouse periodontitis.

6. Subcutaneous chamber model....................................... $\quad 36$

7. Recovery of total anaerobic bacteria from oral gavage model............. 38

8. Analysis of chamber exudate from $P$. gingivalis-challenged subcutaneous chamber model........................................

9. Immunosubversive effects of C5a on P. gingivalis-challenged macrophages

10. C5a-mediated inhibition of nitric oxide production and promotion of $P$. gingivalis survival is cAMP and PKA dependent....

11. P. gingivalis exploits $\mathrm{C} 5 \mathrm{aR}$ signaling to inhibit nitric oxide production and promote its survival in vivo

12. Synergistic activation of the cAMP-PKA pathway requires C5aR-TLR2 crosstalk

13. Lipid raft recruitment and co-localizaion of C5R and TLR2 in macrophages challenged with $P$. gingivalis.... 
14. TLR2 and C5aR signaling synergize to subvert macrophage killing of $P$. gingivalis in a PKA-dependent fashion.........................

15. C5aR signaling inhibits TLR2-dependent IL-12p70 induction in $P$. gingivalis-activated macrophages............................. 66

16. C5aR signaling regulates $P$. gingivalis-induced and TLR2-dependent cytokine production in vivo...

17. Inhibition of $\mathrm{C} 5 \mathrm{aR}$ signaling promotes the in vivo clearance of

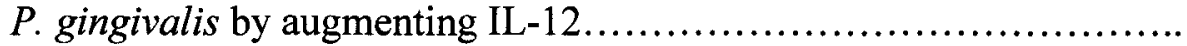

18. Comparative modulatory effects of C5a and C5a ${ }^{\text {desArg }}$ on IL-12p70 production and antimicrobial activities in $P$. gingivalis-challenged macrophages......................................................

19. Comparison of $\mathrm{C} 5 \mathrm{a}$ and $\mathrm{C} 5 \mathrm{a}^{\text {desArg }}$ in intracellular $\mathrm{Ca}^{2+}$ mobilization.....

20. C5aR and TLR2 deficiencies protect against periodontal bone loss...... 


\section{CHAPTER ONE: INTRODUCTION}

\section{Innate immunity: its role in periodontal disease}

Innate immunity is a phylogenetically ancient system of host defense and represents the inherited resistance to infection (70). Until relatively recently, the innate immune response was viewed as a non-specific and temporary expedient to "buy time" until the activation of adaptive immunity, which comprises the system of $\mathrm{B}$ and $\mathrm{T}$ lymphocytes, each of which expresses antigen receptors of exquisite specificity (34). Although lacking the ability to make such fine structural distinctions, innate immunity is nevertheless endowed with considerable specificity. Indeed, germ-line encoded receptors (collectively known as pattern-recognition receptors) can detect and respond to conserved and generally distinct microbial structures, which are shared by related groups of microorganisms (e.g., lipopolysaccharide of gram-negative bacteria or lipoteichoic acid of gram-positive bacteria) (104). Most importantly, innate immunity is sophisticated enough to make judgments that instruct the initiation and progression of the adaptive immune response (34) (104). In this regard, the acquired specificity of the antigen receptors is not the result of co-evolution with microbes but the outcome of randomly generated gene recombination. Thus, even though the adaptive immune receptors can bind virtually any structure, they have no clue on the biological context of the encountered antigen (i.e., should they respond or not?). This information, however, is 
provided by innate immune mechanisms, which act as mediators between detection of infection and induction of the adaptive response. Not surprisingly, successful pathogens which disarm or subvert host defenses target preferentially innate immunity (36) and particularly central systems such as the complement and the Toll-like receptor (TLR) family of pattern-recognition receptors (88) (137).

In the oral cavity, innate immunity contributes significantly to antimicrobial defense, although inadequate or overexuberant activation of the innate response may lead to oral disease, such as periodontitis (32) (37). In this context, periodontal health represents a dynamic state where pro-inflammatory and antimicrobial activities to control infection are optimally balanced by anti-inflammatory mechanisms to prevent unwarranted inflammation (37). This homeostatic balance may be disrupted, however, either by genetic defects in host immunity or by pathogens that undermine host defense mechanisms (37) (79) (83). It should be noted that pathogen-instigated immune suppression of specific pathways and destructive inflammatory responses in the periodontium are not necessarily mutually exclusive, since the latter may arise as a consequence of the inability to control infection (49).

The ability of periodontal pathogens to persist and establish chronic infections suggests that they may have evolved ways to disarm these defense mechanisms or subvert them to their advantage. Understanding the mechanisms of periodontal hostpathogen interplay can offer important insights into the disease pathogenesis and facilitate the rational design of therapeutic interventions. 


\section{Complement and TLRs: a potential for crosstalk}

The term "complement" was coined by Paul Ehrlich in the late 1890s to describe a heat-sensitive activity in serum that is complementary to that of antibody in causing lysis of bacteria (142). In line with this early view, the complement system has been traditionally considered as an antimicrobial enzyme system found in serum and inflammatory exudates like the gingival crevicular fluid (4) (109) (122). However, it is now well appreciated that complement constitutes a fundamental component of innate immunity, by virtue of its ability to orchestrate critical events during immune and inflammatory responses, including regulation of other innate or adaptive immune pathways (63) (90) (99) (165).

The triggering of the complement system involves sequential activation and proteolytic cleavage of a series of serum proteins, leading to recruitment and activation of inflammatory cells, microbial opsonization and phagocytosis, and direct lysis of targeted pathogens (99). In addition to the serum components, the integrated complement system also includes membrane-bound regulators and receptors for interactions with various mediators of the immune system. Complement activation can proceed through three distinct mechanisms, namely the classical, lectin, or alternative pathways (99) (Fig. 1). All three pathways converge at a central step, involving activation of the third component of complement (C3) by pathway-specific C3 convertases (87) (99). Activation of the classical pathway is initiated by antigen-antibody complexes, whereas the lectin pathway is triggered through interaction of a secreted pattern-recognition receptor (the mannose- 
binding lectin) with specific carbohydrate groups found on the surface of a variety of microorganisms. To ensure fast and immediate response to invading pathogens, the complement cascade is maintained at a low level of activity ("tick-over") by the so-called alternative pathway. This pathway is initiated by spontaneous hydrolysis of $\mathrm{C} 3$ to $\mathrm{C} 3\left(\mathrm{H}_{2} \mathrm{O}\right)$, thereby inducing a conformational change that allows binding to complement factor B and formation of the initial alternative pathway $\mathrm{C} 3$ convertase. This results in rapid turn-over of the alternative pathway, as long as there is no sufficient negative regulation as normally occurs with non-self surfaces (e.g., bacteria). In addition to this mechanism, the alternative pathway can be induced by bacterial lipopolysacharide and lipooligosacharide molecules in a way that strictly requires the participation of the plasma protein properdin (77). The alternative pathway may represent up to $80 \%$ of complement activation (99). In all three pathways, proteolytic cleavage of a series of proteins downstream of $\mathrm{C} 3$ leads to the generation of effector molecules, including opsonins ( $\mathrm{C} 3 \mathrm{~b}$, iC3b) and anaphylatoxins (C3a, C5a). The iC3b fragment is generated by further cleavage of microbe-attached $\mathrm{C} 3 \mathrm{~b}$ and mediates phagocytosis by complement receptor- 3 (Fig. 1). The inflammatory anaphylatoxins $\mathrm{C} 3 \mathrm{a}$ and $\mathrm{C} 5 \mathrm{a}$ activate seven-transmembrane domain G-protein-coupled receptors, known as the $\mathrm{C} 3 \mathrm{a}$ receptor and $\mathrm{C} 5 \mathrm{a}$ receptor (CD88), respectively. A newly identified but modestly characterized alternative receptor for C5a is the so-called C5a receptor-like 2 (C5L2). Originally believed to be an antiinflammatory decoy receptor, C5L2 is now thought to play a novel and distinct role in sepsis (160). Another C5 cleavage product, the C5b, initiates the assembly of the C5b-9 membrane attack complex, which induces lysis of complement-targeted bacteria (99) (Fig. 1). 
TLRs comprise a family of pattern recognition receptors named after their similarity to the Drosophila Toll protein (92) (104). Their discovery in the late 1990s has sparked a resurgent interest in innate immunity. Indeed, the study of TLRs has helped appreciate the economical specificity of the innate immune system and that adaptive immunity did not evolve to replace innate immunity, but rather evolved around it. TLRs are transmembrane glycoproteins comprising an $\mathrm{N}$-terminal leucine-rich repeat domain, a transmembrane region, and a C-terminal cytoplasmic signaling domain (71) (75). These receptors are primarily expressed by first-line professional phagocytes (e.g., neutrophils, macrophages, and dendritic cells) and are thus strategically located for early recognition of microbial pathogens (1). To date, 10 human TLRs have been identified which generally sense and respond to distinct types of microbial structures (Fig. 2). For instance, TLR3 responds to double-stranded viral RNA, TLR4 responds to enterobacterial lipopolysaccharide, TLR5 to bacterial flagellin, and TLR9 to microbial CpG DNA. TLR2 is unique in that it heterodimerizes with signaling partners (TLR1 or TLR6) for detecting and responding to microbial cell wall components, such as lipoteichoic acid, lipoproteins, yeast zymosan or fimbriae (1) (10) (80). 


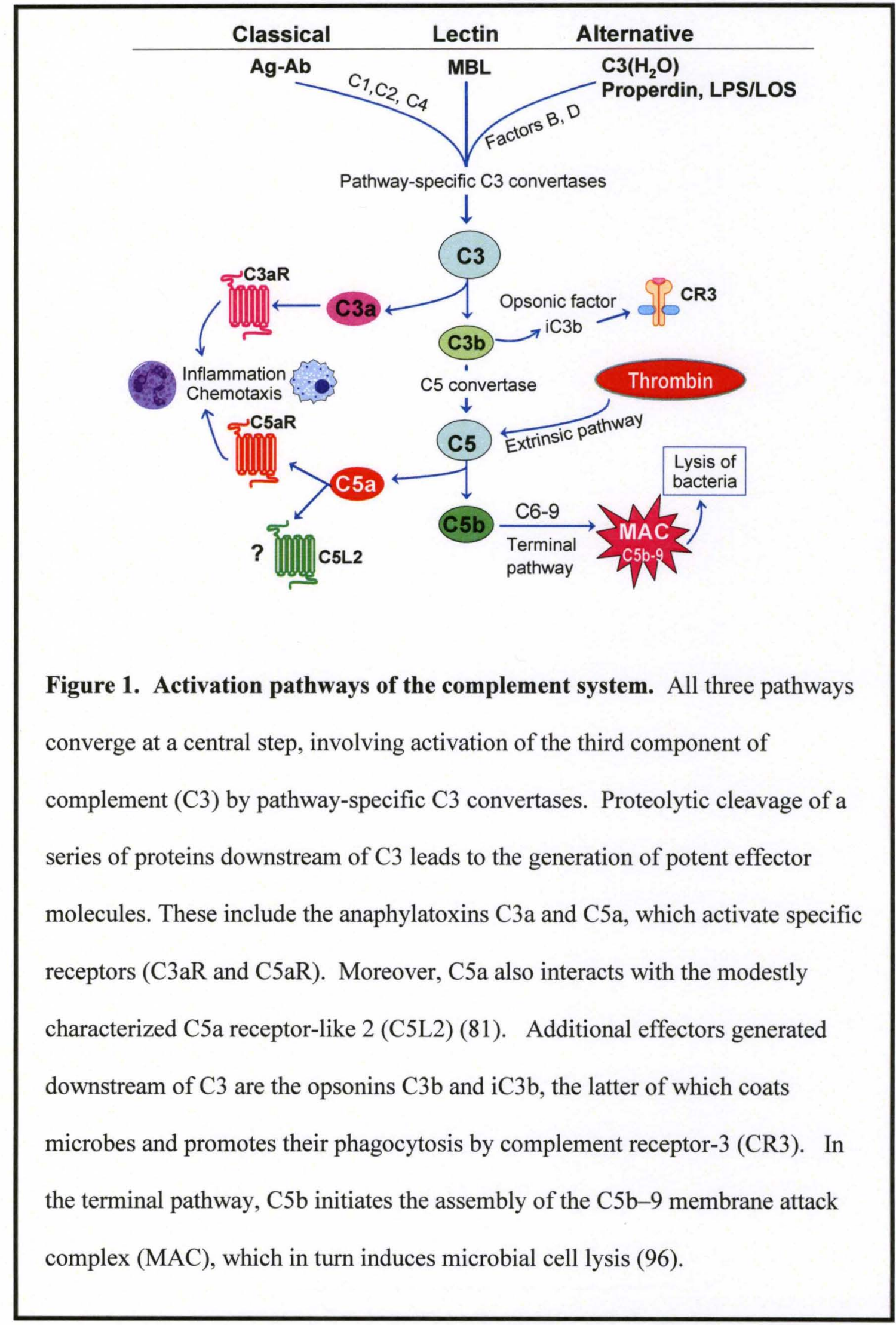


Those TLRs which are mainly responsible for detecting extracellular microbial structures are expressed on the host cell surface (TLRs 1,2, 4, 5, and 6), whereas those specializing in detecting viral or bacterial nucleic acids are appropriately located intracellularly on endocytic vesicles or organelles (TLRs 3, 7, 8 and 9) (Fig. 2). Following ligand binding, TLR signaling is triggered upon recruitment of adaptor proteins to the cytoplasmic TLR domains, which help propagate the signals to downstream kinases and transcription factors. This ultimately leads to induction of immunoregulatory genes that activate or suppress the innate immune and inflammatory response (116) (117). The presence of both common and selective adaptors, in conjunction with the apparent compartmentalization of the TLRs, allows the induction of individual signaling pathways (for at least some TLRs) in addition to a core TLR response (117). It is thus possible that activation of diverse TLR intracellular pathways, dependent upon different TLR ligand specificities, may allow the host to tailor a response that is appropriate against a given pathogen. 


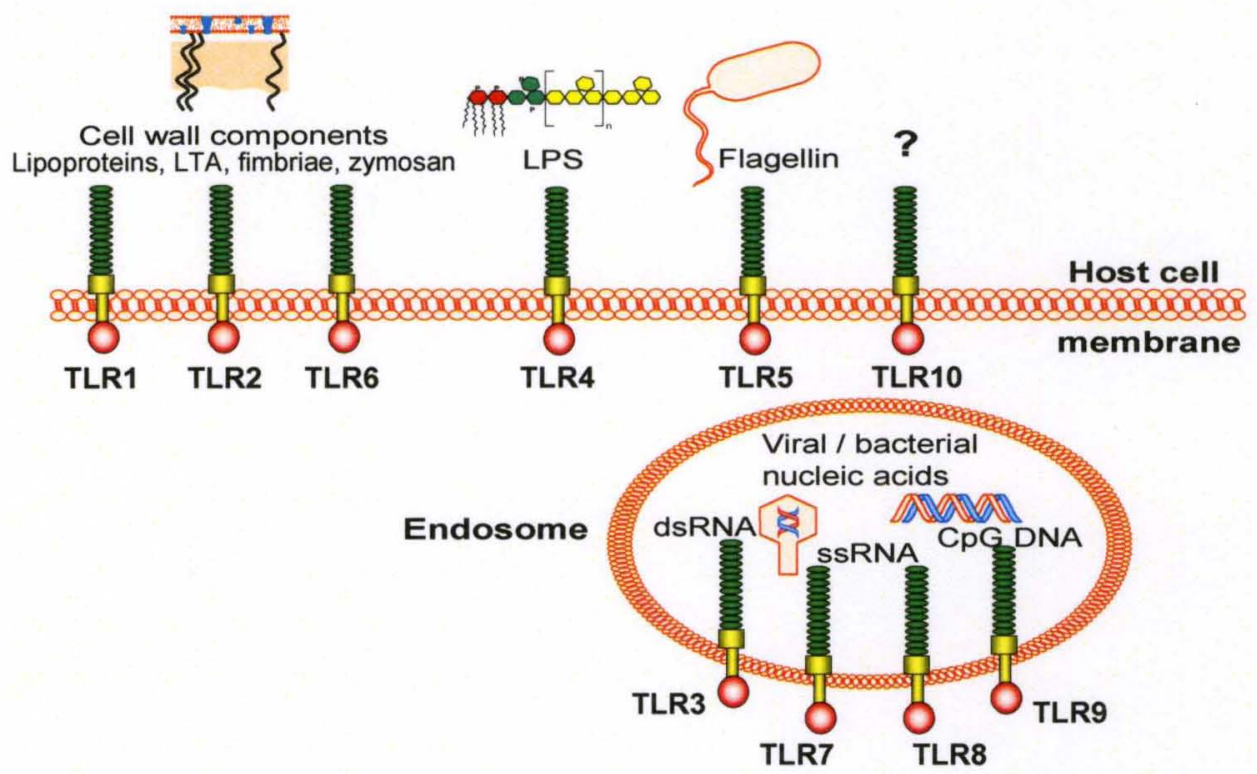

Figure 2. Microbial ligand specificites of human Toll-like receptors (TLRs).

TLR2, in cooperation with its signaling partners, TLR1 or TLR6, detects mostly microbial cell wall components, such as lipoprotein, lipotechoic acid (LTA) or fimbrae (1) (12). TLR4 and TLR5 recognize lipopolysaccharide (LPS) and bacterial flagellin, respectfully, whereas no ligand has been identified for TLR10. Endosomal TLRs such as TLR3, recognizes double-stranded viral RNA, whereas TLR7 and TLR8 recognized single-stranded viral RNA and TLR9 detects microbial CpG DNA. 
Both complement and TLRs are rapidly activated by most pathogens upon encounter with the host, and common microbial molecules like gram-negative bacterial lipopolysaccharide and yeast zymosan can act both as TLR ligands and complement activators. It is conceivable that the coordination of the early innate response would require a crosstalk between the complement and the TLR systems. In this regard, a systematic analysis of crosstalk in intracellular signaling pathways has revealed that a great number of microbe-induced stimuli converge on a relatively limited number of effector signaling pathways (113). In principle, a molecular crosstalk between complement and TLRs could result in cross-regulation of the two systems, including potential synergistic or even antagonistic interactions. These interactions may help enhance host defense or regulate it to prevent excessive inflammatory responses. However, it is also plausible that at least some crosstalk interactions may be instigated by the pathogens themselves for deregulating or modifying the host response in a way that favors their survival. Though only recently has this issue started to be addressed, available evidence indicates bidirectional cooperation between the complement and the TLR system, since complement regulates TLR activation (63) (165), whereas TLR signaling transmodulates the activity of complement receptors (57) (61). 


\section{Periodontitis, associated bacteria, and complement/TLR immunity}

Periodontal disease is possibly the most common chronic disorder of infectious origin in humans, resulting in inflammatory destruction of the tooth-supporting tissues (123). The disease is initiated by certain species of subgingival gram-negative anaerobic bacteria co-existing within dynamic communities of highly-organized architecture (24) (144), originally termed "dental plaque" which predates the more modern term "biofilm" (41) (106). In periodontal health, the ordered structure of the dental plaque biofilm consists predominately of gram-positive, facultative anaerobic bacteria, although the onset of the disease is associated with a shift to gram-negative anaerobic bacteria which begin to colonize the subgingival pocket with greater frequencies (145). Using a colorcoded system, Socransky and colleagues characterized these microbial communities as red, orange, green, purple and yellow complexes, on the basis of cluster analysis, community ordination, and associated disease severity (146). A high prevalence of red complex members such as Porphyromonas gingivalis, Treponema denticola, and Tanerella forsythia correlates strongly with periodontal tissue destruction (65) (146). Prevotella intermedia and Fusobacterium nucleatum, both members of the orange complex, are also associated with various forms of periodontal disease (21) (146) (162).

While the bacteria constitute an essential etiologic factor, it is the host inflammatory reaction to bacterial challenge that primarily mediates periodontal tissue damage (37). This is not to say, however, that the challenge in periodontitis involves simply the issue of controlling the inflammatory response. In a related context, purely anti-inflammatory therapies in sepsis clinical trials have generally failed even if the initial hyper-inflammatory stage was controlled; indeed, many patients would succumb to the 
infection itself at later stages of the disease (134). Therefore, periodontal and other infection-driven inflammatory diseases should be dealt with in ways that address both infection and inflammation. This in turn requires adequate understanding of both protective and destructive aspects of the host response and how pathogens may evade the former and contribute to the latter.

There is strong evidence that complement and TLRs form an important link between infection and various local or systemic autoimmune or inflammatory conditions, such as septic shock, ulcerative colitis, rheumatoid arthritis, systemic lupus erythematosus, atherosclerosis, ischemia/reperfusion injury, and asthma (2) (17) (131) (160). There is also evidence for complement and TLR involvement in periodontal disease. In this regard, a profusion of complement proteins and derived split products are found within the gingival crevicular fluid of periodontitis patients, composing up to $70 \%$ of that found in the serum (127). The functionality of the complement components of the gingival crevicular fluid has been confirmed (18), whereas activated complement fragments have also been detected in the gingival connective tissue (18). Importantly, induction of experimental gingivitis in human volunteers causes progressive elevation of complement cleavage products and correlates with increased microbial plaque accumulation, clinical inflammation, and bleeding on probing (122). These clinical findings suggest a role for complement involvement in periodontal pathogenesis. Moreover, in vitro mechanistic studies have demonstrated complex interactions between periodontal bacteria and the complement system (58) (103) (125).

In addition to elevated complement activity, the inflamed periodontium is infiltrated by TLR-expressing inflammatory cells, whereas healthy gingiva display 
significantly lower levels of TLR expression (110) (111) (129). Besides professional inflammatory cells, gingival epithelial cells and fibroblasts also express TLRs and the level of expression correlates with disease activity (84) (129) (148) (159). In terms of function, TLRs (particularly TLR2 and to a much lesser extent TLR4) have been shown to regulate important immune and inflammatory responses to periodontal bacteria in vivo and in vitro (3) (11) (16) (23) (33) (54) (59) (118) (164).

However, the precise roles, whether protective or destructive, played by the complement and the TLRs in periodontal infection and inflammation are poorly understood. This is partly because these issues have not previously been systematically investigated. Nevertheless, a substantial body of available literature exists, which, if properly synthesized and interpreted, could provide important new insights for future studies.

\section{Porphyromonas gingivalis: master of subversion}

In principle, a host inflammatory response can become destructive when it is deregulated and its magnitude gets out of proportion to the microbial threat, or when it is undermined by pathogens leading to persisting but ineffective inflammation in terms of infection control (37) (49) (83) (135). In the context of periodontitis, $P$. gingivalis could be reasonably characterized as a master of subversion, on the basis of sophisticated sabotage tactics presented below. This gram-negative anaerobic organism expresses an elaborate system of adhesins and proteolytic enzymes (e.g., long and short fimbriae, hemagglutinins, and Arg- and Lys-specific cysteine proteinases known as gingipains), which coordinately enable the pathogen to colonize host tissues and secure critical nutrients (89). As important as these virulence features may be, $P$. gingivalis would 
probably be unable to establish a chronic infection, unless it could have also evolved ways to evade, undermine, or trick the host immune system. This is lucidly exemplified by its capacity to not only subvert both complement and TLR immunity but, moreover, to exploit crosstalk signaling pathways between complement and TLRs.

\section{Neutralization of complement action}

P. gingivalis causes significant inhibition of complement activation, regardless of the initiation pathway involved (classical, lectin, or alternative; Fig. 1), through gingipain-dependent degradation of key complement components, such as the C3 (126) (142). As a consequence, the deposition of opsonins or the membrane attack complex on the pathogen surface is suppressed, unless its gingipain activity is ablated by chemical or genetic means (139) (143). All three gingipain enzymes participate in complement inactivation, although the Arg-specific enzymes (HRgpA and RgpB) are more potent in this regard than the Lys-specific gingipain $(\mathrm{Kgp})(125)$. As a further safety measure, the pathogen appears to hijack physiological mechanisms of inhibiting the complement cascade. In this regard, $P$. gingivalis uses its HRgpA to capture the circulating C4bbinding protein on the bacterial cell surface, thereby acquiring the ability to negatively regulate the classical pathway $\mathrm{C} 3$ convertase (128).

The above summarized findings are consistent with observations that $P$. gingivalis is exquisitely resistant to the lytic action of complement (125) (143). Curiously, however, Arg- and Lys-gingipain mutants are as resistant as the wild-type organism upon their exposure to human serum, even though active complement fragments are readily deposited on their bacterial surface (143). These intriguing observations suggest an inherent protective mechanism that is independent of complement inactivation. Indeed, a 
surface anionic polysaccharide was implicated in this inherent resistance since $P$. gingivalis mutants lacking this structure become readily susceptible to complementmediated lysis (143). Although this anionic polysaccharide may directly confer resistance, the possibility for an indirect effect may not formally be ruled out. In this context, certain pathogens (e.g., Helicobacter pylori and Escherichia coli) acquire resistance against complement lysis by expressing molecules that can bind CD59, a host regulatory protein which inhibits the terminal step of the membrane attack complex formation (88).

It, therefore, appears that $P$. gingivalis may be using a number of different reinforcing mechanisms to ensure its survival in the presence of complement. In this regard, since the inhibitory mechanisms of $P$. gingivalis against complement activation are leaky (125), it makes sense that it has also developed inherent resistance against complement-dependent lysis. However, if the surface anionic polysaccharide is sufficient to provide inherent protection, a plausible question is why the pathogen has additionally evolved ways to suppress a system that cannot kill it. An interesting interpretation is that P. gingivalis may have evolved complement inactivation capacity not for its own protection, but for the benefit of other organisms occupying the same subgingival niche. This action may not be as altruistic as it seems; it may actually offer a survival advantage for $P$. gingivalis, as it depends on other periodontal bacteria for enhanced colonization and full expression of virulence (74) (78) (124). Since $P$. gingivalis is resistant to the lytic action of complement (125) (143), the ability of the complement system to directly offer host protection against this organism is seriously questioned. Nevertheless, it cannot be ruled out that complement activation may indirectly fight this pathogen through 
the recruitment and activation of phagocytic cells. However, $P$. gingivalis may have evolved strategies to diminish or evade its destruction by phagocytes in the presence of complement.

\section{Evasion and subversion of TLRs}

Available evidence suggests that $P$. gingivalis may have also evolved ways to evade or subvert the TLR system, which senses this organism primarily through TLR2, as shown in vitro and in vivo (11) (54). On the other hand, TLR4 appears to play little or no role in cell activation in response to this oral bacterium (11) (54). These observations appear curious given that $P$. gingivalis is a gram-negative organism which expresses a lipopolysaccharide. However, the organism elegantly utilizes specific lipid A 1- and 4'phosphatases and a deacylase which in concert generate a tetra-acylated and dephosphorylated lipid A structure (14). This modification renders the lipopolysaccharide molecule biologically inert, thereby allowing $P$. gingivalis to evade TLR4 activation (14). At the same time, this modification confers protection against polymyxin B and perhaps other cationic anti-microbial peptides (14). Intriguingly, the presence of high concentrations of hemin (an environmental nutrient found in diseased sites) suppresses lipid A 1-phosphatase activity and leads to the production of a monophosphorylated lipid A, which actively antagonizes TLR4 activation (14) (15). Thus, even though $P$. gingivalis may express other molecules with intrinsic TLR4 agonistic activity, TLR4 activation is likely suppressed in the context of the whole organism (Fig. 3), as seen both in vitro and in vivo (11) (54). In this regard, $P$. gingivalis behaves like certain other, non-oral pathogens which have also opted to modify their surface structures so as to escape TLR4 recognition (5) (108) (141). 
The above considerations may explain why TLR2, rather than TLR4, is the predominant TLR involved in $P$. gingivalis recognition. Induction of TLR2 signaling by P. gingivalis requires a signaling partner (TLR1 or TLR6), takes place in membrane lipid rafts where the receptors are recruited ad hoc, and is facilitated by a non-signaling coreceptor (CD14) which constitutively resides in lipid rafts (54). Although the host TLR2 response may be potentially protective, $P$. gingivalis has developed ways to undermine the intended host response. Indeed, the pathogen was shown to manipulate the TLR2 response by instigating a molecular crosstalk between TLR2 and the CXC-chemokine receptor 4 in macrophage lipid rafts (59). Specifically, the binding of $P$. gingivalis fimbriae to $\mathrm{CXC}$-chemokine receptor 4 induces cAMP-dependent protein kinase $\mathrm{A}$ signaling, which in turn suppresses TLR2-dependent activation of nuclear factor- $\mathrm{kB}$ and induction of nitric oxide (Fig. 3) (59). The inhibition of production of this key antimicrobial molecule promotes the ability of $P$. gingivalis to survive in vitro and in vivo (59).

The impact of TLR2 signaling on the ability of $P$. gingivalis to cause experimental periodontitis was examined by two independent studies, which found that TLR2-deficient mice (but not TLR4-deficient or wild-type controls) are protected against periodontal bone loss (11) (42). These findings are consistent with the notion that TLR2 signaling is manipulated by $P$. gingivalis in a way that promotes its virulence. However, an alternative or additional interpretation is that the observed enhanced bone loss in normal mice could be attributed to $P$. gingivalis induction of TLR2-mediated inflammatory osteoclastogenesis (154). 


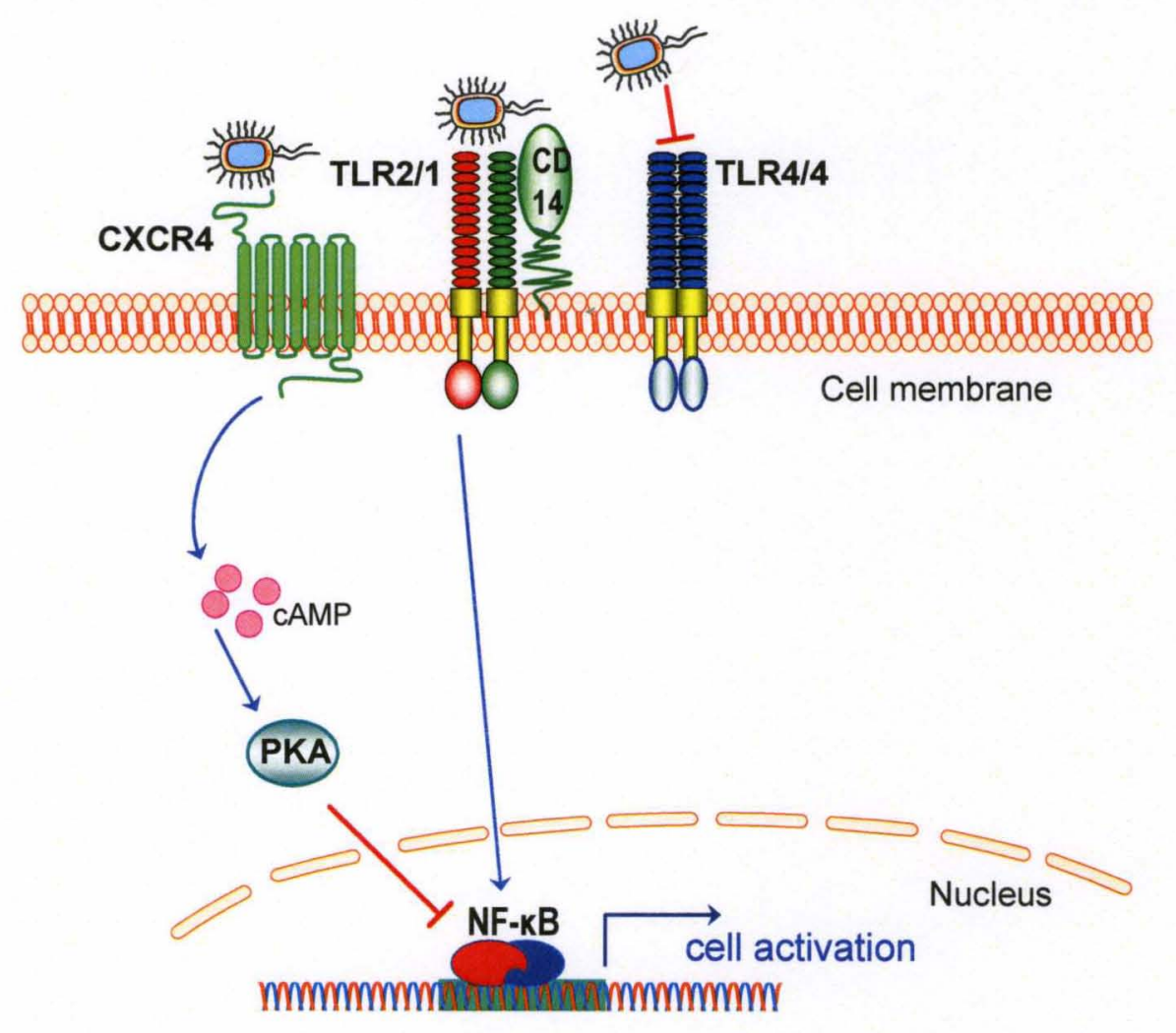

Figure 3. Evasion or subversion of Toll-like receptor (TLR)

activation by Porphyromonas gingivalis. $P$. gingivalis can either evade or actively antagonize TLR4 activation via a modified lipid A structure of its lipopolysaccharide (14) (62). Although activation of TLR2 is not antagonized at the receptor level, $P$. gingivalis instigates a molecular crosstalk between the CXC-chemokine receptor 4 and TLR2. Unlike CD14, which facilitates TLR2 activation by the pathogen (56), CXCR4 suppresses TLR2 signaling via cyclic AMP-dependent protein kinase A (PKA) signaling, which in turn inhibits the activation of nuclear factorkappaB (NF-кB) activation (59) (161). 


\section{Exploitation of crosstalk interactions between TLRs and complement}

TLR2 activation by $P$. gingivalis induces two distinct signaling cascades (57). One of the cascades leads to induction of pro-inflammatory and antimicrobial responses, and represents the pathway that is manipulated by $P$. gingivalis through exploitation of CXC-chemokine receptor 4 . The other cascade represents a pro-adhesive pathway and involves a crosstalk between TLR2 and the complement system (57). Specifically, $P$. gingivalis induces TLR2 inside-out signaling which transactivates the adhesive capacity of complement receptor-3 (62) (Fig. 4). This crosstalk is made possible by the property of complement receptor-3 to cluster with TLRs in lipid rafts of $P$. gingivalis-stimulated cells (54). Once transactivated, however, complement receptor-3 becomes a target of subversive activity by $P$. gingivalis.

Indeed, $P$. gingivalis uses its fimbriae to bind complement receptor-3, which in turn mediates the uptake of this oral pathogen by macrophages (56). Intriguingly, this phagocytic mechanism does not promote the killing of $P$. gingivalis (158), possibly because complement receptor-3 is not linked to vigorous microbicidal mechanisms (135). In contrast, when $P$. gingivalis is phagocytosed by alternative receptors, i.e., when complement receptor-3 is blocked or genetically ablated, the intracellular killing of this pathogen is dramatically enhanced (158).

The interaction of $P$. gingivalis with complement receptor-3 also activates the extracellular signal-regulated kinase $1 / 2$, which in turn selectively inhibits mRNA expression of the p35 and p40 subunits of interleukin-12 (53) (Fig. 4). 


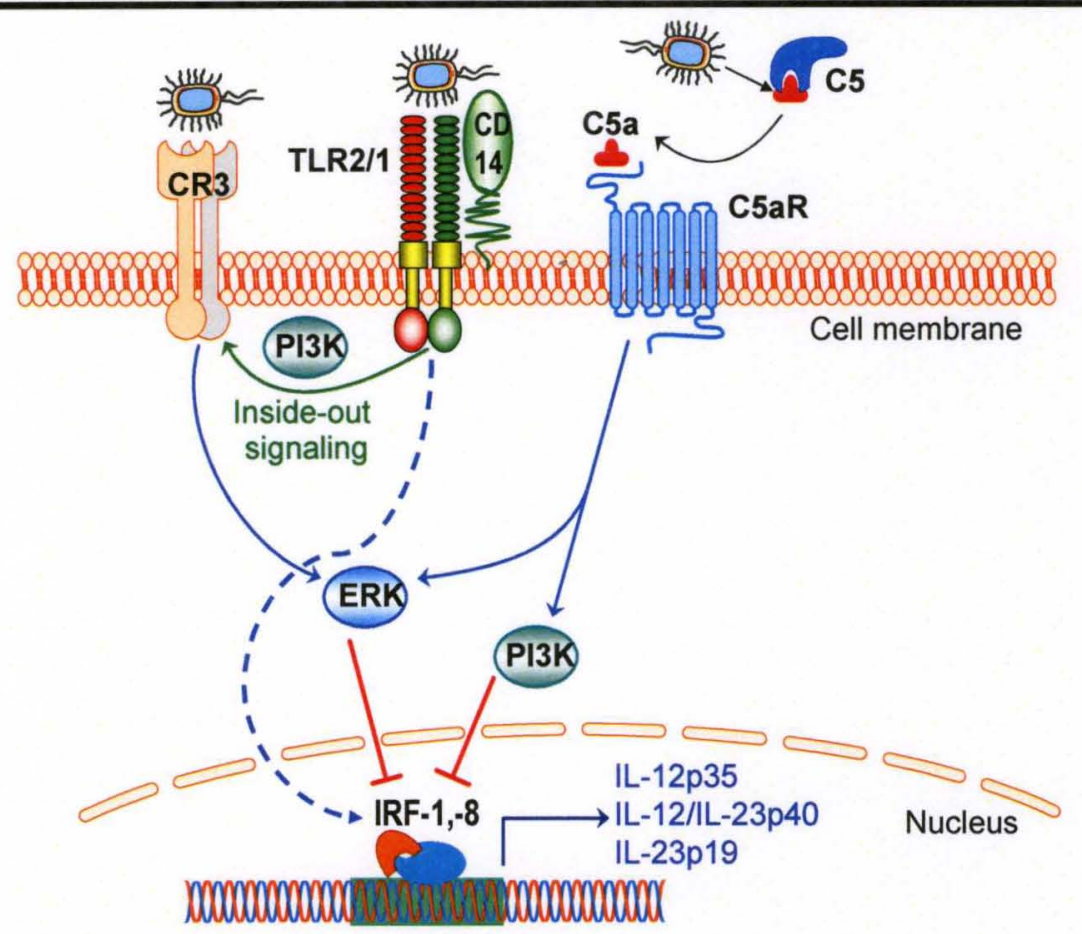

Figure 4. Crosstalk pathways between Toll-like receptors and complement in $\boldsymbol{P}$. gingivalis activated macrophages. TLR2 recognition of $P$. gingivalis, induces PI3K-dependent inside-out signaling which transactivates CR3, thereby inducing ERK1/2 signaling that downregulates the expression of messenger RNA for cytokines of the IL-12 family (53) (54). Moreover, $P$. gingivalis uses its gingipains to attack $\mathrm{C} 5$, consequentely releasing biologically active $\mathrm{C} 5 \mathrm{a}$ that can activate PI3K and ERK1/2 through its receptor (C5aR), in turn suppressing critical transcription factors required for expression of cytokines of the IL-12 family (15) (63) (124). Intriguingly, IL-12 inhibition though these mechanisms results in impaired immune clearance of $P$. gingivalis in vivo (53), suggesting that the pathogen exploits TLR- complement crosstalk signaling to promote its virulence. 
Interleukin-12 (IL-12) is a key cytokine involved in pathogen clearance through regulatory effects on the production of interferon- $\gamma$, which is a potent activator of the macrophage microbicidal capacity (153). Consistent with the above, wild-type mice elicit lower levels of interleukin-12 and interferon- $\gamma$ and display impaired clearance of $P$. gingivalis systemic infection compared to mice that lack complement receptor-3 (53). Similar results are seen after CR3 blockade with a specific antagonist that suppresses $P$. gingivalis induction of periodontal bone loss in mice (53). In brief, there is compelling evidence that complement receptor-3 constitutes an Achilles' heel which confers host susceptibility to $P$. gingivalis infection. In this regard, it seems likely that $P$. gingivalis may have actually co-opted a natural anti-inflammatory mechanism to evade innate immunity. Specifically, complement receptor-3 is heavily committed to phagocytosis of iC3b-coated apoptotic cells, which are not normally recognized as danger (76) (105). This precludes induction of a vigorous host response and, in fact, production of interleukin-12 is inhibited following phagocytosis of apoptotic cells by macrophages (76).

Although $P$. gingivalis inhibits the complement cascade, curiously enough, the pathogen proactively generates one of the active complement fragments. Specifically, all three gingipains (HRgpA, RgpB, and Kgp) act in a C5 convertase-like manner and generate biologically active $\mathrm{C} 5 \mathrm{a}$ through limited degradation of $\mathrm{C} 5$, whereas the $\mathrm{C} 5 \mathrm{~b}$ remnant is functionally inert (125) (161). When C5 is oxidized by hydroxyl radicals (as may occur in the oxidative environment of the inflammatory response) the gingipains generate increased C5a biological activity (31). Furthermore, P. gingivalis may indirectly generate functional $\mathrm{C} 5 \mathrm{a}$ by exploiting the physiological crosstalk between the 
coagulation and the complement systems, which activates the so-called extrinsic pathway (66) (Fig. 1). Indeed, HRgpA and RgpB activate pro-thrombin to form thrombin (68) which, in turn, generates biologically active C5a by acting as a C5 convertase (66) (Fig. 1). Although C5a can potentially play a key role in host defense against infection (46), it seems highly unlikely that $P$. gingivalis uses its enzymes to generate C5a to contribute to its elimination.

An intriguing question, therefore, is whether there is any selective pressure or advantage for $P$. gingivalis to specifically generate $\mathrm{C} 5 \mathrm{a}$, given that this chronically persisting pathogen overall inhibits the complement cascade. A possible scenario is that local generation of excessive levels of C5a could incapacitate the antimicrobial function of gingival crevicular neutrophils rendering them less threatening to $P$. gingivalis. This is because neutrophils become immunologically paralyzed in the presence of high concentrations (10-100 nM) of $\mathrm{C} 5 \mathrm{a}$ and thereby fail to carry out functions such as chemotaxis, phagocytosis, and production of antimicrobial and inflammatory mediators (67) (160). Such immunological dysfunction has been seen both in vitro and in vivo and involves both human and rodent neutrophils (67) (132) (160). In fact, C5a-mediated inhibition of neutrophil killing of $P$. gingivalis does occur, both in vitro and in vivo (J. Krauss and G. Hajishengallis, unpublished data). However, the underlying mechanisms, whether involving immune paralysis or alteration of specific signaling pathways, are currently under investigation. In addition to its potential exploitation by $P$. gingivalis, C5a may amplify periodontal tissue damage through its ability to recruit and activate inflammatory cells. For example, enhanced production of reactive oxygen species by C5a-stimulated neutrophils (46) may contribute to oxidative periodontal tissue 
destruction (12). On the other hand, this host response would not affect $P$. gingivalis, since it is resistant to killing by reactive oxygen species (55) (111).

Even if the gingipain activity of $P$. gingivalis is capable of increasing the microenviromental C5a concentrations to paralyzing levels for the neutrophils, this would not impinge on the function of macrophages, which can also be recruited to the gingival crevice or additionally interact with the pathogen in the periodontal connective tissue (28) (150). Indeed, macrophages are quite resistant to the deleterious effects of high C5a concentrations, because they express relatively modest levels of the $\mathrm{C} 5 \mathrm{a}$ receptor relative to neutrophils (160). For instance, whereas the ability of neutrophils to induce tumor necrosis factor- $\alpha$ (and other innate responses) is inhibited in the presence of C5a at $\geq 10$ $\mathrm{nM}$, the macrophages display potentiated tumor necrosis factor- $\alpha$ responses under the same C5a concentrations (67) (132).

Therefore, even at high levels, C5a does not exert a general immunosuppressive influence on macrophages. Strikingly, however, C5a can specifically downregulate cytokines of the interleukin-12 family. Indeed, C5a-induced signaling in macrophages interferes with TLR-induced expression of mRNA for the interleukin-12 p35, interleukin12/interleukin-23 p40, and interleukin-23 p19 subunits (63) (85). These regulatory effects are possibly mediated through C5a-induced phosphatidylinositol-3 kinase and extracellular signal-regulated kinase $1 / 2$ signaling, which in concert suppress critical transcription factors, the interferon regulatory factor-1 and -8 (63) (Fig. 4). At the protein level, the production of interleukin-12 is inhibited both in vitro and in vivo, leading to suppression of T-helper type 1 cell-mediated immunity (63) (165). Moreover, the ability of C5a to inhibit mRNA expression of both interleukin-23 subunits strongly suggests that 
C5a can interfere with the capacity of this cytokine to support the development of the Thelper type 17 cell subset (9). The physiological significance of these C5a regulatory effects is likely to attenuate potential tissue damage mediated by T-helper type 1 and Thelper type 17 cells, as seen in various pathological inflammatory conditions (37) (95) (138). However, undesirable outcomes may arise when C5a is not produced physiologically but through the uncontrolled action of microbial enzymes, such as the $P$. gingivalis gingipains. Since interleukin-12 is important for immune control of $P$. gingivalis (53), it is possible that this pathogen may exploit the C5a-induced crosstalk with TLR2 for inhibiting IL-12-dependent immune clearance. Such evasion mechanism may be complementary, rather than redundant, since the interaction of $P$. gingivalis with complement receptor-3 causes partial inhibition of interleukin-12 production (about 60\%) (53). The notion that $P$. gingivalis hijacks C5a for its own benefit is additionally supported by observations that the intracellular survival of this pathogen in macrophages is promoted in the presence of C5a (157).

Interestingly, unlike C5a, C3a is extensively degraded by $P$. gingivalis gingipains and does not retain biological activity (161). Whether this is beneficial for the pathogen is uncertain, but it should be noted that $\mathrm{C} 3 \mathrm{a}$ exerts direct antimicrobial effects and readily kills both gram-negative and gram-positive bacteria such as E. coli, Pseudomonas aeruginosa, and Enterococcus faecalis (114). If C3a can kill $P$. gingivalis as well, then its gingipain-mediated inactivation would serve to protect $P$. gingivalis.

In summary, it appears that $P$. gingivalis does not have a purely defensive agenda in dealing with the complement system. In other words, the pathogen may not restrict its action to simply inhibiting the complement cascade, but rather may proactively employ 
specific complement components (such as the complement receptor-3 and the C5a) for bidirectional crosstalk interactions with TLR2 that favor the pathogen (Fig. 4). Therefore, we hypothesized that $P$. gingivalis can modulate TLR2 signaling by co-opting C5a receptor to instigate a subversive crosstalk that promotes its adaptive fitness. We speculated this may involve blunting the killing efforts of recruited leukocytes, without causing a wholesale immunosuppression. Moreover, this pathogen-induced crosstalk may serve to amplify select aspects of the inflammatory response, thereby liberating essential peptide nutrients essential for growth without promoting the antimicrobial defenses of recruited leukocytes that would likely facilitate its destruction. 


\section{CHAPTER TWO: MATERIALS AND METHODS}

\section{Materials and reagents}

Carboxy methyl cellulose (CMC) was purchase from MP Biomedicals, Solon, OH.SQ22536, H89, SB216367, 8-Br-cAMP, AMD3100, forskolin, L-NAME ( $N(\mathrm{G})$ nitro-L-arginine methyl ester), D-NAME ( $N(\mathrm{G})$-nitro-D-arginine methyl ester), and EGTA were purchased from Sigma-Aldrich. Chelelythrin, PKI 6-22, KT5823, and thapsigargin were obtained from Calbiochem. PD98059 was from Cell Signaling Technology. Mouse-specific monoclonal antibodies to TLR2 [clone 6C2] was from eBioscience, TLR5 [85B152.5] from Abcam, and C5aR (20/70) from Cedarlane Laboratories or Hycult. Mouse rIFN- $\gamma$ was from the R\&D Systems. Mouse rC5a was purchased from $\mathrm{R} \& \mathrm{D}$ Systems and $\mathrm{rC} 3 \mathrm{a}$ from Cell Sciences. The cyclic hexapeptide $\operatorname{AcF}(\mathrm{OP}(\mathrm{D}) \mathrm{ChaWR}$ ) (acetylated phenylalanine-(ornithine-proline-(D) cyclohexylalaninetryptophan-arginine), also known as PMX-53, is a specific and potent C5a receptor (CD88) antagonist, was synthesized in the laboratory of John D. Lambris, as previously described (35) (98). A $8^{\Delta 71-73}$, also a generous gift of John D. Lambris, a dual antagonist of both $\mathrm{C} 5 \mathrm{aR}$ and $\mathrm{C} 5 \mathrm{a}-$-like receptor-2, was generated essentially as previously described (49). Specifically, the $A 8^{\Delta 71-73}$ sequence (49) was created by three cycles of mutagenesis of the original human C5a construct (47), using the QuickChange XL Site-Directed Mutagenesis Kit from Stratagene. The three pairs of complementary primers used for mutagenesis are as follows (forward sequences given): 
1) 5'-GTTACGATGGAGCCGCCGTTAATAATGATG-3',

2) 5'- CCGTGCTAATATCTCTTTTAAACGCATGCAATTGGGAAGG-3',

3) 5'-CTCTTTTAAACGCTCGTGAAAGCTTAATTAGC-3',

corresponding to mutations 1) C27A, 2) H67F and D69R, and 3) M70S and $4(71-74)$, respectively. The protein was then expressed and purified as previously described (47). All reagents were used at optimal concentrations determined in preliminary or published studies by our laboratories (36) (47) (59) (113) (165). C5a and C3a were used at concentrations up to $50 \mathrm{nM}$ and $100 \mathrm{nM}$, respectively, which are widely used for in vitro experiments (63) (165). Moreover, these concentrations are consistent with observations that under inflammatory conditions, C5a and C3a may reach serum levels as high as 100 $\mathrm{nM}$ and $400 \mathrm{nM}$, respectively, although even higher levels may be generated at local sites of inflammation (149) (160). All reagents were used at optimal concentrations determined in preliminary or published studies by our laboratories (59) (94) (98). When appropriate, dimethyl sulfoxide (DMSO) was included in medium controls and its final concentration was $\leq 0.2 \%$.

\section{Animals}

Both female BALB/c and C57BL/6 C5aR-deficient mice (with their respective wild-type controls) were used in these studies. The TLR2-deficient mice were originally C57BL/6 (The Jackson Laboratory) and we backcrossed them for nine generations onto a $\mathrm{BALB} / \mathrm{c}$ genetic background prior to use in these studies. The $\mathrm{C} 5 \mathrm{aR}$-deficient mice were 
originally obtained from Dr. Craig Gerard (Harvard Medical School) and are now housed at The Jackson Laboratory. All animal procedures were approved by the Institutional Animal Care and Use Committee and performed in compliance with established federal and state policies.

\section{Culturing of bacterial strains}

P. gingivalis ATCC 33277 and its isogenic KDP128 mutant, which is deficient in all three gingipain genes $(r g p A, \operatorname{rgpB}$, and $k g p)$ (45) (kindly provided by Dr. K. Nakayama, Nagasaki University, Japan), were grown anaerobically from frozen stocks on modified Gifu anaerobic medium-based blood agar plates for $5-6$ days at $37^{\circ} \mathrm{C}$, followed by anaerobic subculturing for $18-24$ hours at $37^{\circ} \mathrm{C}$ in modified Gifu anaerobic medium broth (Nissui Pharmaceutical).

\section{Oral gavage model}

Oral infection of mice proceeded as previously described by Baker et al (8). In brief, Balb/c mice were provided antibiotic-supplemented drinking water $(800 \mathrm{mg}$ sulfamethoxazole and $400 \mathrm{mg}$ trimethoprim per liter of water) for 10 days prior to experiment. Following a 3 day regimen of antibiotic-free water, mice were orally infected with a $10^{9}$ suspension in $2 \%$ CMC in PBS of $P$. gingivalis, repeated every other day for a total of 5 inoculations. Six weeks following the final inoculation, total anaerobic counts of bacteria were enumerated from paper-point samples grown under anaerobic conditions on blood agar plates for 7 days. Moreover, periodontal bone loss was determined by subtracting the measured distance from the cemento-enamel junction 
(CEJ) to the alveolar bone crest (ABC) of $P$. gingivalis-infected from the group of shaminfected mice. Results are expressed as mm change in bone loss.

\section{Subcutaneous chamber model}

Isofluorane anesthetized Balb/c mice were dually implanted with a surgical-grade titanium coil chamber. Following a 7 day healing period, P. gingivalis $\left(10^{9} \mathrm{CFU}\right.$ in 100 $\mu l$ of PBS) was injected into the chambers of each mouse. Chamber exudates were harvested from mice at indicated time points and centrifuged at $1000 \mathrm{rpm}$ for 5 minutes. Subsequently, recruited cells were phenotypically characterized by flow cytometry and supernatants were used to determine viable counts of $P$. gingivalis.

\section{Intracellular survival assay in murine macrophages}

Thioglycollate-elicited macrophages were isolated from the peritoneal cavity of wild-type or mice deficient in TLR2, TLR4, C3aR, or C5aR (The Jackson Laboratory) (54) (165), in compliance with established federal guidelines and institutional policies. The macrophages were cultured at $37^{\circ} \mathrm{C}$ and $5 \% \mathrm{CO}_{2}$ in RPMI 1640 (Invitrogen) supplemented with $10 \%$ heat-inactivated FBS, 2 mM L-glutamine, 100 units/ml penicillin $\mathrm{G}, 100 \mu \mathrm{g} / \mathrm{ml}$ streptomycin, and $0.05 \mathrm{mM}$ 2-ME. None of the experimental treatments, including treatments with $\mathrm{C} 5 \mathrm{a}$ up to $100 \mathrm{nM}$, affected cell viability (monitored by the CellTiter-Blue ${ }^{\mathrm{TM}}$ assay; Promega) compared to medium-only treatments. The viability of phagocytosed $P$. gingivalis was monitored by an antibiotic protection-based intracellular survival assay, as previously described (158). Briefly, mouse peritoneal macrophages

were allowed to phagocytose $P$. gingivalis $\left(\mathrm{MOI}=10: 1 ; 5 \times 10^{6}\right.$ bacteria and $5 \times 10^{5}$ cells) for $30 \mathrm{~min}$ at $37^{\circ} \mathrm{C}$. This was followed by washing to remove extracellular non- 
adherent bacteria and 1-hour treatment with antibiotics $(300 \mu \mathrm{g} / \mathrm{ml}$ gentamicin and 200 $\mu \mathrm{g} / \mathrm{ml}$ metronidazole) to eliminate residual or extracellular adherent bacteria. The macrophages were subsequently cultured overnight (for a total of 24 hours) or for 48 hours. Immediately after, the macrophages were washed and lysed in sterile distilled water and viable counts of internalized $P$. gingivalis were determined by plating serial dilutions of macrophage lysates on blood agar plates subjected to anaerobic culture (158).

\section{Cell signaling and activation assays}

Induction of nitric oxide production was assessed by measuring the amount of $\mathrm{NO}_{2}^{-}$(stable metabolite of nitric oxide) in stimulated culture supernatants using a Griess reaction-based assay kit (R\&D Systems), as previously performed (59). Levels of cAMP in activated cell extracts were measured using a cAMP enzyme immunoassay kit (Cayman Chemical) (94). PKA activity in lysates of activated cells was determined using

the ProFluor ${ }^{\mathrm{TM}}$ PKA assay, according to the instructions of the manufacturer (Promega) (59). Phosphorylation of GSK3 $\beta$ on Ser9 and total GSK3 $\beta$ were monitored using FACE $^{\text {TM }}$ GSK3 3 ELISA kits (Active Motif).

\section{Intraperitoneal infection (i.p.)}

Upon i.p. infection of mice with $P$. gingivalis $\left(5 \times 10^{7} \mathrm{CFU}\right)$, peritoneal lavage was performed 24 hours post-infection and the peritoneal fluid was used to enumerate recovered $\mathrm{CFU}$ (following anaerobic growth on blood agar plates) and measure production of $\mathrm{NO}_{2}{ }^{-}(59)$. 


\section{Quantitative real-time PCR}

Gene expression in resting or activated mouse macrophages was quantified using quantitative real-time PCR. Briefly, RNA was extracted from cell lysates using the PerfectPure RNA cell kit (5 Prime, Fisher) and quantified by spectrometry at 260 and $280 \mathrm{~nm}$. The RNA was reverse-transcribed using the High-Capacity cDNA Archive kit (Applied Biosystems) and quantitative real-time PCR with cDNA was performed using the ABI 7500 Fast System, according to the manufacturer's protocol (Applied Biosystems). TaqMan probes, sense primers, and antisense primers for expression of a house-keeping gene (GAPDH) or iNOS) were purchased from Applied Biosystems.

\section{Confocal microscopy}

To examine co-localization of $P$. gingivalis with C5aR and TLR2, mouse macrophages were grown on chamber slides and exposed to FITC-labeled $P$. gingivalis for $10 \mathrm{~min}$. The cells were then fixed, permeabilized, stained with Texas Red-labeled anti-C5aR plus allophycocyanin-labeled anti-TLR2, and mounted with coverslips for imaging on an Olympus FV500 confocal microscope (158).

\section{Fluorescence resonance energy transfer (FRET)}

Upon stimulation for $10 \mathrm{~min}$ at $37^{\circ} \mathrm{C}$ with $P$. gingivalis, mouse macrophages were labeled with a mixture of Cy3-conjugated (donor) and Cy5-conjugated (acceptor) antibodies. In other experiments shown in Fig. 13A, FITC-labeled $P$. gingivalis was used as donor and TRITC-labeled receptors served as acceptors. The cells were washed and fixed, and energy transfer between various donor-acceptor pairs was calculated from the increase in donor fluorescence after acceptor photobleaching (54) (152). The maximum 
$(\max )$ and minimum $(\min )$ energy transfer efficiencies in the experimental system were determined in control experiments as the energy transfer between two different epitopes on the same molecule or between molecules that do not engage in heterotypic associations, and their values are denoted by dashed lines in Fig. 13A. The conjugation of antibodies to $\mathrm{Cy} 3$ or $\mathrm{Cy} 5$ was performed using kits from Amersham Biosciences

\section{Statistical analysis}

Data were evaluated by analysis of variance and the Dunnett multiple-comparison test using the InStat program (GraphPad Software, San Diego, CA). Where appropriate (comparison of two groups only), two-tailed $t$ tests were performed. $P<0.05$ was taken as the level of significance. All experiments were performed at least twice for verification. 


\section{CHAPTER THREE: MOUSE MODELS OF PERIODONTAL HOST-PATHOGEN INTERACTIONS AND INFLAMMATION}

\section{Introduction}

Periodontitis is a prevalent chronic inflammatory disease that affects the toothsupporting tissues and can exert a systemic impact on health (73) (123) (151). A group of tooth-associated subgingival anaerobic bacteria is strongly associated with periodontitis (146), however, it is the host inflammatory response to uncontrolled bacterial challenge that primarily mediates periodontal tissue destruction (37) (43) (72). Although no single animal model can faithfully reproduce all aspects of periodontitis (or any other disease), the power and significance of animal models involves their capacity to test specific hypotheses involving distinct aspects of periodontal pathogenesis (44). Knowledge gathered from different but complementary models can be synthesized appropriately to obtain unique insights into the mechanisms of periodontitis. Despite their limitations, animal models are absolutely necessary for determining cause-andeffect relationships and for assessing the potential of novel therapeutic compounds. Such studies cannot be adequately served by in vitro experiments. Moreover, causal mechanistic relationships cannot normally be addressed in human studies which are often correlative in nature (44). It should also be noted that clinical trials can be initiated only 
after safety and efficacy has been demonstrated in animal models. As models of human disease, mice provide unique advantages beyond their relatively low cost and ease of handling. These include extensive background information on their immune system and a wide range of immunologic and cellular/molecular reagents. Moreover, the availability of a host of transgenic mouse lines can be used to study the impact of specific immunoregulatory genes.

\section{Inflammatory periodontal bone loss: the oral gavage model}

A mouse periodontitis model was developed by Baker and colleagues (6) (7) (8) ('Baker' or 'Oral gavage' model) and is now widely used with various modifications. Reproducible gingival inflammation and alveolar bone loss can be induced in this model following oral gavage with Porphyromonas gingivalis (7) (158) or other periodontal pathogens, such as Aggregatibacter actinomycetemcomitans (38) (115), Tannerella forsythia (140) or Porphyromonas gulae, an animal periopathogen equivalent to human P. gingivalis (60). The model can be further modified to involve a co-infection, e.g., $P$. gingivalis and Fusobacterium nucleatum (78) (124). Additionally, the oral gavage model of periodontitis has been used for rapid and cost-effective identification of pathogenic mechanisms and potential therapeutics (7) (38) (42) (53) (86) (115). Specifically, these mouse studies have helped determine the role of defined innate receptors or cytokines in periodontal tissue destruction, substantiate a genetic basis for host susceptibility or resistance to periodontal disease, identify virulence factors and evasion strategies of periodontal pathogens, and offer potential mechanistic links between periodontal and systemic diseases (44). 
A ANTIBIOTICS

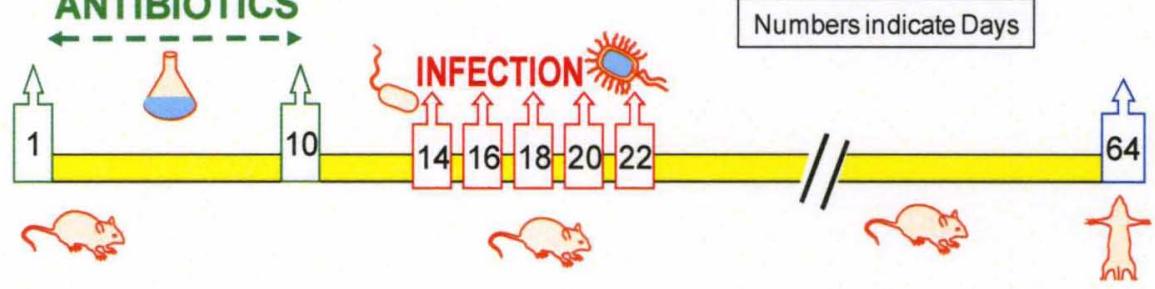

B

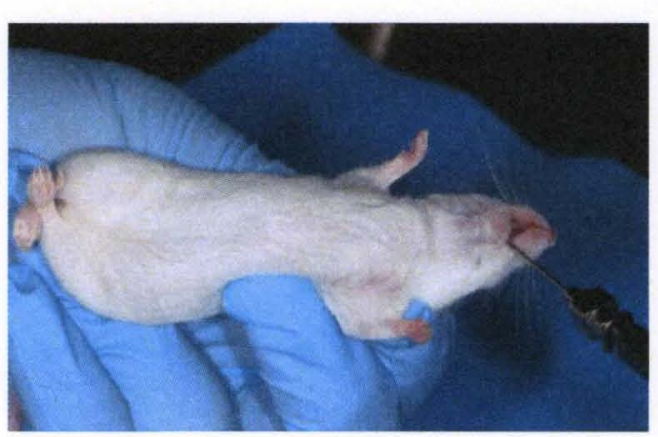

Figure 5. Oral gavage model of $P$. gingivalis-induced mouse

periodontitis. (A) Timeline of the experimental protocol. (B) Oral inoculation of mice with $P$. gingivalis using a ball-ended feeding needle. The mouse is restrained by grasping the skin over the shoulders and holding the tail. 


\section{Host cell-periodontal bacteria interactions: the subcutaneous chamber model}

A widely used mouse model to study host-pathogen interactions is the so-called chamber model, which was introduced to periodontal research by Genco and colleagues (39). The chamber comprises a coil-shaped titanium wire that is surgically implanted subcutaneously into the mid-dorsal region of the mouse. As the exterior encapsulates with connective tissue during the healing phase of implantation, the interior lumen becomes increasingly hypoxic (44), creating an environment reminiscent of the periodontal pocket. Oral bacteria can be injected into the chamber lumen and their interactions with recruited inflammatory cells can be assessed accurately and quantitatively (11) (39) (111). A major advantage of the chamber model is that some of these parameters, especially monitoring viable species-specific bacterial counts, are difficult to assess quantitatively in mucosal infection models. Additionally, inflammatory responses of recruited leukocytes can also be evaluated. Moreover, long-term versions of the chamber model can be used to monitor respective leukocyte populations recruited into the chamber or to study bacterial interactions over time. This model is thus appropriate for investigating interactions of periodontal bacteria with recruited inflammatory cells under conditions that faithfully mimic the subgingival environment. 
A

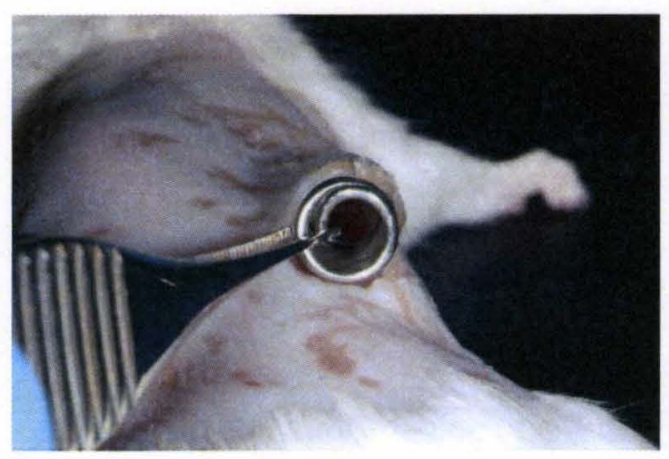

c

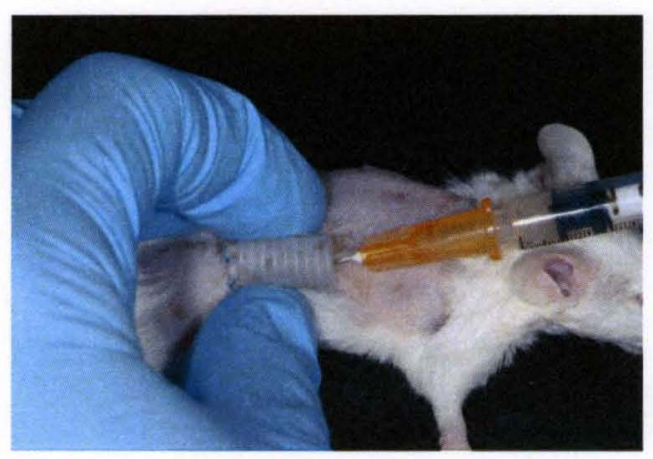

\section{B}

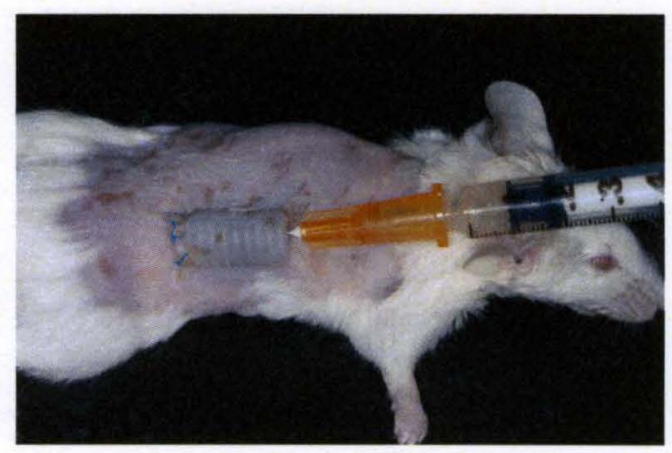

D

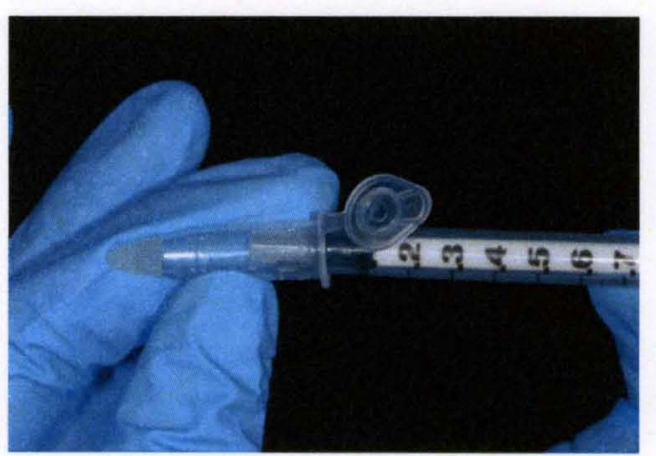

Figure 6. Subcutaneous chamber model. (A) Subcutaneous implantation of surgical grade titanium-coil chamber. (B) Intrachamber injection of $P$. gingivalis $\left(10^{9}\right)$ following 7 day healing period. Aspiration (C) of chamber fluid, immediately following desired inoculation period, and collection (D) for further analysis. 


\section{Results}

$P$. gingivalis augments the population of indigenous microflora in the oral gavage model

To ascertain the effects of oral challenge with $P$. gingivalis $(\mathrm{Pg})$ on the recovery of indigenous anaerobic bacteria residing within the oral cavity, total colony formingunits (CFUs) were enumerated and contrasted to CFUs recovered from sham-infected mice (Fig. 7B). Our results clearly demonstrate that the presence of $P$. gingivalis $(\mathrm{Pg})$ significantly augments the population size of resident oral anaerobic bacteria recovered by paper-point sampling from the oral cavity compared to sham-infected control mice. Indeed, the co-presence of $P$. gingivalis $(\mathrm{Pg})$ within the periodontium potentiated the overall number of indigenous oral microflora by two orders of magnitude.

Neutrophils are impaired in their ability to promote the clearance of $P$. gingivalis in the subcutaneous chamber model

Using the subcutaneous chamber model, we monitored inflammatory cell recruitment and investigated the fate of $P$. gingivalis within an in vivo setting that closely mimics the environment of the periodontal crevice. We observed that the overwhelming majority of cells recruited in response to intrachamber challenge with $P$. gingivalis were neutrophils ( $>97 \%$ at $24 \mathrm{~h}$ post-infection) (Fig. $8 \mathrm{~B}$ ). However, we found that despite a massive influx into the chamber, neutrophils were impaired in their ability to adequately clear the infection, observed at either early or late time points (Fig. 8A). 

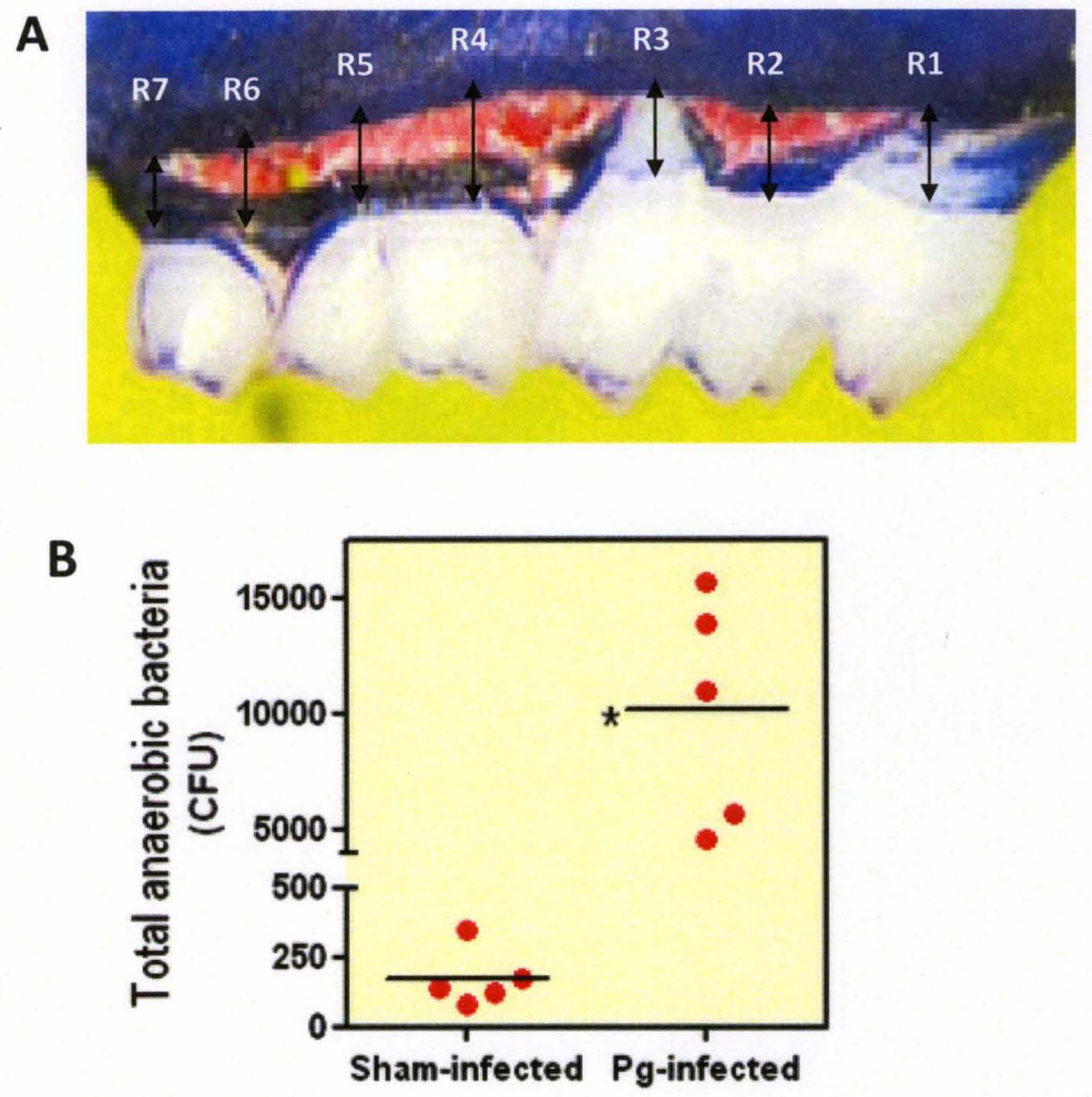

Figure 7. Recovery of total anaerobic bacteria from oral gavage model.

(A) Pre-determined buccal sites in the right maxilla (R1-R7) for measuring CEJ-ABC distances. (B) Oral infection with $P$. gingivalis (Pg) causes major increases in the numbers of the indigenous oral anaerobic bacteria $(p<0.01$ vs. sham-infected mice) recovered by paper-point sampling. 

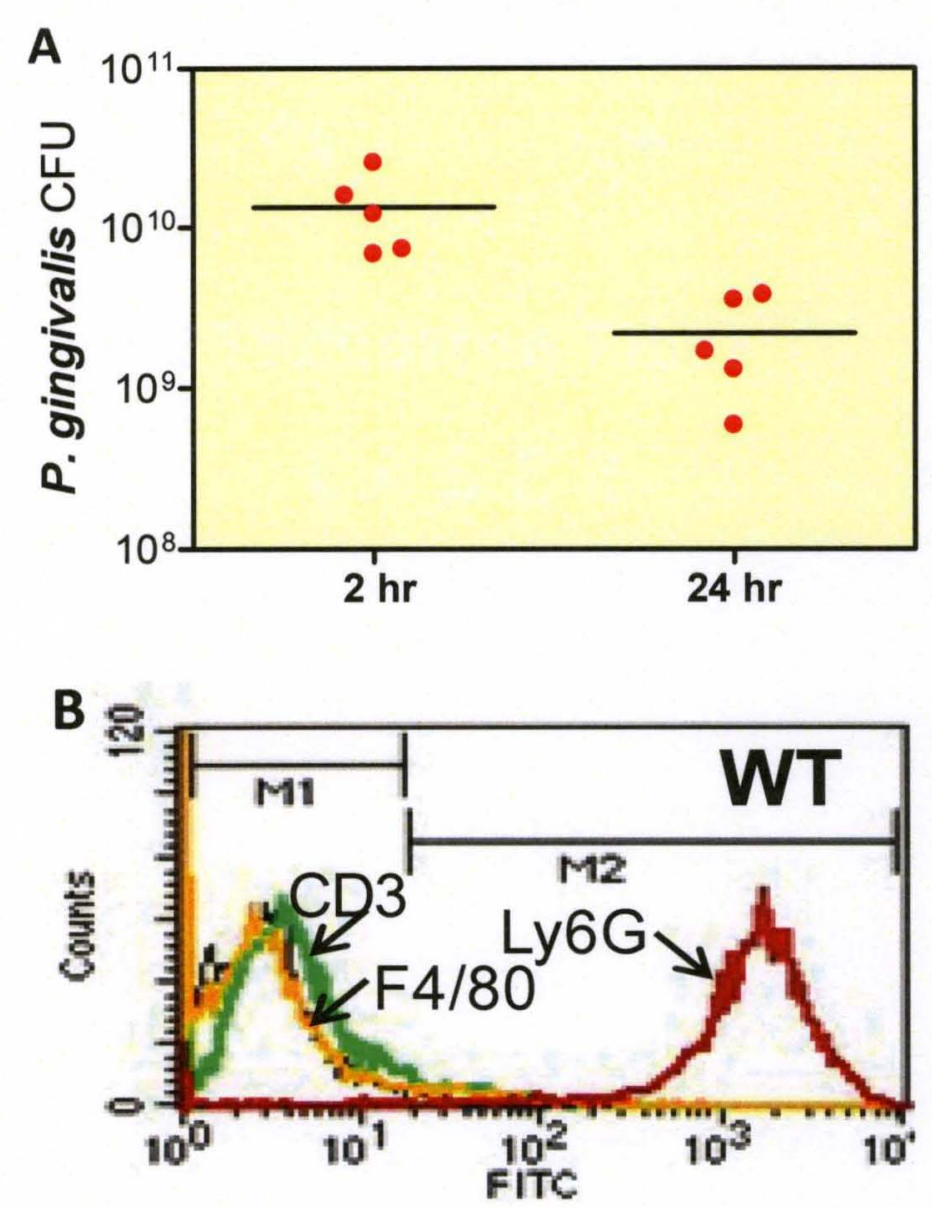

Figure 8. Analysis of chamber exudates from $P$. gingivalis-challenged subcutaneous chamber model. (A) Recovery of viable $P$. gingivalis colony-forming units (CFUs) at 2 and 24 hours post-intrachamber challenge. (B) Phenotypic characterization [CD3 (green), F4/80 (yellow) and Ly6G (red)] of recruited leukocytes 24 hours post-intrachamber infection with $P$. gingivalis. 


\section{DISCUSSION}

The bimodal nature of periodontal disease requires an experimental system that can equally address both host and bacterial factors (mutually inclusive contributors) that promote periodontal tissue destruction. Due to its experimental versatility, the mouse oral gavage model, an in vivo experimental system (7), is a time-honored and faithful rendition of periodontal disease. For example, through the use of genetically altered mice, the oral gavage model can be employed to monitor changes in gene expression within the gingival tissues as well as quantify appreciable bone loss in the presence of keynote periodontal pathogens, such as Porphyromonas gingivalis (7) (8) (44) (58). In addition to examining host determinants that contribute to periodontal disease, microbial counts can also be enumerated. Intriguingly, through the use of this in vivo model, we demonstrate that the presence of $P$. gingivalis can stimulate a substantial rise in the overall numbers of indigenous oral anaerobic bacteria residing within the oral cavity (Fig. 7B). These findings suggest that alterations in the oral microbial profile correspond with the prevalence of $P$. gingivalis, underscoring its importance for potentially promoting survival and virulence of the entire microbial community (21) (22) (49) (82).

The dichotomy of both protective and destructive immunity in the periodontium highlights the critical importance of discerning the precise roles leukocytes play with regards to periodontal disease. Although well-accepted and heavily utilized, the oral gavage model offers a rather panoramic readout of mucosal responses to infection. However, the subcutaneous chamber model provides an alternative in vivo model that can be utilized to determine specific host and bacterial factors driving both protective and destructive aspects of periodontal disease. Our studies reveal that in response to 
challenge with $P$. gingivalis, the lumen of the subcutaneous chamber becomes predominated almost exclusively by neutrophils (Fig. 8B), similar to an environment encountered within the gingival crevice, where $\geq 95 \%$ of total leukocytes are indeed neutrophils (28). Strikingly, $P$. gingivalis can survive and persist within the chamber although high numbers of neutrophils are chemoattracted there (Fig. 8A). These finding suggest that neutrophils may not be particularly adept at clearing $P$. gingivalis from the gingival crevice and may, in fact, play a destructive rather than protective role in periodontitis.

In general, the strength of the chamber model involves the whole-animal aspect for accurately quantifiable host responses or microbiological parameters (inflammatory cell recruitment, cytokine responses, bacterial clearance or persistence, and so on) (11) (39) (44). Since the significance of animal models involves their capacity to test defined concepts or hypotheses, rather than their fidelity to all aspects of a given disease (44), the chamber model is suitable to determine how specific host response genes or putative virulence factors shape the outcome of host interactions with periodontal bacteria (28) (111). Therefore, the chamber model can complement the oral gavage model for a more complete and nuanced understanding of the periodontal host-pathogen interplay. 


\section{CHAPTER FOUR: MICROBIAL HIJACKING OF COMPLEMENT-TOLL- LIKE RECEPTOR CROSSTALK}

\section{Introduction}

Although traditionally perceived as an antimicrobial enzyme system in serum, complement is now recognized as a central component of host defense impacting both innate and adaptive immunity (99). More recently, complement was suggested to crosstalk with another major innate defense system, the Toll-like receptors (TLRs), to apparently coordinate the host response to infection (52) (63). Not surprisingly, given its importance in fighting pathogens, complement constitutes a key target of immune evasion by microbes which cause persisting infections (52). Here we describe a novel strategy of immune subversion, involving microbial exploitation of the fifth complement component (C5) for corrupting TLR immunity via a hitherto unknown mechanism of complement-TLR crosstalk.

The pathogen involved in these subversive interactions, Porphyromonas

gingivalis, is a gram-negative anaerobic bacterium. This organism is strongly associated with periodontitis, a highly prevalent oral chronic inflammatory disease, and is moreover implicated in systemic conditions such as atherosclerosis and aspiration pneumonia (10). Although $P$. gingivalis inhibits the overall complement cascade regardless of the initiation pathway involved, curiously enough, this pathogen selectively generates biologically active C5a (69) (116). C5a generation by $P$. gingivalis is mediated by its 
Arg-specific cysteine proteinases (HRgpA and RgpB gingipains) which act in a C5 convertase-like manner (69) (116). Interestingly, upon release of C5a from C5, the C5b remnant is proteolytically destroyed by $P$. gingivalis ( 6 ) to apparently prevent activation of the terminal complement pathway, which leads to the formation of the membrane attack complex (99). Since C5a is a powerful chemoattractant and activator of phagocytes (88), it seems counterproductive for a pathogen to actively contribute to C5a generation. An intriguing question, therefore, is whether there is any survival advantage for $P$. gingivalis to specifically generate C5a in its periodontal niche, where complement proteins are abundantly present at up to $70 \%$ of their concentration in serum (116).

Below we present evidence that $P$. gingivalis paradoxically employs the proinflammatory C5a for targeted immune suppression of macrophages through a novel crosstalk mechanism between the $\mathrm{C} 5 \mathrm{a}$ receptor $(\mathrm{C} 5 \mathrm{aR})$ and TLR2, the predominant TLR utilized by this organism in vitro and in vivo (123) (137). This is the first report for a pathogen capable of proactively instigating and exploiting crosstalk signaling between complement and TLRs, rather than undermining either system independently as previously shown for a number of other microbes (52) (161).

\section{Results}

\section{C5a and subversion of macrophage function}

We were prompted to investigate whether C5a signaling is advantageous to $P$. gingivalis by earlier observations that its enzymatic activity selectively generates functional C5a, despite overall inhibiting the complement cascade (69) (116). We first examined whether C5a influences the macrophage intracellular killing of $P$. gingivalis. 
Strikingly, the ability of this pathogen to survive intracellularly in mouse macrophages was significantly promoted by C5a, but not by the related anaphylatoxin C3a (Fig.9, A and B). This unexpected pro-microbial effect of C5a was also observed in interferon (IFN)- $\gamma$-primed macrophages (Fig. 9, C and D). The elevated viable cell counts of $P$. gingivalis in C5a-treated macrophages could not be attributed to possible differences in the initial bacterial loads, since $P$. gingivalis phagocytosis was not significantly affected by the absence or presence of C5a or C3a (data not shown).

We next investigated the mechanism(s) underlying C5a-mediated inhibition of the macrophage intracellular killing capacity. In this regard, we hypothesized that the combined action of $\mathrm{C} 5 \mathrm{a}$ and $P$. gingivalis on macrophages may induce immunosuppressive signaling. We first used real-time quantitative PCR to determine whether C5a upregulates the expression of negative regulators of TLR signaling in $P$. gingivalis-stimulated macrophages. Although the bacterium alone upregulated the expression of some of the investigated regulators, including the suppressor of cytokine signaling-1, the interleukin-1 receptor-associated kinase $M$, and the ubiquitin-editing enzyme A20, no synergistic or additive effects were seen in the concomitant presence of P. gingivalis and C5a (data not shown). Therefore, these regulatory molecules are not likely involved in C5a-mediated suppression of macrophage killing of $P$. gingivalis. Moreover, although induction of cAMP can induce immunosuppressive signaling (12), C5a by itself failed to induce a cAMP response in macrophages (Fig. 9E). Strikingly, however, C5a synergized with $P$. gingivalis resulting in $>3$-fold elevation of the intracellular cAMP levels relative to $P$. gingivalis stimulation alone (Fig. 9E). The 
synergy was observed as early as $10 \mathrm{~min}$ after cell stimulation, peaked at 1 hour, but significantly elevated cAMP levels were sustained for at least 24 hours (Fig. 9E).

This upregulatory effect of C5a was dose-dependent (data not shown) and was totally abrogated by a C5aR antagonist (C5aRA), the cyclic hexapeptide AcF(OP(D)ChaWR) (Fig. 9F), indicating that C5a acted through the classic C5aR (CD88), rather than the alternative C5a-like receptor 2 (C5L2).

Given that $P$. gingivalis is exquisitely resistant to killing by the oxidative burst (160), we investigated whether C5a interferes with induction of nitric oxide as a possible mechanism for its pro-microbial effect. The underlying rationale was that $P$. gingivalis is sensitive to nitric oxide-mediated killing (11) (54). Indeed, C5a significantly inhibited, via a C5aR-dependent mechanism, the production of nitric oxide in $P$. gingivalisstimulated macrophages, even in cells primed with IFN- $\gamma$ (Fig. 9G). The C5aR specificity of the C5a-driven augmentation of cAMP and suppression of nitric oxide in $P$. gingivalis-challenged macrophages was confirmed by lack of these effects in C5aRdeficient (C5ar $\left.{ }^{-1}\right)$ macrophages (Fig. 9, $\mathrm{H}$ and I, respectively). In toto, our findings suggest that C5aR activation by C5a results in suppression of $P$. gingivalis intracellular killing associated with elevation of cAMP and reduction of nitric oxide. 

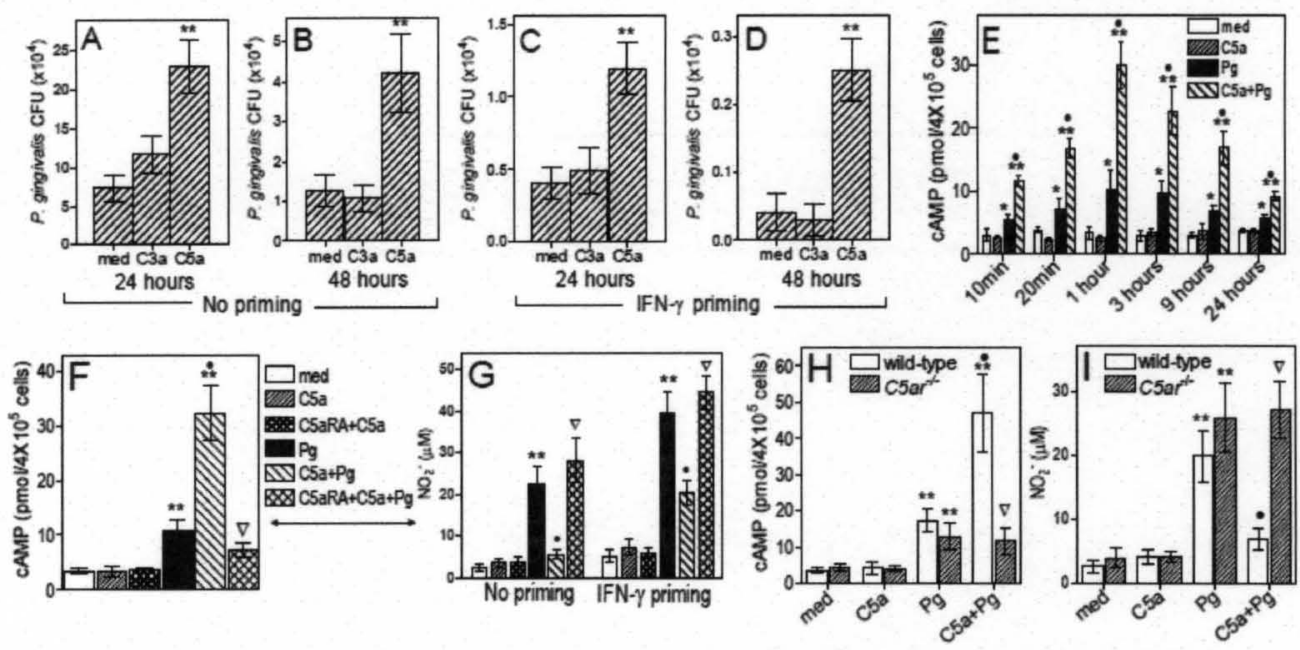

Figure 9. Immunosubversive effects of C5a on $P$. gingivalis-challenged

macrophages. Untreated (A, B) or IFN- $\gamma$ primed (C, D) macrophages were incubated with $P$. gingivalis in the presence or absence of C3a (200 nM) or C5a $(50 \mathrm{nM})$. Colony counts of internalized bacteria were enumerated at $24(\mathrm{~A}, \mathrm{C})$ or 48 hours (B, D) post-infection (E) P. gingivalis-challenged macrophages, in the absence or presence of $\mathrm{C} 5 \mathrm{a}$, were assayed for intracellular cAMP production for the times indicated. (F) Similar experiment as in (E), involving 1 hour of incubation and the use of a specific C5a receptor antagonist (C5aRA; $1 \mu \mathrm{M}) .(\mathrm{G})$ Unprimed or IFN- $\gamma$-primed macrophages were assayed for $\mathrm{NO}_{2}^{-}$production after incubation with or without $P$. gingivalis, C5a, or C5aRA. Induction of cAMP $(\mathrm{H})$ and $\mathrm{NO}_{2}^{-}$(I) production with macrophages from wild-type or C5aR-deficient $\left({\mathrm{C} 5 \mathrm{ar}^{-1}}^{-1}\right)$ mice. Data are means $\pm \mathrm{SD}(\mathrm{n}=3)$ from typical experiments performed three (A-D, F and G) or two (E, H, and I) times yielding consistent results. ${ }^{*} \mathrm{P}<$ 0.05 and $* * \mathrm{P}<0.01$ compared to medium only treatments. $\bullet \mathrm{P}<0.01$ in $\mathrm{C} 5 \mathrm{a}+\mathrm{Pg}$ compared to Pg alone. Inverted triangles indicate significant $(\mathrm{P}<0.01)$ reversal of C5a effects by C5aRA or C5aR deficiency. 


\section{C5a immunosubversive effects are strictly dependent on cAMP-PKA signaling}

We investigated whether the C5a-mediated inhibition of nitric oxide production depends upon the ability of C5a to stimulate synergistic elevation of cAMP. Indeed, the inhibitory $\mathrm{C} 5 \mathrm{a}$ effect on nitric oxide was reversed in macrophages pretreated with inhibitors of cAMP synthesis (SQ22536) or of PKA (H89 and PKI 6-22) but not of irrelevant kinases (chelerythrin or KT5823) (Fig. 10A), indicating that the C5a effect is mediated by cAMP-dependent PKA signaling. Importantly, the upregulation of nitric oxide levels by inhibitors of cAMP or of PKA was linked to significantly reduced intracellular survival of $P$. gingivalis in those same cells (Fig. 10B). Moreover, macrophage pretreatment with $\mathrm{C} 5 \mathrm{aRA}$ counteracted the protective effect of $\mathrm{C} 5 \mathrm{a}$ on $P$. gingivalis intracellular viability, whereas L-NAME (nitric oxide synthesis inhibitor) mimicked C5a and overrode the C5aRA effect (Fig. 10C). In contrast, D-NAME, an inactive enantiomer control, had no effect in that regard (Fig. 10C). Interestingly, the ability of inhibitors of cAMP or of PKA to reverse the immunosuppressive C5a effect progressively declined with increasing delay of their addition to the culture system (Fig. 10D). Therefore, $P$. gingivalis needs to immediately activate cAMP-dependent PKA signaling to suppress the macrophage killing capacity, consistent with the requirement for early availability of $\mathrm{C} 5 \mathrm{a}$ in order to disable $P$. gingivalis-challenged macrophages. 

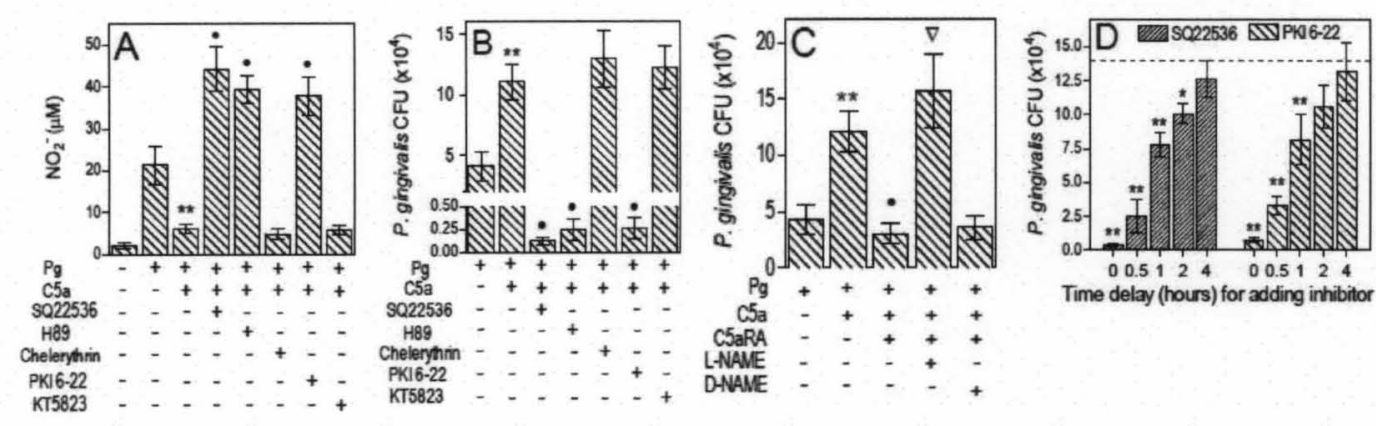

Figure 10. C5a-mediated inhibition of nitric oxide production and promotion of $\mathrm{P}$. gingivalis survival is cAMP and PKA dependent. (A, B) Mouse macrophages were pretreated or not with SQ22536 (cAMP synthesis inhibitor), H89 (PKA inhibitor), chelerythrin (protein kinase C inhibitor), PKI 6-22 (peptide inhibitor of PKA), or KT5823 (peptide inhibitor of protein kinase G), and then infected with $P$. gingivalis with or without C5a. (C) Macrophages were pretreated with L-NAME (or D-NAME), C5aRA, or both and then infected with $P$. gingivalis with or without C5a. (D) Macrophages were incubated with $P$. gingivalis and C5a in the absence or presence of SQ22536 or PKI 6-22, added before P. gingivalis and $\mathrm{C} 5 \mathrm{a}$ ("0 time delay") or with increasing delay times, as indicated. $\mathrm{NO}_{2}{ }^{-}$ production (A) and viable counts of internalized bacteria (B-D) were determined at 24 hours after infection. In (D), the dashed line indicates $P$. gingivalis CFUs in the absence of inhibitors $\left[13.7 \pm 2.7\left(\times 10^{4}\right)\right.$ CFUs]. Results are means $\pm \operatorname{SD}(n=3)$ from typical experiments performed at least twice with consistent results. ${ }^{*} \mathrm{P}<$ 0.05 and $* * \mathrm{P}<0.01$ compared to corresponding controls. $\bullet \mathrm{P}<0.01$ in $\mathrm{C} 5 \mathrm{a}+\mathrm{Pg}$ with inhibitor or antagonist compared to $\mathrm{C} 5 \mathrm{a}+P g$ only. In $(\mathrm{C})$, the inverted triangle shows significant $(\mathrm{P}<0.01)$ reversal of the $\mathrm{C} 5 \mathrm{aRA}$ effect. 


\section{In vivo exploitation of C5aR signaling for inhibition of nitric oxide and promotion of microbial survival}

To determine if C5aR signaling promotes $P$. gingivalis virulence also in vivo, we investigated the pathogen's ability to survive in mice after intraperitoneal infection, in the absence or presence of C5aRA. At 24 hours post-infection, the peritoneal lavage fluid from C5aRA-treated mice contained significantly lower $P$. gingivalis $\mathrm{CFU}$ compared to control mice ( $>95 \%$ reduction; Fig. 11A). Consistent with this, C5ar- mice were superior to wild-type controls in controlling the $P$. gingivalis infection (Fig. 11A). The wild-type control mice were additionally found to be bacteremic for $P$. gingivalis (4 out of 5 mice in this group had positive blood cultures 24 hours post-infection), whereas no bacteremia could be detected in $C 5 a r^{-/-}$or C5aRA-treated wild-type mice, further indicating that $\mathrm{C} 5 \mathrm{aR}$ signaling promotes $P$. gingivalis virulence. Additional support that the reduced peritoneal bacterial burden in the absence of $\mathrm{C} 5 \mathrm{aR}$ signaling reflects increased $P$. gingivalis killing (rather than $P$. gingivalis escaping and taking up residence in internal organs) was obtained by lack of $P$. gingivalis CFU detection in homogenates of several organs examined (spleen, kidney, liver, and lungs) from either $C 5 \mathrm{ar}^{-/-}$or wildtype mice. The ability of C5aRA-treated mice for enhanced clearance of $P$. gingivalis correlated with elevated nitric oxide production (relative to control mice), whereas LNAME counteracted both effects (Fig. 11, B and C). Therefore, as shown in vitro, the in vivo exploitation of $\mathrm{C} 5 \mathrm{aR}$ signaling by $P$. gingivalis for enhanced survival involves a nitric oxide-dependent mechanism. 

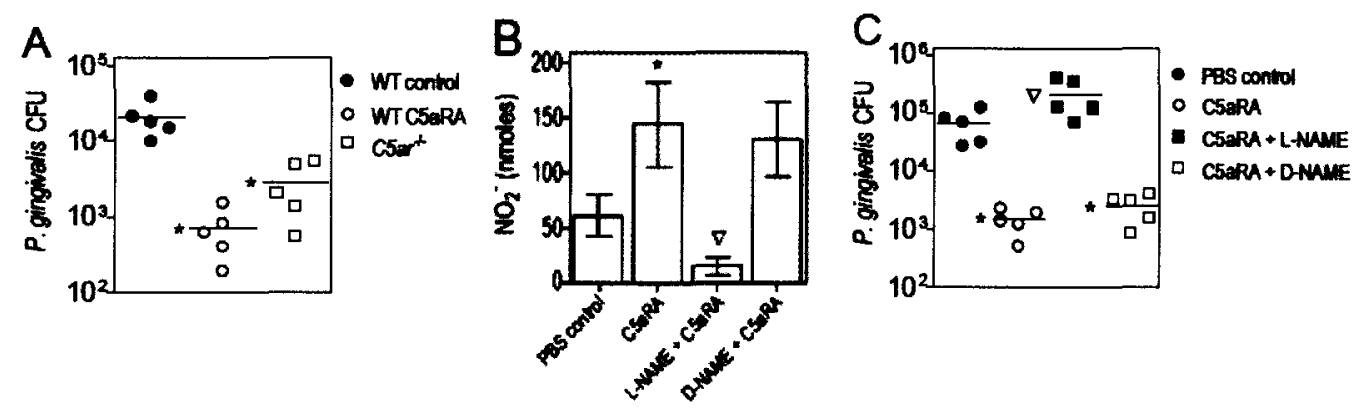

Figure 11. $P$. gingivalis exploits C5aR signaling to inhibit nitric oxide production and promote its survival in vivo. (A) Wild-type (WT) mice were intraperitoneally pre-treated with C5aRA (1 mg per kilogram body weight) or phosphate-buffered saline (PBS), followed by intraperitoneal infection of these

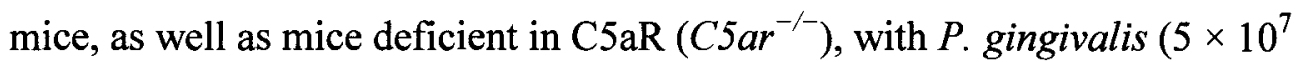
CFU). Wild-type mice were intraperitoneally pre-treated or not with C5aRA, with or without L-NAME or D-NAME $(0.1 \mathrm{ml}$ of $12.5 \mathrm{mM}$ solution, corresponding to $0.34 \mathrm{mg}$ per mouse), followed by intraperitoneal infection with P. gingivalis (B and C). Peritoneal fluid was harvested 24 hours after infection and used to determine viable $P$. gingivalis $\mathrm{CFU}\left(\mathrm{A}\right.$ and $\mathrm{C}$ ) and $\mathrm{NO}_{2}{ }^{-}$production (B). Data are from typical experiments performed twice yielding consistent findings and represent means $\pm \mathrm{SD}(\mathrm{n}=5$ mice) or are shown for each individual mouse with horizontal lines denoting mean values. ${ }^{*} \mathrm{P}<0.01$ compared to controls. The inverted triangles show significant $(P<0.01)$ reversal of the C5aRA effects. 


\section{Synergistic activation of the cAMP-PKA pathway requires C5aR-TLR2 crosstalk}

A systematic analysis of crosstalk in intracellular signaling pathways has revealed that receptor-mediated elevation of intracellular $\mathrm{Ca}^{2+}$ may potentiate cAMP induction by appropriate stimuli (36). If the synergistic effect of C5a on cAMP induction (Fig. 9E) depends upon its $\mathrm{Ca}^{2+}$-mobilizing activity, then this synergy should be inhibited by thapsigargin, an inhibitor of the endoplasmic reticulum $\mathrm{Ca}^{2+}$-ATPase which blocks the C5a-induced intracellular $\mathrm{Ca}^{2+}$ response (121). Indeed, macrophage pretreatment with thapsigargin abrogated the synergistic C5a effect on $P$. gingivalis-induced cAMP, whereas EGTA, which chelates extracellular $\mathrm{Ca}^{2+}$, had a relatively minimal and statistically insignificant effect (Fig. 12A). Significant reversal of the C5a effect on cAMP induction was also seen in cells pretreated with pertussis toxin (Fig. 12A), suggesting $\mathrm{Ga}_{\mathrm{i}}$-coupled C5aR signaling (49).

In the absence of C5a, the ability of $P$. gingivalis to induce cAMP depends on its interaction with the CXC-chemokine receptor 4 (CXCR4) (11). We thus initially speculated that the synergistic C5a effect on cAMP induction could involve a crosstalk between C5aR and CXCR4. Although CXCR4 blockade by AMD3100 (at $1 \mu \mathrm{g} / \mathrm{ml}$ which completely inhibits the CXCR4- $P$. gingivalis interaction (11)) modestly attenuated the synergistic C5a effect on cAMP production, the synergism was still profoundly manifested ( $>6$-fold difference between $\mathrm{AMD}+\mathrm{C} 5 \mathrm{a}+\mathrm{Pg}$ vs. AMD+Pg; Fig. 12B). Moreover, $P$. gingivalis failed to elevate intracellular cAMP in CXCR4-transfected CHOK1 cells, although it induced cAMP production in cells co-transfected with CXCR4 and TLR2 (data not shown). Therefore, CXCR4 is not directly involved in cAMP induction but cooperates in that regard with TLR2, which on its own induces a rather weak cAMP 
response (data not shown). We next showed that the synergistic C5a effect on cAMP induction actually involves a crosstalk with TLR2.

Indeed, the ability of C5a to synergistically induce cAMP and activate PKA in $P$. gingivalis-stimulated wild-type macrophages was utterly absent in similarly stimulated $T l r 2^{-/-}$macrophages, which displayed only background activity levels (Fig. 12, C and D). However, the inherent capacity of $T \operatorname{tr} 2^{-/-}$macrophages to elevate intracellular cAMP and activate PKA was confirmed by including a forskolin control (direct adenylate cyclase activator) (Fig. 12, C and D). This novel concept of C5aR-TLR2 crosstalk for synergistic cAMP-dependent PKA activation is consistent with additional findings from an in vivo experiment. Indeed, the PKA activity detected in freshly explanted peritoneal macrophages from $P$. gingivalis-infected mice was significantly reduced by TLR2 or C5aR deficiency, but not by TLR4 or C3aR deficiency, relative to cells from wild-type mice (Fig. 12E).

We also showed that another synergistic interaction downstream of this receptor crosstalk involved PKA-dependent phosphorylation of glycogen synthase kinase-3 $\beta$ (GSK3 $\beta$ ) on Ser9 (Fig. 12F), an event that inactivates this kinase which would otherwise positively regulate cell activation (47). Indeed, although C5a or P. gingivalis by themselves only slightly increased Ser9-phosphorylation of GSK3 $\beta$, their combination displayed a synergistic effect which was inhibited by PKI 6-22 (but not by PD98059 control, an inhibitor of mitogen-activated protein kinase kinase) (Fig. 12F). Importantly, the GSK3 $\beta$ inhibitor SB216763 mimicked the inhibitory C5a effect on $P$. gingivalisinduced iNOS expression and nitric oxide production, as did 8-Br-cAMP (PKA agonist; 
positive control) (Fig. 12G). Thus, GSK3 $\beta$ appears to regulate iNOS and nitric oxide downstream of PKA in C5a plus $P$. gingivalis-challenged macrophages.

The C5aR-TLR2 crosstalk is also consistent with confocal microscopy findings revealing for the first time co-localization of the two receptors in $P$. gingivalis-stimulated macrophages (Fig. 13B), and with fluorescence resonance energy transfer (FRET) experiments indicating that C5aR, TLR2, and $P$. gingivalis come into molecular proximity (Fig. 13A). Indeed, FRET analysis revealed significant energy transfer between Cy3-labeled C5aR and Cy5-labeled TLR2 in $P$. gingivalis-stimulated but not resting macrophages (Fig. 13A). No significant energy transfer was detected between Cy3-labeled C5aR and Cy5-labeled TLR5 or MHC Class I (controls) under the same conditions (Fig. 13A). Moreover, significant energy transfer was observed between FITC-labeled $P$. gingivalis and TRITC-labeled C5aR or TLR2 (but not TLR5 or MHC Class I) (Fig. 13A). However, unlike TLR2 which can directly be engaged by $P$. gingivalis (59) (137), C5aR appeared to associate indirectly with $P$. gingivalis in a TLR2dependent way; indeed, the $P$. gingivalis-C5aR FRET association was abrogated in $T l r 2^{-1-}$ macrophages (Fig. 13A). Taken together, the findings firmly establish a crosstalk between C5aR and TLR2 for synergistic induction of cAMP signaling.

FRET analysis further revealed that in $P$. gingivalis-challenged macrophages, C5aR also associates with CXCR4 (Fig. 13A), suggesting co-association of all three receptors (CXCR4, TLR2, C5aR). These interactions likely occur in lipid rafts since all three receptors (but not TLR5 or MHC Class I) come within FRET proximity with an established lipid raft marker (GM1 ganglioside) in P. gingivalis-stimulated macrophages, unless the rafts are disrupted by methyl- $\beta$-cyclodextrin (data not shown). Although the 
C5aR-TLR2 crosstalk can proceed independently of CXCR4 and potently upregulates cAMP (Fig. 12B), maximal cAMP induction requires cooperation of all three receptors (Fig. 14). 

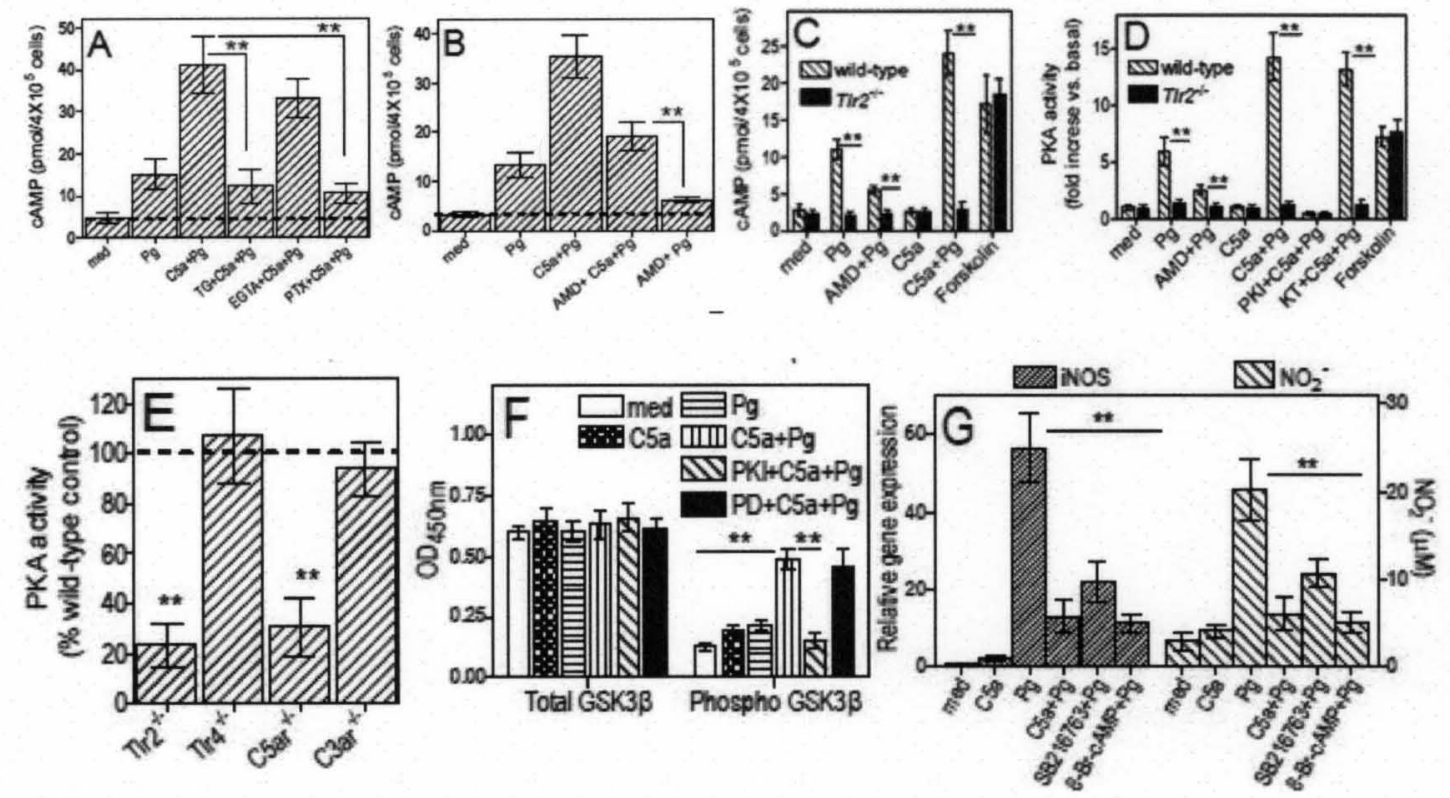

Figure 12. Synergistic activation of the cAMP-PKA pathway requires C5aR-

TLR2 crosstalk. (A-D) Macrophages pre-treated with either thapsigargin (TG), EGTA, pertussis toxin (PTX) (A) or AMD3100 (B-D) were stimulated with $P$. gingivalis with or without $\mathrm{C} 5 \mathrm{a}$ and assayed for cAMP production (A-C) or PKA activity (D) with or without PKI-6-22 (PKA inhibitor) and an irrelevant kinase inhibitor (KT5823). (E) PKA activities from freshly explanted peritoneal macrophages were determined from $P$. gingivalis-infected mice. (F) P. gingivalischallenged macrophages, pretreated with PKI-6-22 or PD98059, were assayed for GSK3b Ser9-phosphorylation and total GSK3b, in the absence or presence of C5a. (G) Macrophages stimulated with $P$. gingivalis with or without C5a, SB216763, or 8Br-cAMP were assayed for iNOS (4 hours) or $\mathrm{NO}_{2}^{-}$(24 hours). Data are means \pm SD. $* \mathrm{P}<0.05 ; * * \mathrm{P}<0.01$ between the indicated groups or compared to controls (E). 

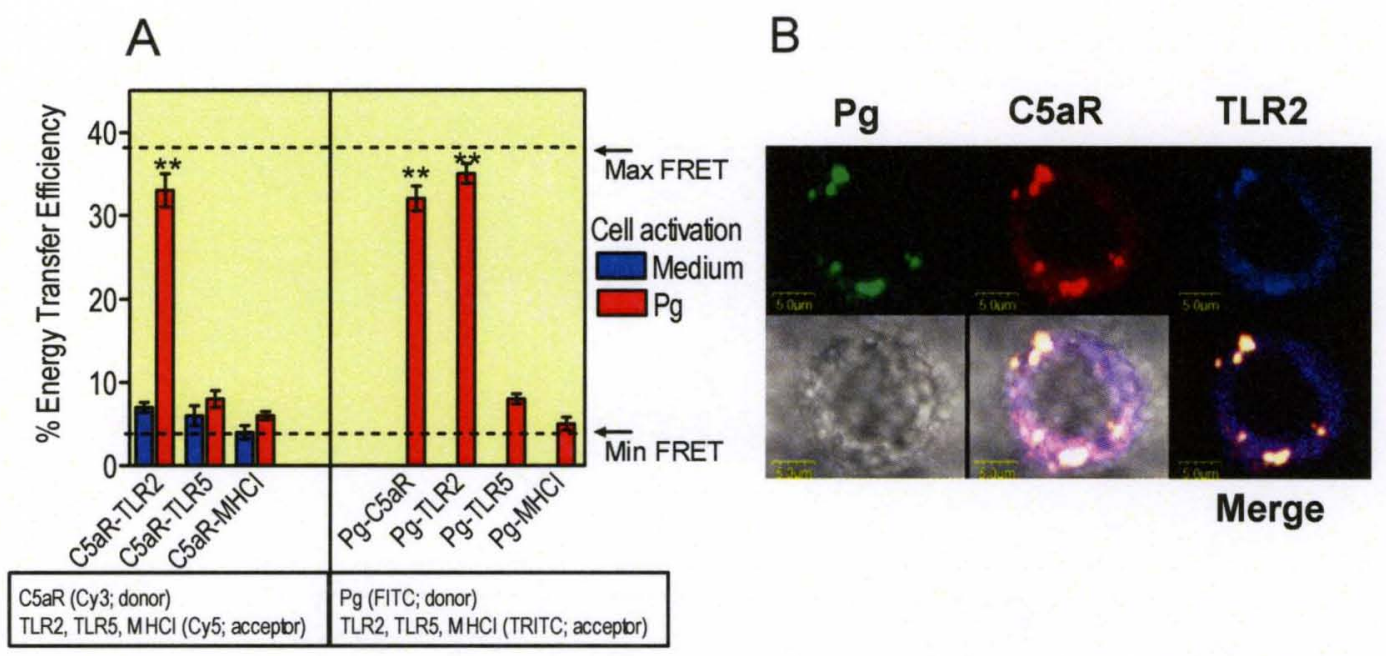

Merge

Figure 13. Lipid raft recruitment and co-localizaion of C5R and TLR2

in macrophages challenged with $\boldsymbol{P}$. gingivalis. (A) FRET between the indicated donors and acceptors measured from the increase in donor (Cy3 or FITC) fluorescence after acceptor (Cy5 or TRITC) photobleaching. (B) Confocal co-localization of $P$. gingivalis (green), C5aR (red), and TLR2 (blue). Bottom right, merged image. 


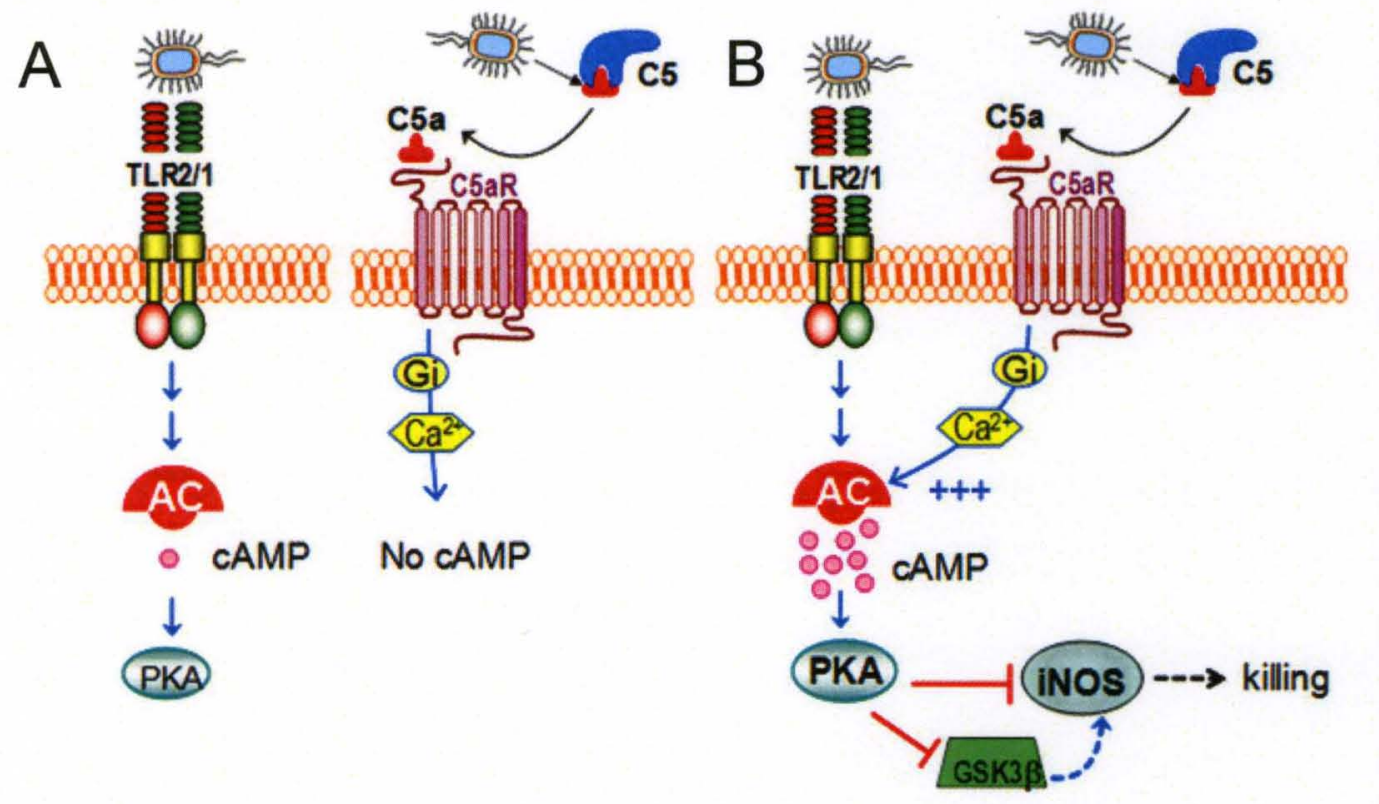

Figure 14. TLR2 and C5aR signaling synergize to subvert macrophage killing of $\boldsymbol{P}$. gingivalis in a PKA-dependent fashion. $P$. gingivalis induces a weak TLR2-dependent induction of cAMP production (left), whereas CXCR4 or C5aR signaling alone fails to do so (middle). However, $P$. gingivalis-induced TLR2 signaling with concomitant activation of C5aR and, to a lesser extent, CXCR4 synergistically enhances the immunosuppressive cAMP-PKA pathway that inactivates GSK3b and impairs iNOS-dependent killing. 


\section{DISCUSSION}

A molecular crosstalk between the complement system and the TLRs seems essential to appropriately coordinate the early innate response to infection (63) (165). Here, we addressed the intriguing possibility that at least some of the complement-TLR interplay may be instigated by pathogens, such as $P$. gingivalis, for promoting their adaptive fitness. The necessity for this evasion mechanism may be related to the fact that P. gingivalis cannot antagonize TLR2 activation at the receptor level, as it does with TLR4 (113). Therefore, it can be stated that this pathogen has evolved a subversive C5aR-TLR2 crosstalk mechanism for blunting the TLR2 antimicrobial response (Fig. 14), as an alternative to direct TLR2 antagonism. Notably, $P$. gingivalis does not rely on immunological mechanisms for $\mathrm{C} 5 \mathrm{aR}$ activation, since it can activate this receptor through gingipain-mediated local generation of C5a (69). We confirmed and expanded the biochemical demonstration of $\mathrm{C} 5 \mathrm{a}$ generation by purified gingipains acting on purified C5 substrate (69), by estimating that $P$. gingivalis generates high levels of C5a $(32.7 \pm 4.3 \mathrm{nM})$ upon 30-min incubation in heat-inactivated human serum. Notably, unlike C5a, C3a is extensively degraded and inactivated by $P$. gingivalis (69). Since C3a (but not C5a) exerts direct bactericidal effects (113), C3a destruction by $P$. gingivalis may serve to protect this pathogen.

The striking ability of C5a to synergize for cAMP production with $P$. gingivalis in a pertussis toxin-sensitive and TLR2-dependent way could be explained as follows. The

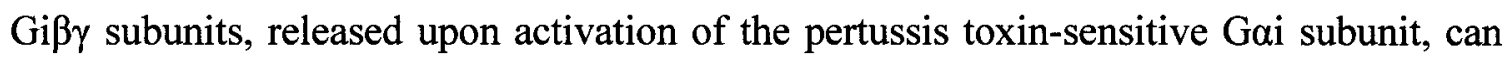
potently regulate adenylate cyclase (AC) activity, either positively or negatively depending on the enzyme isoform (107). Thus, although Gi $\beta \gamma$ cannot stimulate AC by 
themselves, they can dramatically upregulate the activity of several $\mathrm{AC}$ isoforms in the presence of an appropriate stimulus. Such stimulus is apparently provided by $P$. gingivalis activation of TLR2. Importantly, the AC isoforms which are positively regulated by Giß $\gamma$ are not those that are sensitive to the inhibitory action of Gai (107). Since the ability of C5a to synergize with $P$. gingivalis for cAMP production is additionally dependent on intracellular $\mathrm{Ca}^{2+}, \mathrm{Gi} \beta \gamma$ may possibly mediate their stimulatory effects on $\mathrm{AC}$ activity through their $\mathrm{Ca}^{2+}$-mobilizing effects.

A major mechanism underlying the regulatory effects of cAMP on cell activation involves the ability of cAMP-dependent PKA to phosphorylate the cAMP response element-binding protein (CREB), which effectively competes with the p65 subunit of nuclear factor- $\mathrm{kB}$ for limiting amounts of common transcriptional cofactors (125). Besides being under nuclear factor- $\mathrm{kB}$ control, the iNOS is additionally regulated by IFN- $\gamma$; interestingly, however, PKA also inhibits the IFN regulatory factor- 1 that is required for the synergistic IFN- $\gamma$ contribution to iNOS transcription (24) (101). Moreover, as supported by the figure $12 \mathrm{~F}$ data, PKA can phosphorylate and inactivate GSK3 $\beta$, thus abrogating its stimulatory effect on pro-inflammatory gene expression (47). Since PKA activation causes greater iNOS inhibition than GSK3 $\beta$ inactivation (Fig. $12 \mathrm{G}$ ), it is likely that PKA may inhibit iNOS also in a GSK3 $\beta$-independent way (Fig. 14).

Although modest TLR-induced cAMP induction may control excessive proinflammatory signaling, sustained high levels of cAMP instigated by pathogens (and thus out of host control) may impair host defense. P. gingivalis is the first pathogen shown to exploit complement and TLRs to cause cAMP-dependent immune subversion in vitro and in vivo. It should be noted, however, that the interaction of C5a with P. gingivalis- 
challenged macrophages did not induce a generalized or nonspecific macrophage immunosuppression, since C5a actually enhanced $P$. gingivalis-induced interleukin-6 (IL6) production (data not shown). This sophisticated subversive crosstalk instigated by $P$. gingivalis (Fig. 14) serves in lieu of "built-in" adenylate cyclase which is not expressed by this bacterium, in contrast to Bordetella pertussis which disables human or mouse phagocytes by means of its own adenylate cyclase (14).

Macrophages can interact with $P$. gingivalis not only in periodontal tissues but also in the setting of systemic inflammatory diseases such as atherosclerosis (10) (114) (160). Our previous findings that $P$. gingivalis persists intracellularly in macrophages for at least $72 \mathrm{~h}$ (147) were confirmed by an independent group, which additionally showed that up to $25 \%$ of the cells undergo necrosis by $72 \mathrm{~h}$ and release cellular contents (100). It is thus conceivable that viable $P$. gingivalis could be released from necrotic macrophages, especially in the presence of $\mathrm{C} 5 \mathrm{a}$ which dramatically promotes its intracellular persistence. This possibility becomes intriguing in view of epidemiological and mechanistic links between periodontitis and atherosclerosis (10) (114). However, whether the documented localization of viable $P$. gingivalis bacteria in atherosclerotic plaques (27) can be attributed to relocation of infected macrophages from periodontal tissues is currently uncertain. Nevertheless, the pathogen's capacity to exit initially infected host cells and then enter and multiply within new hosts, including vascular cells, has been documented (29) (156).

C5aR activation in macrophages was also shown to inhibit TLR4-induced mRNA expression of IL-12p35, IL-12/IL-23p40, and IL-23p19, and production of IL-12p70 and IL-23 protein, through C5a-induced phosphatidylinositol-3 kinase and extracellular 
signal-regulated kinase $1 / 2$ signaling (63) (64) (165). The physiological significance of these C5a regulatory effects is likely to attenuate potential tissue damage mediated by various T cell effector subsets (e.g., Th1 and Th17, regulated by IL-12 and IL-23, respectively), as seen in various pathological inflammatory conditions (91). However, undesirable outcomes may arise when $\mathrm{C} 5 \mathrm{a}$ is not produced physiologically but rather through the uncontrolled action of microbial enzymes. In this context, pathogen-induced generation of C5a may modify TLR signaling and skew the T helper response in ways that could interfere with protective immunity. Therefore, on the basis of our findings and the reports on IL-12 and IL-23 regulation by C5a, it becomes evident that pathogens may exploit TLR-C5aR crosstalk in various ways.

In summary, this work constitutes the first report of complement-TLR crosstalk for synergistic cAMP induction which disables macrophages. From a therapeutic viewpoint, C5aR blockade effectively deprived this pathogen of crucial survival tactics and may thus confer protection against periodontitis and associated systemic diseases like atherosclerosis. Since C5a can be generated by both complement and non-complement C5 convertases that also include microbial enzymes (69) (112) (136), it becomes important to identify other pathogens that exploit C5a-mediated subversive crosstalk signaling with TLRs. This will have important implications for novel counter-strategies to neutralize microbial virulence. Our findings further suggest that, in the course of evolution, chronically persisting pathogens may not have simply "learned" to breach complement and the TLRs separately, but, as hereby exemplified by $P$. gingivalis, to also exploit their communication hubs. 


\section{CHAPTER FIVE: THE C5A RECPTOR IMPAIRS IL-12-DEPENDENT CLEARANCE OF PORPHYROMONAS GINGIVALIS AND IS REQUIRED FOR INDUCTION OF PERIODONTAL BONE}

\section{Introduction}

In addition to its role in pathogen recognition and elimination, the complement network regulates immune and inflammatory responses through direct effects on immune cells or via crosstalk with TLRs and other signaling pathways (130). Both complement and TLRs are rapidly activated in response to infection and their crosstalk may serve to coordinate the host response through synergistic or antagonistic interactions. These interactions may respectively enhance host defense or control it to prevent immunopathology. However, the propensity of complement and TLRs for communication may be exploited by microbial pathogens to manipulate the host response in ways that promote their adaptive fitness (52).

In this context, we have recently shown that the periodontal pathogen Porphyromonas gingivalis induces a subversive crosstalk between the complement C5a receptor $(\mathrm{C} 5 \mathrm{aR})$ and TLR2 that impairs nitric oxide-dependent intracellular killing in macrophages (157). Interestingly, $P$. gingivalis can control both receptors: it can directly engage TLR2 through cell-surface ligands (4), whereas it can activate C5aR (CD88) through local conversion of C5 to C5a using its own enzymes (157). Indeed, this bacterium does not have to rely on immunological mechanisms for C5a generation, but 
rather expresses extracellular cysteine proteinases (gingipains) which function as C5 convertase-like enzymes (125) (157).

C5aR activation has been also shown to downregulate TLR4-induced production of IL-12 in vitro and in vivo (63) (85) (165). This effect is exerted at the transcriptional level since C5aR signaling in macrophages inhibits TLR4-induced mRNA expression of the IL-12p35 and IL-12/IL-23p40 subunits. Since IL-12 is a key cytokine in Th1 differentiation and cell-mediated immunity, this C5aR-TLR4 crosstalk may represent a regulatory mechanism to control IL-12 production and thereby prevent or attenuate possible immunopathology (52). However, undesirable outcomes could arise if C5a is produced at excessively high levels, as may happen in sepsis. Under such conditions, the crosstalk between C5a-activated C5aR and TLR4 could severely suppress IL-12 and interfere with protective Th1 immunity (52) (63).

High levels of C5a can be generated also through the uncontrolled action of C5convertase-like microbial enzymes like the $P$. gingivalis gingipains (157). We therefore hypothesized that $P$. gingivalis may take advantage of C5a-induced signaling to suppress biologically active IL-12 (IL-12p70). Given that IL-12p70 induces IFN- $\gamma$ and mediates bacterial clearance through activated phagocytes (153), possible inhibition of this cytokine by $P$. gingivalis through $\mathrm{C} 5 \mathrm{aR}$ exploitation could contribute to its ability to evade immune control. In this chapter, we show that C5a (and, to a lesser extent, its desarginated derivative C5 $\mathrm{a}^{\text {desArg }}$ ) inhibits TLR2-dependent induction of IL-12p70, but enhances induction of pro-inflammatory and bone-resorptive cytokines (IL-1 $\beta$, IL-6, and TNF- $\alpha$ ), in response to $P$. gingivalis. These in vitro observations were confirmed by in vivo studies, which additionally showed that C5aR-dependent inhibition of IL-12p70 
promotes the survival of this pathogen. Moreover, C5aR signaling was required for the ability of $P$. gingivalis to induce periodontal bone loss in a mouse model of experimental periodontitis. Therefore, $P$. gingivalis exploits C5aR to promote its adaptive fitness and cause periodontal disease. This immune subversion mechanism has important therapeutic implications given the current availability of safe, selective, and potent $\mathrm{C} 5 \mathrm{aR}$ antagonists.

\section{Results}

\section{P. gingivalis proactively and selectively inhibits IL-12p70 production via C5aR-}

\section{TLR2 crosstalk}

We investigated whether C5a inhibits $P$. gingivalis-induced IL-12p70 in peritoneal macrophages. E. coli LPS-stimulated macrophages were used as a control since C5a has been shown to inhibit IL-12p70 through a C5a/C5aR-LPS/TLR4 crosstalk (63). The host TLR response against $P$. gingivalis is predominantly mediated by TLR2 both in vitro and in vivo (54) (55) (11). Therefore, we additionally examined whether possible C5a-mediated inhibition of $P$. gingivalis-induced IL-12p70 could involve a C5aR-TLR2 crosstalk. We found that the abilities of both $P$. gingivalis and LPS to induce IL-12p70 production were significantly inhibited by C5a $(p<0.01$; Fig. 15A). These inhibitory effects were specifically mediated by C5aR signaling since they were completely reversed by a specific C5aR antagonist (C5aRA) $(p<0.01$; Fig. 15A).

Intriguingly, we observed that $\mathrm{C} 5 \mathrm{aR}$ blockade significantly enhanced the induction of IL-12p70 production, even in $P$. gingivalis-stimulated macrophages that were not treated with exogenous C5a $(p<0.01$; Fig. 15A). However, we did not observe this upregulatory effect of C5aR antagonism in LPS-stimulated macrophages (Fig. 15A). 
We previously showed that $P$. gingivalis uses its gingipains to generate C5a in complement-inactivated serum (157). Therefore, we reasoned that endogenously generated C5a limits $P$. gingivalis-induced IL-12p70 production, which is thus enhanced in the presence of $\mathrm{C} 5 \mathrm{aRA}$. This notion was substantiated by the finding that the isogenic mutant KDP128, which lacks all three gingipain genes, failed to regulate IL-12p70, unless exogenous C5a was added in the cell cultures (Fig. 15B). Indeed, C5aRA had no effect on KDP128-induced IL-12p70 in the absence of exogenously added C5a (Fig. 15B). The ability of $P$. gingivalis to induce IL-12p70 was completely abrogated in TLR2-deficient macrophages, whereas, as expected, LPS-induced IL-12p70 was unaffected (Fig. 15C). Taken together, these data indicate that $P$. gingivalis activates a C5aR-TLR2 crosstalk which inhibits IL-12p70 production in macrophages.

The C5aR crosstalk pathways with TLR2 or TLR4 for IL-12p70 regulation appear to be similar, since the inhibitory effects of C5a were abrogated by treatment with the MEK1/2-specific inhibitor U0126 but not by the PI3K inhibitor wortmannin $(p<0.01$; Fig. 15D). This implicates the MEK-ERK1/2 pathway in C5aR-mediated regulation of both TLR2- and TLR4-induced IL-12p70. On the other hand, the PI3K pathway is minimally involved, if at all (63). The C5aR-dependent inhibition of IL-12p70 in $P$. gingivalis-stimulated macrophages was selective for this cytokine, since other proinflammatory cytokines (IL-6 and TNF- $\alpha$ ) were augmented ( $p<0.01$; Fig. 1E). In conclusion, $P$. gingivalis proactively and selectively inhibits IL-12p70 production by activating a C5aR-TLR2 crosstalk without requirement for immunological mechanisms of complement activation. 

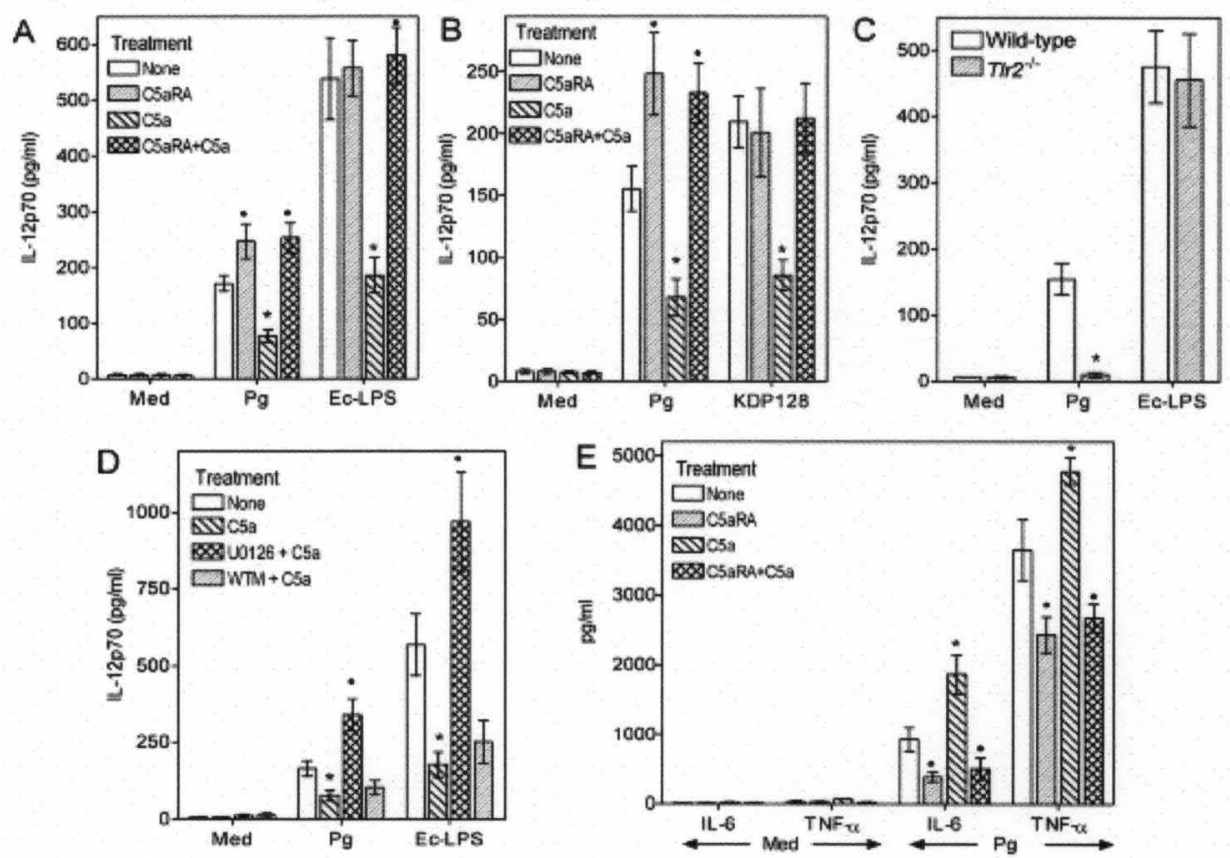

Figure 15: C5aR signaling inhibits TLR2-dependent IL-12p70 induction in

P. gingivalis-activated macrophages. IFN- $\gamma$ primed wild-type (A-D) or TLR2-deficient (C) mouse peritoneal macrophages were stimulated with medium, $P$. gingivalis, or E. coli LPS. Panel B includes the use of an isogenic mutant (KDP128) which is deficient in all three gingipain genes. Macrophages were pre-treated with C5aRA (A-B), U0126 or wortmannin (D) prior to challenge with C5a, P. gingivalis, or Ec-LPS. Culture supernatants were assayed for induction of the indicated cytokines after $24 \mathrm{~h}$ of incubation. Data are means $\pm \mathrm{SD}$ ( $n=3$ sets of macrophages). Asterisks show statistically significant $(p<0.01)$ inhibition (A-D; IL-12p70) or enhancement (E; IL-6 and TNF- $\alpha$ ) of cytokine production, whereas black circles indicate statistically significant $(p<0.01)$ reversal of these modulatory effects. 


\section{C5aR signaling in vivo differentially regulates $P$. gingivalis-induced cytokine}

responses

We next investigated the biological significance of the C5aR-mediated inhibition of IL-12p70 production. First, it was essential to determine whether C5aR signaling can regulate $P$. gingivalis-induced IL-12p70 production also in vivo. For this purpose, wildtype mice were i.p. administered C5aRA followed by i.p. challenge with $P$. gingivalis. Mice deficient in C5aR or TLR2 were similarly challenged with $P$. gingivalis, and all mice were sampled $5 \mathrm{~h}$ post-infection by peritoneal lavage. In addition to IL-12p 70 , we determined production of IFN- $\gamma$ (which is positively regulated by IL-12p70 (153)), IL-23 (an IL-12 family cytokine which shares a common IL-12/IL-23p40 subunit with IL$12 \mathrm{p} 70$ (119), as well as pro-inflammatory cytokines that have been implicated in inflammatory bone resorption in periodontitis (IL-1 $\beta$, IL-6, and TNF- $\alpha$ ) (43). C5aRAtreated wild-type mice and C5aR-deficient mice elicited significantly higher levels of IL12p70, IFN- $\gamma$, and IL-23 compared to PBS-treated wild-type controls $(p<0.01-0.05$; Fig. 16). In contrast, the induction of IL-1 $\beta$, IL- 6 , and TNF- $\alpha$ production was inhibited by C5aR blockade or C5aR deficiency ( $p<0.01$; Fig. 2). On the other hand, the induction of all tested cytokines was abrogated in TLR2-deficient mice $(p<0.01$; Fig. 2$)$. These data confirm that C5aR signaling in vivo selectively inhibits the ability of $P$. gingivalis to induce TLR2-dependent IL-12 family cytokines (IL-12p70 and IL-23). Additionally, the observed downregulation of IFN- $\gamma$ is most likely secondary to inhibition of IL-12p70 production. On the other hand, maximal induction of IL-1 $\beta$, IL-6, and TNF- $\alpha$ requires intact signaling by both C5aR and TLR2. 


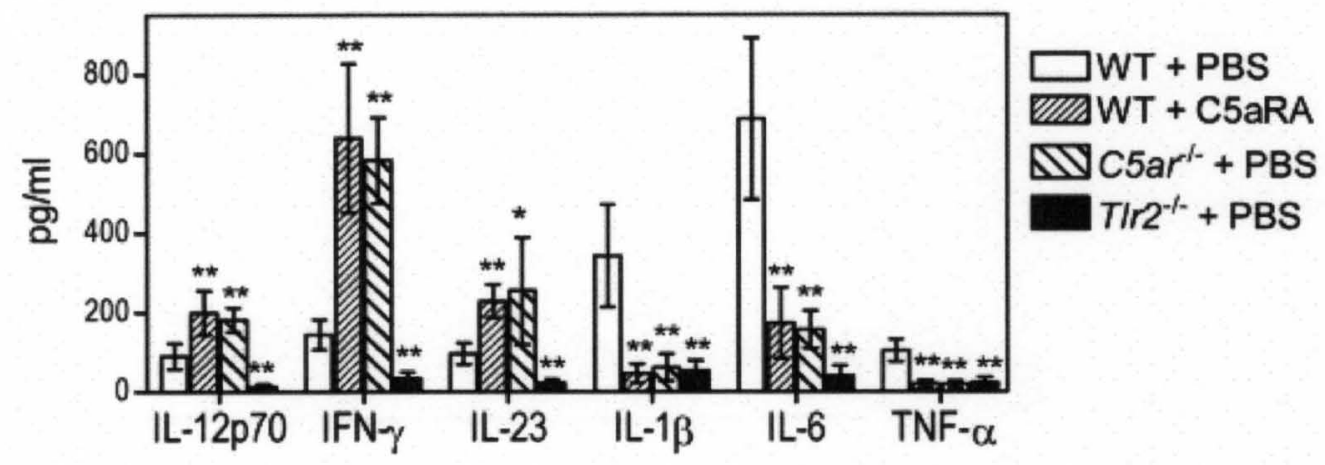

Figure 16. C5aR signaling regulates $P$. gingivalis-induced and TLR2dependent cytokine production in vivo. 10-12 week-old wild-type (WT) mice, which were pretreated or not with C5aRA (i.p.; $25 \mu \mathrm{g} / \mathrm{mouse}$ ), as well as mice deficient in $\mathrm{C} 5 \mathrm{aR}\left(\mathrm{C} \mathrm{ar} r^{-/}\right)$or $\operatorname{TLR} 2\left(\mathrm{Tlr}^{-/-}\right)$, were i.p. infected with $P$. gingivalis $\left(5 \times 10^{7} \mathrm{CFU}\right)$. Peritoneal lavage was performed $5 \mathrm{~h}$ post-infection and the peritoneal fluid was used to measure the levels of the indicated cytokines. Mice not infected with $P$. gingivalis had undetectable levels of the cytokines investigated. Data are means $\pm \mathrm{SD}(n=$ 5 mice). ${ }^{*}, p<0.01$ and ${ }^{* *}, p<0.01$ vs. WT+PBS control. 


\section{C5aR-mediated inhibition of IL-12p70 promotes $P$. gingivalis survival in vivo}

Whether the C5aR-mediated inhibitory effect on IL-12p70 production (Fig. 16) is exploited by $P$. gingivalis was addressed in subsequent experiments. Wild-type mice were i.p. treated with C5aRA (or PBS control) and infected with $P$. gingivalis by the same route. The C5aRA-treated mice comprised several groups, including mice given anti-IL-12 IgG, anti-IL-23p19 IgG, or non-immune IgG control. Treatment with anti-IL23 p19 was included because the anti-IL-12 Ab reacts with both IL-12p70 subunits, p35 and $\mathrm{p} 40$, the latter of which is shared by the heterodimeric IL-23 (IL-12/IL-23p40 and IL$23 p 19(119))$. Thus, the experiment was designed in a way that would allow specific implication of IL-12p70 or both IL-12p70 and IL-23 in P. gingivalis immune clearance. At 24h post-infection, the peritoneal lavage fluid from C5aRA-treated mice contained about $2 \log _{10}$ units less $P$. gingivalis CFU compared to mice pretreated with PBS control $(p<0.01$; Fig. 17A). However, the enhanced ability of C5aRA-treated mice to clear $P$. gingivalis was significantly $(p<0.01)$ counteracted by anti-IL-12 treatment, though not by anti-IL-23p19 or non-immune IgG (Fig. 17A). Viable $P$. gingivalis CFU counts were not detected in the blood or in homogenates of several organs examined (spleen, kidney, liver, and lungs) from any of the mouse groups. Taken together with the Fig. 16 findings, these data show that C5aR signaling inhibits IL-12p70 production and this inhibitory effect is exploited by $P$. gingivalis to resist immune clearance. This conclusion was further substantiated by similar findings from a related experiment in which C5aRAtreated mice were replaced by C5aR-deficient mice (Fig. 17B). 


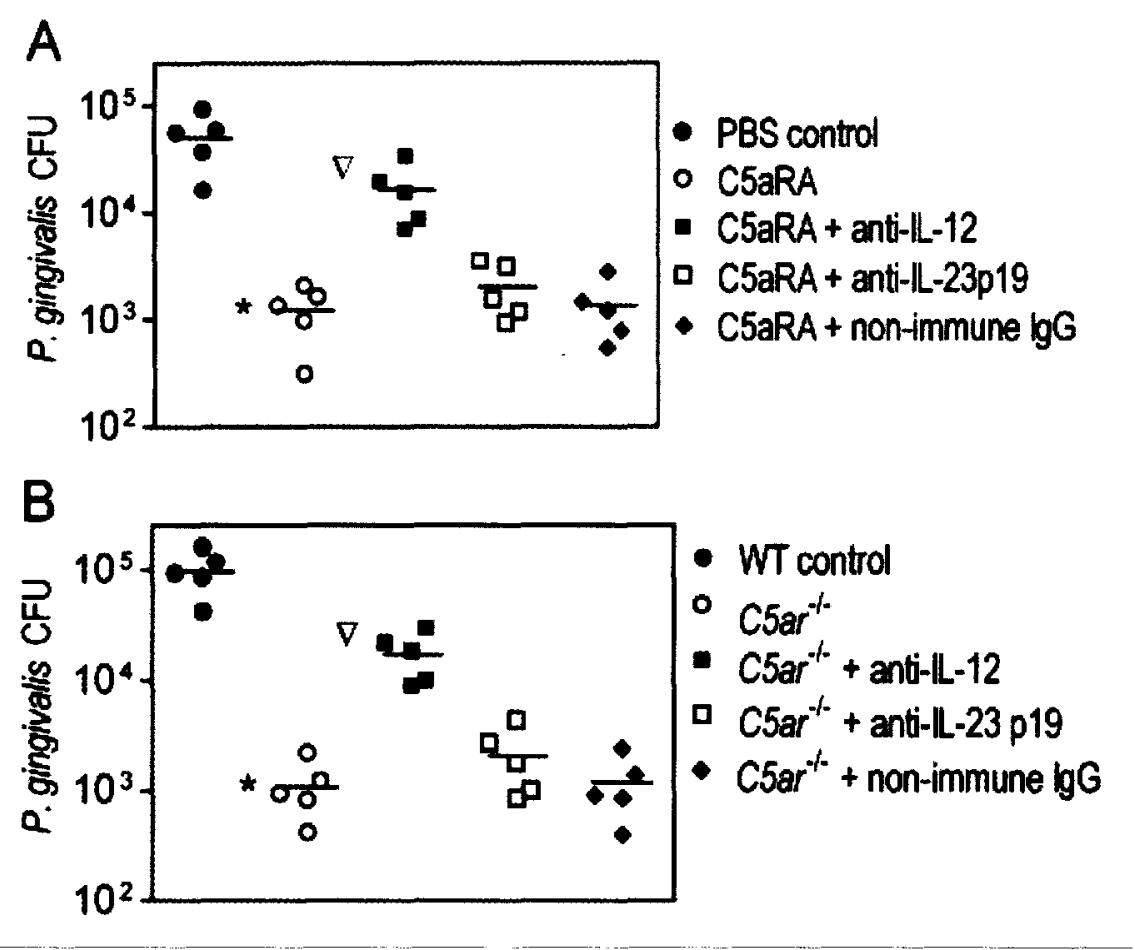

Figure 17. Inhibition of C5aR signaling promotes the in vivo clearance of P. gingivalis by augmenting IL-12. (A) Wild-type mice were pre-treated or not with C5aRA (i.p.; $25 \mu \mathrm{g} /$ mouse), in the presence or absence of goat polyclonal anti-mouse IL-12 IgG, anti-mouse IL-23p19 IgG, or equal amount of non-immune IgG (i.p.; $0.1 \mathrm{mg} /$ mouse). The mice were then infected i.p. with $P$. gingivalis $\left(5 \times 10^{7} \mathrm{CFU}\right)$. (B) Similar experiment in which C5aRAtreated mice were replaced by C5aR-deficient $\left(C 5 a r^{-1-}\right)$ mice. Peritoneal lavage was performed $24 \mathrm{~h}$ post-infection and the peritoneal fluid was used to determine viable $P$. gingivalis CFU counts. Data are shown for each individual mouse with horizontal lines indicating mean values. ${ }^{*}, p<0.01$ vs. controls. The inverted triangles indicate significant $(p<0.01)$ reversal of the effects of C5aRA or C5aR deficiency by anti-IL-12. 


\section{Comparison of C5a and C5a ${ }^{\text {desArg }}$ in regulating IL-12p70 and other macrophage}

activities

The peritoneal fluid of $P$. gingivalis-infected mice from the above described experiments was also assayed by mouse C5a ELISA. C5a was detected at $2304 \pm 527$ $\mathrm{pg} / \mathrm{ml}(n=5 \mathrm{mice})$ and $1629 \pm 378 \mathrm{pg} / \mathrm{ml}(n=5 \mathrm{mice})$ at, respectively, $5 \mathrm{~h}$ and $24 \mathrm{~h}$ postinfection. C5a is relatively unstable in biological fluids and is rapidly converted to its desarginated form (C5a $\left.{ }^{\text {desArg }}\right)$. In fact, a large part of detected C5a may represent C5 $\mathrm{a}^{\text {desArg }}$ since the capturing antibody used in the sandwich ELISA (BD Pharmingen) recognizes a neoepitope exposed in both $\mathrm{C} 5 \mathrm{a}$ and $\mathrm{C} 5 \mathrm{a}^{\text {desArg }}$ (though not in intact C5). C5 $\mathrm{a}^{\text {desArg }}$ does not have anaphylactic action but retains a number of other biological activities (97) (102) (107). We thus investigated whether it shares the capacity of C5a to regulate IL-12p70. We found that $\mathrm{C} 5 \mathrm{a}^{\mathrm{des} A r g}$ can also inhibit $P$. gingivalis-induced IL12 p70 production, though not as strongly as C5a. Specifically, C5a ${ }^{\text {desArg }}$ mediated significant $(p<0.05)$ inhibition of IL-12p70 at $50 \mathrm{nM}$ but not at $10 \mathrm{nM}$, at which concentration C5a was already effective (Fig. 18A). However, the increased stability and thus higher prevalence of $\mathrm{C} 5 \mathrm{a}^{\text {desArg }}$ compared to intact $\mathrm{C} 5$ a suggests a possible significant role for the desarginated molecule in IL-12p70 regulation.

Although C5 $\mathrm{a}^{\text {desArg }}$ binds also to the C5a-like receptor-2 (C5L2) with high affinity (120) (130), its observed modulatory effect on IL-12p70 production was likely mediated via the C5aR (CD88). In this regard, C5aRA by itself caused full reversal of the inhibitory effect of $\mathrm{C} 5 \mathrm{a}^{\mathrm{desArg}}$, whereas a dual C5aR/C5a-like receptor-2 antagonist (A8 ${ }^{\Delta 71-}$

${ }^{73}$ ) (120) (133) had a comparable effect (Fig. 18B). In contrast, the C3aR antagonist 
SB290157 (control) did not influence the ability of C5a $\mathrm{a}^{\text {desArg }}$ to inhibit induction of IL12p70 by $P$. gingivalis (Fig. 18B).

We previously implicated C5a in synergistic interactions with $P$. gingivalis that elevate cAMP in macrophages, leading to inhibition of nitric oxide production and of intracellular killing (157). We investigated whether these evasion mechanisms can also be activated by $C 5 \mathrm{a}^{\text {desArg }}$. Side-by-side comparison revealed no significant differences between $\mathrm{C} 5 \mathrm{a}$ and $\mathrm{C} 5 \mathrm{a}^{\mathrm{des} A r g}$ when tested at $50 \mathrm{nM}$ in elevating cAMP, inhibiting nitric oxide, and promoting its intracellular survival (Fig. 18, C-E). However, when the compounds were tested at $10 \mathrm{nM}, \mathrm{C} 5 \mathrm{a}$ exhibited stronger effects than C5 ${ }^{\text {desArg }}$ (Fig.18, C-E). In view of the strict dependence of $\mathrm{C} 5 \mathrm{a}$ on intracellular $\mathrm{Ca}^{2+}$ mobilization to synergistically elevate cAMP (157), we hypothesized that $\mathrm{C} 5 \mathrm{a}^{\text {desArg }}$ could similarly induce intracellular $\mathrm{Ca}^{2+}$ responses. Indeed, at $50 \mathrm{nM}, \mathrm{C} 5 \mathrm{a}$ and $\mathrm{C} 5 \mathrm{a}^{\text {des Arg }}$ induced comparable intracellular $\mathrm{Ca}^{2+}$ mobilization in macrophages (Fig. 19A), whereas only C5a was active in that regard in neutrophils (Fig. 19B). Taken together, the data from Figs. 18 and 19 indicate that $P$. gingivalis can exploit C5a even after its conversion to $\mathrm{C} 5 \mathrm{a}^{\mathrm{desArg}}$, thereby undermining macrophage defense functions (induction of IL-12p70, activation of intracellular killing). 

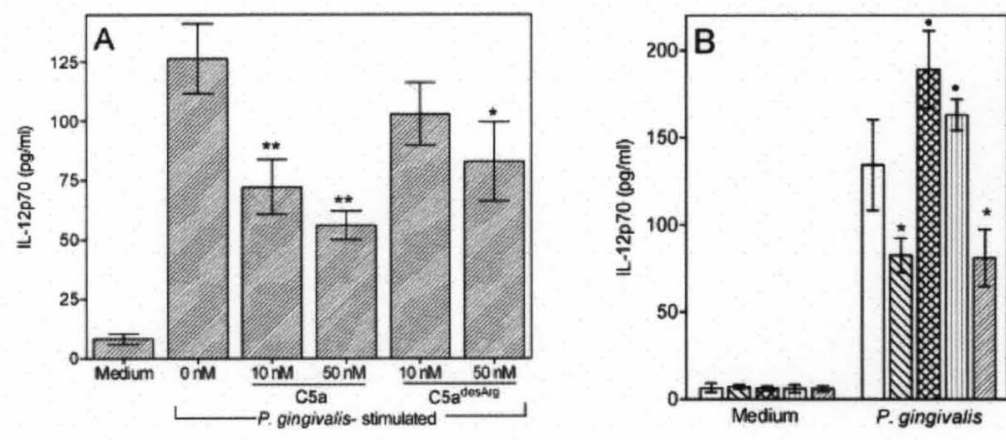

Treatment

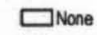

WC5a dederp

C5aRA + C5a dockes

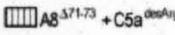

$C 23 a R A+C 5 a$ andero
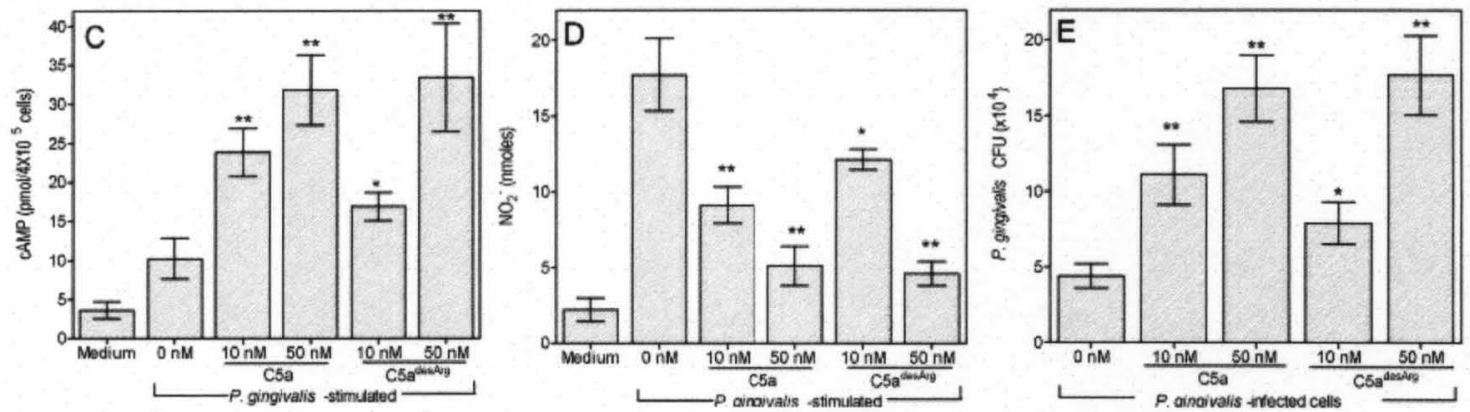

Figure 18. Comparative modulatory effects of C5a and C5a ${ }^{\text {desArg }}$ on IL-12p70 production and antimicrobial activities in $\boldsymbol{P}$. gingivalis-challenged macrophages. Groups of mouse peritoneal macrophages were incubated with $P$. gingivalis in the absence or presence of $\mathrm{C} 5 \mathrm{a}$ or $\mathrm{C} 5 \mathrm{a}^{\mathrm{des} A r g}$ (at 10 or $50 \mathrm{nM}$ ) and assayed for (A) induction of IL-12p70 (after 24h), (C) generation of cAMP (1h), (D) $\mathrm{NO}_{2}^{-}(24 \mathrm{~h})$, and (E) viable counts $(\mathrm{CFU})$ of internalized bacteria $(24 \mathrm{~h})$. In panel $\mathrm{B}$, the macrophages were pre-treated with C5aRA, the dual C5aR/C5a-like receptor-2 antagonist $A 8^{\Delta 71-73}$, or the C3aR antagonist SB290157 to determine the receptor by which C5a $\mathrm{a}^{\operatorname{des} A r g}(50 \mathrm{nM})$ inhibits IL-12p70 production. Data are means $\pm \mathrm{SD}$ ( $n=3$ sets of macrophages). ${ }^{*}, p<0.05$ and ${ }^{* *}, p<$ 0.01 compared to no $\mathrm{C} 5 \mathrm{a}$ or $\mathrm{C} 5 \mathrm{a}^{\mathrm{des} A r g}(0 \mathrm{nM})$. In B, black circles indicate statistically significant $(p<0.01)$ reversal of the inhibitory effect of $\mathrm{C} 5 \mathrm{a}^{\mathrm{des} A r g}$. In panels $\mathrm{C}-\mathrm{E}$, no significant differences were found between C5a and C5 $\mathrm{a}^{\text {desArg }}$ when tested at $50 \mathrm{nM}$. 

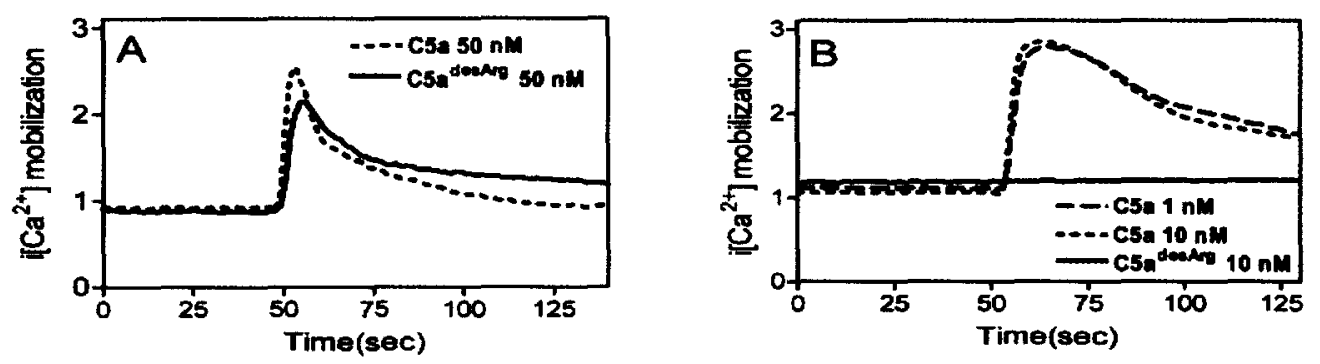

Figure 19. Comparison of $\mathrm{C5a}$ and $\mathrm{C5a}^{\text {desArg }}$ in intracellular $\mathrm{Ca}^{2+}$ mobilization. Mouse peritoneal macrophages (A) or neutrophils (B) were loaded with the ratiometric calcium indicator Indo-1 AM and stimulated with $\mathrm{C} 5 \mathrm{a}$ or $\mathrm{C} 5 \mathrm{a}^{\text {desArg }}$ at the indicated concentrations (lower concentrations were used for neutrophils since they are more sensitive to C5a than macrophages (49)). $\mathrm{Ca}^{2+}$ mobilization was measured in a spectrofluorometer and the traces are representative of three experiments. 


\section{C5aR mediates periodontal bone loss}

The involvement of C5aR signaling in $P$. gingivalis immune evasion and in the induction of pro-inflammatory cytokines (Figs. 15-18), such as IL-1 $\beta$, IL-6, and TNF- $\alpha$ that mediate periodontal bone resorption (43), suggested that C5aR may play an important role in $P$. gingivalis-induced periodontitis. Indeed, $P$. gingivalis failed to induce significant periodontal bone loss in C5aR-deficient BALB/c or C57BL/6 mice, in stark contrast to corresponding wild-type mice which developed significant bone loss relative to sham-infected controls ( $p<0.01$; Fig. $20 \mathrm{~A}, \mathrm{~B}$, and E). TLR2 participates in crosstalk interactions with $\mathrm{C} 5 \mathrm{aR}$ that promote mechanisms of $P$. gingivalis immune evasion (157) and induce production of bone-resorptive cytokines (Fig. 16). Sensibly, therefore, TLR2-deficient BALB/c mice were similarly shown to be resistant to $P$. gingivalis-induced periodontal bone loss (Fig. $20 \mathrm{C}$ and E).

Mice used for $P$. gingivalis-induced periodontitis studies are usually 8-12 weekold and sham-infected controls do not develop appreciable bone loss (44). However, aging mice, like aging humans, gradually develop naturally-occurring inflammatory periodontal bone loss (due to chronic exposure to indigenous periodontal bacteria), which becomes quite dramatic after 9 months of age (51) (93). To determine the role of C5aR in the age-associated periodontitis model, we raised C5aR-deficient BALB/c mice and wildtype controls until the age of 16 months. We found that old C5aR-deficient mice are significantly protected against age-associated periodontitis relative to similarly aged wild-type controls $(p<0.01$; Fig. 20D). Therefore, C5aR is involved in chronic, ageassociated periodontal bone loss. However, it is currently uncertain whether C5aR is exploited by mouse periodontal bacteria as shown for $P$. gingivalis. 

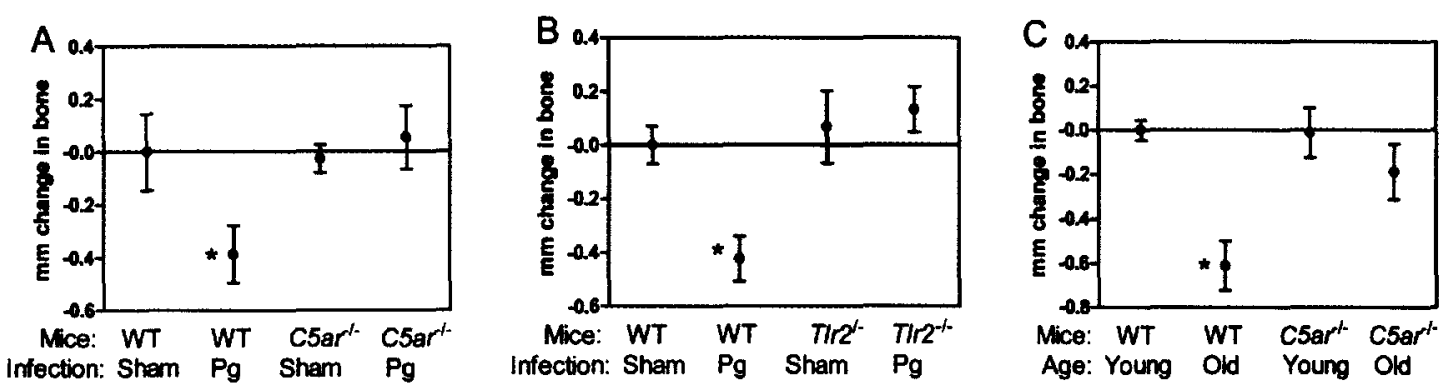

Figure 20. C5aR and TLR2 deficiencies protect against periodontal bone loss. Mice deficient in C5aR $\left(\mathrm{C}^{2} a r^{-/-}\right)(\mathrm{A}, \mathrm{BALB} / \mathrm{c} ; \mathrm{B}, \mathrm{C} 57 \mathrm{BL} / 6)$ or TLR2 $\left(\mathrm{Tl}^{-/-}\right)(\mathrm{C}$; $\mathrm{BALB} / \mathrm{c}$ ) and appropriate wild-type controls were orally infected or not with $P$. gingivalis and assessed for induction of periodontal bone loss six weeks later. Mice used in these experiments were 10-12 week-old. (D) Induction of naturally occurring periodontal bone loss in 16-month-old wild-type or $\mathrm{C} 5 \mathrm{ar}^{-/-} \mathrm{BALB} / \mathrm{c}$ mice relative to their young counterparts $(\leq 12$ weeks of age). (E) Representative images of $P$. gingivalis-induced bone loss under wild-type or C5aR- or TLR2-deficient conditions: P. gingivalis-infected $\mathrm{CS}_{\mathrm{ar}} \mathrm{H}^{-/}$or $\mathrm{Tl} \mathrm{2}^{-/-}$mice display considerably smaller CEJ-ABC distances (yellow arrows) compared to infected wild-type mice, but quite comparable to those of sham-infected wild-type mice. Data are means $\pm \operatorname{SD}\left(n=5\right.$ mice). ${ }^{*}, p<$ 0.01 compared to corresponding sham-infected controls (A and B) or young counterparts (C). 


\section{Discussion}

Clinical and histological observations implicate complement in periodontal inflammation and pathogenesis, although the precise mechanisms or pathways involved have remained largely undefined (48). However, our findings clearly implicate the C5a$\mathrm{C} 5 \mathrm{aR}$ axis in periodontal tissue destruction and immune evasion by periodontal bacteria.

Our present data suggest that $P$. gingivalis may exploit $\mathrm{C} 5 \mathrm{aR}$ to promote its adaptive fitness in diverse ways. On the one hand, C5aR signaling inhibits TLR2dependent IL-12p70 induction and interferes with immune clearance of $P$. gingivalis. On the other hand, the $P$. gingivalis-instigated C5aR-TLR2 crosstalk leads to enhanced production of other pro-inflammatory cytokines (IL-1 $\beta$, IL-6, and TNF- $\alpha$ ). Therefore, this pathogen does not appear to cause a generalized immunosuppression but, rather, has evolved the ability to selectively target pathways that could result in its elimination. Consequently, $P$. gingivalis is an asaccharolytic organism with a strict requirement for peptides and hemin, and thus depends on the continuous flow of inflammatory serum exudate (gingival crevicular fluid) to obtain these essential nutrients and survive in its periodontal niche (34). In fact, non-selective immunosuppression would not be advantageous for $P$. gingivalis; whereas such strategy would certainly afford protection against host immunity; however, $P$. gingivalis would likely be condemned to starvation. . Therefore, the proactive release of C5a by $P$. gingivalis and the ensuing C5a-induced inflammation (increased vascular permeability and pro-inflammatory synergy with TLRs) can contribute to nutrient procurement. Moreover, the ability of $P$. gingivalis to induce C5aR-dependent periodontal bone loss expands the useful space for increased niche for the pathogen. 
On the basis of the above discussion, it becomes apparent that $P$. gingivalis uses a quite antithetical strategy relative to Staphylococcus aureus which promotes its survival by actually blocking $\mathrm{C} 5 \mathrm{a}$ binding and $\mathrm{C} 5 \mathrm{aR}$ activation, via a secreted protein known as CHIPS (chemotaxis inhibitory protein of $S$. aureus) (25). This mechanism inhibits C5ainduced inflammation and phagocytic cell chemotaxis and protects $S$. aureus from neutrophils and macrophages (25). On the other hand, the protozoan parasite Leishmania major also exploits C5aR for evading host immunity, which is restored in C5aR-deficient mice that consequently do not develop necrotizing dermal lesions as wild-type animals do (63). However, unlike $P$. gingivalis, $L$. major has to rely on C5a generation by the physiological complement cascade in order to exploit $\mathrm{C} 5 \mathrm{aR}$.

P. gingivalis-induced inflammation via the C5aR-TLR2 crosstalk may have important implications from a clinical perspective, since it is likely to cause collateral tissue damage (inflammatory periodontal bone destruction). This notion is supported by our findings that mice deficient in C5aR or TLR2 are both resistant to $P$. gingivalisinduced periodontitis. The fact that induction of bone loss is essentially prevented in the absence of either C5aR or TLR2 signaling, argues against the possibility that C5aR and TLR2 contribute to periodontal pathogenesis through independent effector mechanisms. In this regard, both receptors are under $P$. gingivalis control and are induced to crosstalk, while in physical proximity (157), cooperatively leading to immune evasion and induction of inflammatory/bone-resorptive cytokines.

Both the C5a and C3a anaphylatoxins are readily metabolized in serum and lose their C-terminal arginine due to carboxypeptidase activity (107). The resulting C3a fragment $\left(\mathrm{C}^{\mathrm{des} A r g}\right)$ is biologically inert in terms of $\mathrm{C} 3 \mathrm{a}$ receptor-dependent functions, 
but retains antimicrobial activity which is exerted independently of the receptor (114). On the other hand, C5 $\mathrm{a}^{\text {desArg }}$ can still bind C5aR, albeit with a lower affinity and a different mode of interaction relative to intact C5a (19) (107). Although C5a ${ }^{\text {desArg }}$ is devoid of C5a spasmogenic (anaphylactic) activity, it retains other C5a activities to varying degrees depending on function and cell type involved. For example, monocytes/macrophages, but not neutrophils, do not appear to distinguish between C5a and $C 5 \mathrm{a}^{\text {desArg }}$ in terms of induction of chemotaxis or lysosomal enzyme release (13) (97) (102). Our findings that $\mathrm{C} 5 \mathrm{a}^{\mathrm{des} A r g}$ retains the ability to inhibit $P$. gingivalis-induced IL$12 p 70$ and nitric oxide production has important implications: being considerably more stable than $\mathrm{C} 5 \mathrm{a}$ (107), C5 $\mathrm{a}^{\text {desArg }}$ may provide a persisting stimulus for sustained manipulation of the antimicrobial response and destructive inflammation, properties that characterize chronic conditions like periodontitis. Intriguingly, whereas $P$. gingivalis attacks $\mathrm{C} 5$ and generates biologically active $\mathrm{C} 5 \mathrm{a} / \mathrm{C} 5 \mathrm{a}^{\mathrm{desArg}}$, it extensively degrades $\mathrm{C} 3$ and C3a which thus do not retain biological activity (161). Since C3a (but not C5a) exerts direct antimicrobial effects and readily kills both gram-negative and gram-positive bacteria (114), it is possible that degradation and inactivation of C3a by $P$. gingivalis may serve to protect this pathogen.

The data from this study collectively suggest that $P$. gingivalis has evolved to not only endure the host response (by selectively suppressing critical 'killing' pathways, such as IL-12-dependent clearance), but also to benefit from the inflammatory response, while at the same time contributing to periodontal pathogenesis. The ability of $P$. gingivalis to inhibit innate immune functions via $\mathrm{C} 5 \mathrm{aR}$ exploitation may also allow bystander bacteria, i.e., co-habiting the same niche, to evade immune control. In this context, $P$. gingivalis is 
thought of as a keystone periodontal species that could promote the survival and virulence of the entire microbial community (20) (22) (49) (82).

In addition to being a prevalent and costly chronic condition that destroys toothsupporting tissues, severe periodontitis exerts a systemic impact on health and the patients run increased risk for diseases such as atherosclerosis, diabetes, and perhaps rheumatoid arthritis (26) (30) (123) (151). Therefore, it becomes important to identify promising therapeutics for the treatment of this oral disease. Since C5aR- or TLR2deficient mice are both resistant to periodontal bone loss, at least in principle, pharmacological blockade of either C5aR or TLR2 could inhibit periodontitis. However, the availability of highly effective and safe C5aR antagonists, some of which have completed phase II trials (for rheumatoid arthritis and psoriasis) (131) (155), and the relative paucity of effective TLR2 antagonists, suggest that C5aR is a preferential and promising target of local therapeutic intervention to treat human periodontitis. From a mechanistic viewpoint, C5aR blockade may counteract the ability of periodontal bacteria to evade critical antimicrobial responses or to stimulate non-resolving/destructive inflammation, and thus should be capable of both controlling the infection and inhibiting periodontal bone loss. 


\section{REFERENCES}

1. Akira, S., and K. Takeda. 2004. Toll-like receptor signalling. Nat Rev Immunol 4:499-511.

2. Andreakos, E., B. Foxwell, and M. Feldmann. 2004. Is targeting Toll-like receptors and their signaling pathway a useful therapeutic approach to modulating cytokine-driven inflammation? Immunol Rev 202:250-65.

3. Asai, Y., Y. Ohyama, K. Gen, and T. Ogawa. 2001. Bacterial fimbriae and their peptides activate human gingival epithelial cells through Toll-like receptor 2 . Infect Immun 69:7387-95.

4. Attstrom, R., A. B. Laurel, U. Lahsson, and A. Sjoholm. 1975. Complement factors in gingival crevice material from healthy and inflamed gingiva in humans. J Periodontal Res 10:19-27.

5. Backhed, F., S. Normark, E. K. Schweda, S. Oscarson, and A. RichterDahlfors. 2003. Structural requirements for TLR4-mediated LPS signalling: a biological role for LPS modifications. Microbes Infect 5:1057-63.

6. Baker, P. J., M. Dixon, R. T. Evans, L. Dufour, E. Johnson, and D. C. Roopenian. 1999. CD4(+) T cells and the proinflammatory cytokines gamma interferon and interleukin- 6 contribute to alveolar bone loss in mice. Infect Immun 67:2804-9.

7. Baker, P. J., M. Dixon, and D. C. Roopenian. 2000. Genetic control of susceptibility to Porphyromonas gingivalis-induced alveolar bone loss in mice. Infect Immun 68:5864-8.

8. Baker, P. J., R. T. Evans, and D. C. Roopenian. 1994. Oral infection with Porphyromonas gingivalis and induced alveolar bone loss in immunocompetent and severe combined immunodeficient mice. Arch Oral Biol 39:1035-40.

9. Bettelli, E., T. Korn, and V. K. Kuchroo. 2007. Th17: the third member of the effector T cell trilogy. Curr Opin Immunol 19:652-7. 
10. Beutler, B., Z. Jiang, P. Georgel, K. Crozat, B. Croker, S. Rutschmann, X. Du, and K. Hoebe. 2006. Genetic analysis of host resistance: Toll-like receptor signaling and immunity at large. Annu Rev Immunol 24:353-89.

11. Burns, E., G. Bachrach, L. Shapira, and G. Nussbaum. 2006. Cutting Edge: TLR2 is required for the innate response to Porphyromonas gingivalis: activation leads to bacterial persistence and TLR2 deficiency attenuates induced alveolar bone resorption. J Immunol 177:8296-300.

12. Chapple, I. L., and J. B. Matthews. 2007. The role of reactive oxygen and antioxidant species in periodontal tissue destruction. Periodontol 2000 43:160232.

13. Chenoweth, D. E., M. G. Goodman, and W. O. Weigle. 1982. Demonstration of a specific receptor for human $\mathrm{C} 5 \mathrm{a}$ anaphylatoxin on murine macrophages. $\mathrm{J}$ Exp Med 156:68-78.

14. Coats, S. R., J. W. Jones, C. T. Do, P. H. Braham, B. W. Bainbridge, T. T. To, D. R. Goodlett, R. K. Ernst, and R. P. Darveau. 2009. Human Toll-like receptor 4 responses to $P$. gingivalis are regulated by lipid A 1- and 4'phosphatase activities. Cell Microbiol.

15. Coats, S. R., T. T. Pham, B. W. Bainbridge, R. A. Reife, and R. P. Darveau. 2005. MD-2 mediates the ability of tetra-acylated and penta-acylated lipopolysaccharides to antagonize Escherichia coli lipopolysaccharide at the TLR4 signaling complex. J Immunol 175:4490-8.

16. Coats, S. R., R. A. Reife, B. W. Bainbridge, T. T. Pham, and R. P. Darveau. 2003. Porphyromonas gingivalis lipopolysaccharide antagonizes Escherichia coli lipopolysaccharide at toll-like receptor 4 in human endothelial cells. Infect Immun 71:6799-807.

17. Cook, D. N., D. S. Pisetsky, and D. A. Schwartz. 2004. Toll-like receptors in the pathogenesis of human disease. Nat Immunol 5:975-9.

18. Courts, F. J., R. J. Boackle, H. H. Fudenberg, and M. S. Silverman. 1977. Detection of functional complement components in gingival crevicular fluid from humans with periodontal diseases. J Dent Res 56:327-31.

19. Crass, T., W. Bautsch, S. A. Cain, J. E. Pease, and P. N. Monk. 1999. Receptor activation by human C5a des Arg74 but not intact C5a is dependent on an interaction between Glu199 of the receptor and Lys68 of the ligand. Biochemistry 38:9712-7.

20. Darveau, R. P. 2009. Bacteria modulate host-cell responses by capitalizing on the lipid raft structure. Future Microbiol 4:155-7. 
21. Darveau, R. P. 2009. The oral microbial consortium's interaction with the periodontal innate defense system. DNA Cell Biol 28:389-95.

22. Darveau, R. P. 2010. Periodontitis: a polymicrobial disruption of host homeostasis. Nat Rev Microbiol 8:481-490.

23. Darveau, R. P., T. T. Pham, K. Lemley, R. A. Reife, B. W. Bainbridge, S. R. Coats, W. N. Howald, S. S. Way, and A. M. Hajjar. 2004. Porphyromonas gingivalis lipopolysaccharide contains multiple lipid A species that functionally interact with both toll-like receptors 2 and 4. Infect Immun 72:5041-51.

24. Davey, M. E., and J. W. Costerton. 2006. Molecular genetics analyses of biofilm formation in oral isolates. Periodontol 2000 42:13-26.

25. de Haas, C. J., K. E. Veldkamp, A. Peschel, F. Weerkamp, W. J. Van Wamel, E. C. Heezius, M. J. Poppelier, K. P. Van Kessel, and J. A. van Strijp. 2004. Chemotaxis inhibitory protein of Staphylococcus aureus, a bacterial antiinflammatory agent. J Exp Med 199:687-95.

26. de Pablo, P., I. L. Chapple, C. D. Buckley, and T. Dietrich. 2009. Periodontitis in systemic rheumatic diseases. Nat Rev Rheumatol 5:218-24.

27. Delgado, M. A., R. A. Elmaoued, A. S. Davis, G. Kyei, and V. Deretic. 2008. Toll-like receptors control autophagy. EMBO J 27:1110-21.

28. Delima, A. J., and T. E. Van Dyke. 2003. Origin and function of the cellular components in gingival crevice fluid. Periodontol 2000 31:55-76.

29. Dendorfer, U., P. Oettgen, and T. A. Libermann. 1994. Multiple regulatory elements in the interleukin- 6 gene mediate induction by prostaglandins, cyclic AMP, and lipopolysaccharide. Mol Cell Biol 14:4443-54.

30. Desvarieux, M., R. T. Demmer, T. Rundek, B. Boden-Albala, D. R. Jacobs, Jr., R. L. Sacco, and P. N. Papapanou. 2005. Periodontal microbiota and carotid intima-media thickness: the Oral Infections and Vascular Disease Epidemiology Study (INVEST). Circulation 111:576-82.

31. Discipio, R. G., P. J. Daffern, M. Kawahara, R. Pike, J. Travis, T. E. Hugli, and J. Potempa. 1996. Cleavage of human complement component C5 by cysteine proteinases from Porphyromonas (Bacteroides) gingivalis. Prior oxidation of C5 augments proteinase digestion of C5. Immunology 87:660-7.

32. Dixon, D. R., B. W. Bainbridge, and R. P. Darveau. 2004. Modulation of the innate immune response within the periodontium. Periodontol 2000 35:53-74. 
33. Eskan, M. A., G. Hajishengallis, and D. F. Kinane. 2007. Differential activation of human gingival epithelial cells and monocytes by Porphyromonas gingivalis fimbriae. Infect Immun 75:892-8.

34. Fearon, D. T. 1997. Seeking wisdom in innate immunity. Nature 388:323-4.

35. Finch, A. M., A. K. Wong, N. J. Paczkowski, S. K. Wadi, D. J. Craik, D. P. Fairlie, and S. M. Taylor. 1999. Low-molecular-weight peptidic and cyclic antagonists of the receptor for the complement factor C5a. J Med Chem 42:196574.

36. Finlay, B. B., and G. McFadden. 2006. Anti-immunology: evasion of the host immune system by bacterial and viral pathogens. Cell 124:767-82.

37. Gaffen, S. L., and G. Hajishengallis. 2008. A new inflammatory cytokine on the block: re-thinking periodontal disease and the $\mathrm{Th} 1 / \mathrm{Th} 2$ paradigm in the context of Th17 cells and IL-17. J Dent Res 87:817-28.

38. Garlet, G. P., C. R. Cardoso, A. P. Campanelli, B. R. Ferreira, M. J. AvilaCampos, F. Q. Cunha, and J. S. Silva. 2007. The dual role of p55 tumour necrosis factor-alpha receptor in Actinobacillus actinomycetemcomitans-induced experimental periodontitis: host protection and tissue destruction. Clin Exp Immunol 147:128-38.

39. Genco, C. A., C. W. Cutler, D. Kapczynski, K. Maloney, and R. R. Arnold. 1991. A novel mouse model to study the virulence of and host response to Porphyromonas (Bacteroides) gingivalis. Infect Immun 59:1255-63.

40. Genco, C. A., B. M. Odusanya, J. Potempa, J. Mikolajczyk-Pawlinska, and J. Travis. 1998. A peptide domain on gingipain $R$ which confers immunity against Porphyromonas gingivalis infection in mice. Infect Immun 66:4108-14.

41. Gibbons, R. J., S. S. Socransky, W. C. Dearaujo, and J. Vanhoute. 1964. Studies of the Predominant Cultivable Microbiota of Dental Plaque. Arch Oral Biol 9:365-70.

42. Gibson, F. C., 3rd, T. Ukai, and C. A. Genco. 2008. Engagement of specific innate immune signaling pathways during Porphyromonas gingivalis induced chronic inflammation and atherosclerosis. Front Biosci 13:2041-59.

43. Graves, D. 2008. Cytokines that promote periodontal tissue destruction. J Periodontol 79:1585-91.

44. Graves, D. T., D. Fine, Y. T. Teng, T. E. Van Dyke, and G. Hajishengallis. 2008. The use of rodent models to investigate host-bacteria interactions related to periodontal diseases. J Clin Periodontol 35:89-105. 
45. Grenier, D., S. Roy, F. Chandad, P. Plamondon, M. Yoshioka, K. Nakayama, and D. Mayrand. 2003. Effect of inactivation of the Arg- and/or Lys-gingipain gene on selected virulence and physiological properties of Porphyromonas gingivalis. Infect Immun 71:4742-8.

46. Guo, R. F., and P. A. Ward. 2005. Role of C5a in inflammatory responses. Annu Rev Immunol 23:821-52.

47. Gyurko, R., G. Boustany, P. L. Huang, A. Kantarci, T. E. Van Dyke, C. A. Genco, and F. C. Gibson, 3rd. 2003. Mice lacking inducible nitric oxide synthase demonstrate impaired killing of Porphyromonas gingivalis. Infect Immun 71:4917-24.

48. Hajishengallis, G. 2010. Complement and periodontitis. Biochem Pharmacol.

49. Hajishengallis, G. 2009. Porphyromonas gingivalis-host interactions: open war or intelligent guerilla tactics? Microbes Infect 11:637-45.

50. Hajishengallis, G. 2009. Toll gates to periodontal host modulation and vaccine therapy. Periodontol 2000 51:181-207.

51. Hajishengallis, G. 2010. Too old to fight? Aging and its toll on innate immunity. Mol Oral Microbiol 25:25-37.

52. Hajishengallis, G., and J. D. Lambris. 2010. Crosstalk pathways between Tolllike receptors and the complement system. Trends Immunol 31:154-63.

53. Hajishengallis, G., M. A. Shakhatreh, M. Wang, and S. Liang. 2007. Complement receptor 3 blockade promotes IL-12-Mediated Clearance of Porphyromonas gingivalis and Negates Its Virulence In Vivo. J Immunol 179:2359-67.

54. Hajishengallis, G., R. I. Tapping, E. Harokopakis, S. Nishiyama, P. Ratti, R. E. Schifferle, E. A. Lyle, M. Triantafilou, K. Triantafilou, and F. Yoshimura. 2006. Differential interactions of fimbriae and lipopolysaccharide from Porphyromonas gingivalis with the Toll-like receptor 2-centred pattern recognition apparatus. Cell Microbiol 8:1557-70.

55. Hajishengallis, G., M. Wang, G. J. Bagby, and S. Nelson. 2008. Importance of TLR2 in early innate immune response to acute pulmonary infection with Porphyromonas gingivalis in mice. J Immunol 181:4141-9.

56. Hajishengallis, G., M. Wang, E. Harokopakis, M. Triantafilou, and K. Triantafilou. 2006. Porphyromonas gingivalis fimbriae proactively modulate 
beta 2 integrin adhesive activity and promote binding to and internalization by macrophages. Infect Immun 74:5658-66.

57. Hajishengallis, G., M. Wang, and S. Liang. 2009. Induction of distinct TLR2mediated proinflammatory and proadhesive signaling pathways in response to Porphyromonas gingivalis fimbriae. J Immunol 182:6690-6.

58. Hajishengallis, G., M. Wang, S. Liang, M. A. Shakhatreh, D. James, S. Nishiyama, F. Yoshimura, and D. R. Demuth. 2008. Subversion of innate immunity by periodontopathic bacteria via exploitation of complement receptor-3. Adv Exp Med Biol 632:203-19.

59. Hajishengallis, G., M. Wang, S. Liang, M. Triantafilou, and K. Triantafilou. 2008. Pathogen induction of CXCR4/TLR2 cross-talk impairs host defense function. Proc Natl Acad Sci U S A 105:13532-7.

60. Hardham, J., M. Reed, J. Wong, K. King, B. Laurinat, C. Sfintescu, and R. T. Evans. 2005. Evaluation of a monovalent companion animal periodontal disease vaccine in an experimental mouse periodontitis model. Vaccine 23:314856.

61. Harokopakis, E., M. H. Albzreh, M. H. Martin, and G. Hajishengallis. 2006. TLR2 transmodulates monocyte adhesion and transmigration via Rac1- and PI3Kmediated inside-out signaling in response to Porphyromonas gingivalis fimbriae. $\mathrm{J}$ Immunol 176:7645-56.

62. Harokopakis, E., and G. Hajishengallis. 2005. Integrin activation by bacterial fimbriae through a pathway involving CD14, Toll-like receptor 2, and phosphatidylinositol-3-kinase. Eur J Immunol 35:1201-10.

63. Hawlisch, H., Y. Belkaid, R. Baelder, D. Hildeman, C. Gerard, and J. Kohl. 2005. C5a negatively regulates toll-like receptor 4 -induced immune responses. Immunity 22:415-26.

64. Hershko, D. D., B. W. Robb, G. Luo, and P. O. Hasselgren. 2002. Multiple transcription factors regulating the IL- 6 gene are activated by cAMP in cultured Caco-2 cells. Am J Physiol Regul Integr Comp Physiol 283:R1140-8.

65. Holt, S. C., and J. L. Ebersole. 2005. Porphyromonas gingivalis, Treponema denticola, and Tannerella forsythia: the "red complex", a prototype polybacterial pathogenic consortium in periodontitis. Periodontol 2000 38:72-122.

66. Huber-Lang, M., J. V. Sarma, F. S. Zetoune, D. Rittirsch, T. A. Neff, S. R. McGuire, J. D. Lambris, R. L. Warner, M. A. Flierl, L. M. Hoesel, F. Gebhard, J. G. Younger, S. M. Drouin, R. A. Wetsel, and P. A. Ward. 2006. 
Generation of $\mathrm{C} 5 \mathrm{a}$ in the absence of $\mathrm{C} 3$ : a new complement activation pathway. Nat Med 12:682-7.

67. Huber-Lang, M. S., E. M. Younkin, J. V. Sarma, S. R. McGuire, K. T. Lu, R. F. Guo, V. A. Padgaonkar, J. T. Curnutte, R. Erickson, and P. A. Ward. 2002. Complement-Induced Impairment of Innate Immunity During Sepsis. J Immunol 169:3223-3231.

68. Imamura, T., A. Banbula, P. J. Pereira, J. Travis, and J. Potempa. 2001. Activation of human prothrombin by arginine-specific cysteine proteinases (Gingipains R) from porphyromonas gingivalis. J Biol Chem 276:18984-91.

69. Iwasaki, A., and R. Medzhitov. 2010. Regulation of adaptive immunity by the innate immune system. Science 327:291-5.

70. Janeway, C. A., Jr., and R. Medzhitov. 2002. Innate immune recognition. Annu Rev Immunol 20:197-216.

71. Jin, M. S., S. E. Kim, J. Y. Heo, M. E. Lee, H. M. Kim, S. G. Paik, H. Lee, and J. O. Lee. 2007. Crystal structure of the TLR1-TLR2 heterodimer induced by binding of a tri-acylated lipopeptide. Cell 130:1071-82.

72. Kantarci, A., H. Hasturk, and T. E. Van Dyke. 2006. Host-mediated resolution of inflammation in periodontal diseases. Periodontol 2000 40:144-63.

73. Kebschull, M., R. T. Demmer, and P. N. Papapanou. 2010. "Gum bug, leave my heart alone!"--epidemiologic and mechanistic evidence linking periodontal infections and atherosclerosis. J Dent Res 89:879-902.

74. Kesavalu, L., S. Sathishkumar, V. Bakthavatchalu, C. Matthews, D. Dawson, M. Steffen, and J. L. Ebersole. 2007. Rat model of polymicrobial infection, immunity, and alveolar bone resorption in periodontal disease. Infect Immun $75: 1704-12$.

75. Kim, H. M., B. S. Park, J. I. Kim, S. E. Kim, J. Lee, S. C. Oh, P. Enkhbayar, N. Matsushima, H. Lee, O. J. Yoo, and J. O. Lee. 2007. Crystal structure of the TLR4-MD-2 complex with bound endotoxin antagonist Eritoran. Cell 130:90617.

76. Kim, S., K. B. Elkon, and X. Ma. 2004. Transcriptional suppression of interleukin-12 gene expression following phagocytosis of apoptotic cells. Immunity $21: 643-53$.

77. Kimura, Y., T. Miwa, L. Zhou, and W. C. Song. 2008. Activator-specific requirement of properdin in the initiation and amplification of the alternative pathway complement. Blood 111:732-40. 
78. Kinane, D. F., and G. Hajishengallis. 2009. Polymicrobial infections, biofilms, and beyond. J Clin Periodontol 36:404-5.

79. Kinane, D. F., M. Peterson, and P. G. Stathopoulou. 2006. Environmental and other modifying factors of the periodontal diseases. Periodontol 2000 40:107-19.

80. Kline, K. A., S. Falker, S. Dahlberg, S. Normark, and B. HenriquesNormark. 2009. Bacterial adhesins in host-microbe interactions. Cell Host Microbe 5:580-92.

81. Klos, A., A. J. Tenner, K. O. Johswich, R. R. Ager, E. S. Reis, and J. Kohl. 2009. The role of the anaphylatoxins in health and disease. Mol Immunol $46: 2753-66$.

82. Krauss, J. L., J. Potempa, J. D. Lambris, and G. Hajishengallis. 2010. Complementary Tolls in the periodontium: how periodontal bacteria modify complement and Toll-like receptor responses to prevail in the host. Periodontol $200052: 141-62$.

83. Kumpf, O., and R. R. Schumann. 2008. Genetic influence on bloodstream infections and sepsis. Int J Antimicrob Agents 32 Suppl 1:S44-50.

84. Kusumoto, Y., H. Hirano, K. Saitoh, S. Yamada, M. Takedachi, T. Nozaki, Y. Ozawa, Y. Nakahira, T. Saho, H. Ogo, Y. Shimabukuro, H. Okada, and S. Murakami. 2004. Human gingival epithelial cells produce chemotactic factors interleukin-8 and monocyte chemoattractant protein-1 after stimulation with Porphyromonas gingivalis via toll-like receptor 2. J Periodontol 75:370-9.

85. la Sala, A., M. Gadina, and B. L. Kelsall. 2005. G(i)-protein-dependent inhibition of IL-12 production is mediated by activation of the phosphatidylinositol 3-kinase-protein 3 kinase B/Akt pathway and JNK. J Immunol 175:2994-9.

86. Lalla, E., I. B. Lamster, M. Feit, L. Huang, A. Spessot, W. Qu, T. Kislinger, Y. Lu, D. M. Stern, and A. M. Schmidt. 2000. Blockade of RAGE suppresses periodontitis-associated bone loss in diabetic mice. J Clin Invest 105:1117-24.

87. Lambris, J. D. 2008. Current topics in complement II, vol. Springer, New York, NY.

88. Lambris, J. D., D. Ricklin, and B. V. Geisbrecht. 2008. Complement evasion by human pathogens. Nat Rev Microbiol 6:132-42.

89. Lamont, R. J., and H. F. Jenkinson. 1998. Life below the gum line: pathogenic mechanisms of Porphyromonas gingivalis. Microbiol Mol Biol Rev 62:1244-63. 
90. Lappegard, K. T., D. Christiansen, A. Pharo, E. B. Thorgersen, B. C. Hellerud, J. Lindstad, E. W. Nielsen, G. Bergseth, D. Fadnes, T. G. Abrahamsen, E. A. Hoiby, L. Schejbel, P. Garred, J. D. Lambris, M. Harboe, and T. E. Mollnes. 2009. Human genetic deficiencies reveal the roles of complement in the inflammatory network: lessons from nature. Proc Natl Acad Sci U S A 106:15861-6.

91. Lavelle, E. C., A. Jarnicki, E. McNeela, M. E. Armstrong, S. C. Higgins, O. Leavy, and K. H. Mills. 2004. Effects of cholera toxin on innate and adaptive immunity and its application as an immunomodulatory agent. J Leukoc Biol 75:756-63.

92. Lemaitre, B., E. Nicolas, L. Michaut, J. M. Reichhart, and J. A. Hoffmann. 1996. The dorsoventral regulatory gene cassette spatzle/Toll/cactus controls the potent antifungal response in Drosophila adults. Cell 86:973-83.

93. Liang, S., K. B. Hosur, H. Domon, and G. Hajishengallis. 2010. Periodontal inflammation and bone loss in aged mice. J Periodontal Res 45:574-8.

94. Liang, S., M. Wang, K. Triantafilou, M. Triantafilou, H. F. Nawar, M. W. Russell, T. D. Connell, and G. Hajishengallis. 2007. The A subunit of type IIb enterotoxin (LT-IIb) suppresses the proinflammatory potential of the B subunit and its ability to recruit and interact with TLR2. J Immunol 178:4811-9.

95. Lubberts, E. 2008. IL-17/Th17 targeting: on the road to prevent chronic destructive arthritis? Cytokine 41:84-91.

96. Magalhaes, M. A., C. X. Sun, M. Glogauer, and R. P. Ellen. 2008. The major outer sheath protein of Treponema denticola selectively inhibits Racl activation in murine neutrophils. Cell Microbiol 10:344-54.

97. Marder, S. R., D. E. Chenoweth, I. M. Goldstein, and H. D. Perez. 1985. Chemotactic responses of human peripheral blood monocytes to the complementderived peptides C5a and C5a des Arg. J Immunol 134:3325-31.

98. Markiewski, M. M., R. A. DeAngelis, F. Benencia, S. K. Ricklin-Lichtsteiner, A. Koutoulaki, C. Gerard, G. Coukos, and J. D. Lambris. 2008. Modulation of the antitumor immune response by complement. Nat Immunol 9:1225-35.

99. Markiewski, M. M., and J. D. Lambris. 2007. The role of complement in inflammatory diseases from behind the scenes into the spotlight. Am J Pathol $171: 715-27$.

100. Martin, E., C. Nathan, and Q. W. Xie. 1994. Role of interferon regulatory factor 1 in induction of nitric oxide synthase. J Exp Med 180:977-84. 
101. Martin, M., K. Rehani, R. S. Jope, and S. M. Michalek. 2005. Toll-like receptor-mediated cytokine production is differentially regulated by glycogen synthase kinase 3. Nat Immunol 6:777-84.

102. McCarthy, K., and P. M. Henson. 1979. Induction of lysosomal enzyme secretion by alveolar macrophages in response to the purified complement fragments C5a and C5a des-arg. J Immunol 123:2511-7.

103. McDowell, J. V., B. Huang, J. C. Fenno, and R. T. Marconi. 2009. Analysis of a unique interaction between the complement regulatory protein factor $\mathrm{H}$ and the periodontal pathogen Treponema denticola. Infect Immun 77:1417-25.

104. Medzhitov, R., P. Preston-Hurlburt, and C. A. Janeway, Jr. 1997. A human homologue of the Drosophila Toll protein signals activation of adaptive immunity. Nature 388:394-7.

105. Mevorach, D., J. O. Mascarenhas, D. Gershov, and K. B. Elkon. 1998. Complement-dependent clearance of apoptotic cells by human macrophages. $\mathbf{J}$ Exp Med 188:2313-20.

106. Millin, D. J., and M. H. Smith. 1961. Nature and composition of dental plaque. Nature 189:664-5.

107. Monk, P. N., A. M. Scola, P. Madala, and D. P. Fairlie. 2007. Function, structure and therapeutic potential of complement $\mathrm{C} 5 \mathrm{a}$ receptors. Br J Pharmacol $152: 429-48$.

108. Montminy, S. W., N. Khan, S. McGrath, M. J. Walkowicz, F. Sharp, J. E. Conlon, K. Fukase, S. Kusumoto, C. Sweet, K. Miyake, S. Akira, R. J. Cotter, J. D. Goguen, and E. Lien. 2006. Virulence factors of Yersinia pestis are overcome by a strong lipopolysaccharide response. Nat Immunol 7:1066-73.

109. Morgan, B. P. 1999. Regulation of the complement membrane attack pathway. Crit Rev Immunol 19:173-98.

110. Mori, Y., A. Yoshimura, T. Ukai, E. Lien, T. Espevik, and Y. Hara. 2003. Immunohistochemical localization of Toll-like receptors 2 and 4 in gingival tissue from patients with periodontitis. Oral Microbiol Immunol 18:54-8.

111. Mydel, P., Y. Takahashi, H. Yumoto, M. Sztukowska, M. Kubica, F. C. Gibson, 3rd, D. M. Kurtz, Jr., J. Travis, L. V. Collins, K. A. Nguyen, C. A. Genco, and J. Potempa. 2006. Roles of the host oxidative immune response and bacterial antioxidant rubrerythrin during Porphyromonas gingivalis infection. PLoS Pathog 2:e76. 
112. Nagata, A., T. Tanaka, A. Minezawa, M. Poyurovsky, T. Mayama, S. Suzuki, N. Hashimoto, T. Yoshida, K. Suyama, A. Miyata, H. Hosokawa, T.

Nakayama, and I. Tatsuno. 2009. cAMP activation by PACAP/VIP stimulates IL-6 release and inhibits osteoblastic differentiation through VPAC2 receptor in osteoblastic MC3T3 cells. J Cell Physiol 221:75-83.

113. Natarajan, M., K. M. Lin, R. C. Hsueh, P. C. Sternweis, and R. Ranganathan. 2006. A global analysis of cross-talk in a mammalian cellular signalling network. Nat Cell Biol 8:571-80.

114. Nordahl, E. A., V. Rydengard, P. Nyberg, D. P. Nitsche, M. Morgelin, M. Malmsten, L. Bjorck, and A. Schmidtchen. 2004. Activation of the complement system generates antibacterial peptides. Proc Natl Acad Sci U S A 101:16879-84.

115. Novak, E. A., H. Shao, C. A. Daep, and D. R. Demuth. 2010. Autoinducer-2 and $\mathrm{QseC}$ control biofilm formation and in vivo virulence of Aggregatibacter actinomycetemcomitans. Infect Immun 78:2919-26.

116. O'Neill, L. A. 2008. When signaling pathways collide: positive and negative regulation of toll-like receptor signal transduction. Immunity 29:12-20.

117. O'Neill, L. A., and A. G. Bowie. 2007. The family of five: TIR-domaincontaining adaptors in Toll-like receptor signalling. Nat Rev Immunol 7:353-64.

118. Onishi, S., K. Honma, S. Liang, P. Stathopoulou, D. Kinane, G. Hajishengallis, and A. Sharma. 2008. Toll-like receptor 2-mediated interleukin8 expression in gingival epithelial cells by the Tannerella forsythia leucine-rich repeat protein BspA. Infect Immun 76:198-205.

119. Oppmann, B., R. Lesley, B. Blom, J. C. Timans, Y. Xu, B. Hunte, F. Vega, N. Yu, J. Wang, K. Singh, F. Zonin, E. Vaisberg, T. Churakova, M. Liu, D. Gorman, J. Wagner, S. Zurawski, Y. Liu, J. S. Abrams, K. W. Moore, D. Rennick, R. de Waal-Malefyt, C. Hannum, J. F. Bazan, and R. A. Kastelein. 2000. Novel p19 protein engages IL-12p40 to form a cytokine, IL-23, with biological activities similar as well as distinct from IL-12. Immunity 13:715-25.

120. Otto, M., H. Hawlisch, P. N. Monk, M. Muller, A. Klos, C. L. Karp, and J. Kohl. 2004. C5a mutants are potent antagonists of the C5a receptor (CD88) and of C5L2: position 69 is the locus that determines agonism or antagonism. J Biol Chem 279:142-51.

121. Parry, G. C., and N. Mackman. 1997. Role of cyclic AMP response elementbinding protein in cyclic AMP inhibition of NF-kappaB-mediated transcription. J Immunol 159:5450-6. 
122. Patters, M. R., C. E. Niekrash, and N. P. Lang. 1989. Assessment of complement cleavage in gingival fluid during experimental gingivitis in man. $\mathbf{J}$ Clin Periodontol 16:33-7.

123. Pihlstrom, B. L., B. S. Michalowicz, and N. W. Johnson. 2005. Periodontal diseases. Lancet 366:1809-20.

124. Polak, D., A. Wilensky, L. Shapira, A. Halabi, D. Goldstein, E. I. Weiss, and Y. Houri-Haddad. 2009. Mouse model of experimental periodontitis induced by Porphyromonas gingivalis/Fusobacterium nucleatum infection: bone loss and host response. J Clin Periodontol 36:406-10.

125. Popadiak, K., J. Potempa, K. Riesbeck, and A. M. Blom. 2007. Biphasic effect of gingipains from Porphyromonas gingivalis on the human complement system. J Immunol 178:7242-50.

126. Potempa, J., and R. N. Pike. 2009. Corruption of innate immunity by bacterial proteases. J Innate Immun 1:70-87.

127. Potempa, M., J. Potempa, T. Kantyka, K. A. Nguyen, K. Wawrzonek, S. P. Manandhar, K. Popadiak, K. Riesbeck, S. Eick, and A. M. Blom. 2009. Interpain A, a cysteine proteinase from Prevotella intermedia, inhibits complement by degrading complement factor C3. PLoS Pathog 5:e1000316.

128. Potempa, M., J. Potempa, M. Okroj, K. Popadiak, S. Eick, K. A. Nguyen, K. Riesbeck, and A. M. Blom. 2008. Binding of complement inhibitor C4b-binding protein contributes to serum resistance of Porphyromonas gingivalis. J Immunol $181: 5537-44$.

129. Ren, L., W. K. Leung, R. P. Darveau, and L. Jin. 2005. The expression profile of lipopolysaccharide-binding protein, membrane-bound CD14, and toll-like receptors 2 and 4 in chronic periodontitis. J Periodontol 76:1950-9.

130. Ricklin, D., G. Hajishengallis, K. Yang, and J. D. Lambris. 2010. Complement: a key system for immune surveillance and homeostasis. Nat Immunol 11:785-97.

131. Ricklin, D., and J. D. Lambris. 2007. Complement-targeted therapeutics. Nat Biotechnol 25:1265-75.

132. Riedemann, N. C., R. F. Guo, K. D. Bernacki, J. S. Reuben, I. J. Laudes, T. A. Neff, H. Gao, C. Speyer, V. J. Sarma, F. S. Zetoune, and P. A. Ward. 2003. Regulation by C5a of neutrophil activation during sepsis. Immunity 19:193-202.

133. Rittirsch, D., M. A. Flierl, B. A. Nadeau, D. E. Day, M. Huber-Lang, C. R. Mackay, F. S. Zetoune, N. P. Gerard, K. Cianflone, J. Kohl, C. Gerard, J. V. 
Sarma, and P. A. Ward. 2008. Functional roles for C5a receptors in sepsis. Nat Med 14:551-7.

134. Rittirsch, D., M. A. Flierl, and P. A. Ward. 2008. Harmful molecular mechanisms in sepsis. Nat Rev Immunol 8:776-87.

135. Rosenberger, C. M., and B. B. Finlay. 2003. Phagocyte sabotage: disruption of macrophage signalling by bacterial pathogens. Nat Rev Mol Cell Biol 4:385-96.

136. Ross, P. J., E. C. Lavelle, K. H. Mills, and A. P. Boyd. 2004. Adenylate cyclase toxin from Bordetella pertussis synergizes with lipopolysaccharide to promote innate interleukin- 10 production and enhances the induction of $\mathrm{Th} 2$ and regulatory $\mathrm{T}$ cells. Infect Immun 72:1568-79.

137. Roy, C. R., and E. S. Mocarski. 2007. Pathogen subversion of cell-intrinsic innate immunity. Nat Immunol 8:1179-87.

138. Sato, K. 2008. Th17 cells and rheumatoid arthritis--from the standpoint of osteoclast differentiation. Allergol Int 57:109-14.

139. Schenkein, H. A., and C. R. Berry. 1991. Activation of complement by Treponema denticola. J Dent Res 70:107-10.

140. Sharma, A., S. Inagaki, K. Honma, C. Sfintescu, P. J. Baker, and R. T. Evans. 2005. Tannerella forsythia-induced alveolar bone loss in mice involves leucine-rich-repeat BspA protein. J Dent Res 84:462-7.

141. Shin, H., M. Mally, M. Kuhn, C. Paroz, and G. R. Cornelis. 2007. Escape from immune surveillance by Capnocytophaga canimorsus. J Infect Dis 195:37586.

142. Silverstein, A. M. 2002. The collected papers of Paul Ehrlich : why was volume 4 never published? Bull Hist Med 76:335-9.

143. Slaney, J. M., A. Gallagher, J. Aduse-Opoku, K. Pell, and M. A. Curtis. 2006. Mechanisms of resistance of Porphyromonas gingivalis to killing by serum complement. Infect Immun 74:5352-61.

144. Socransky, S. J., R. G. Pirrallo, and J. M. Rubin. 1998. Out-of-hospital treatment of hypoglycemia: refusal of transport and patient outcome. Acad Emerg Med 5:1080-5.

145. Socransky, S. S., and A. D. Haffajee. 2005. Periodontal microbial ecology. Periodontol 2000 38:135-87. 
146. Socransky, S. S., A. D. Haffajee, M. A. Cugini, C. Smith, and R. L. Kent, Jr. 1998. Microbial complexes in subgingival plaque. J Clin Periodontol 25:134-44.

147. Sunahara, R. K., and R. Taussig. 2002. Isoforms of mammalian adenylyl cyclase: multiplicities of signaling. Mol Interv 2:168-84.

148. Tabeta, K., K. Yamazaki, S. Akashi, K. Miyake, H. Kumada, T. Umemoto, and H. Yoshie. 2000. Toll-like receptors confer responsiveness to lipopolysaccharide from Porphyromonas gingivalis in human gingival fibroblasts. Infect Immun 68:3731-5.

149. Takabayashi, T., E. Vannier, B. D. Clark, N. H. Margolis, C. A. Dinarello, J. F. Burke, and J. A. Gelfand. 1996. A new biologic role for C3a and C3a desArg: regulation of TNF-alpha and IL-1 beta synthesis. J Immunol 156:345560 .

150. Teng, Y. T. 2006. Protective and destructive immunity in the periodontium: Part 2--T-cell-mediated immunity in the periodontium. J Dent Res 85:209-19.

151. Tonetti, M. S., F. D'Aiuto, L. Nibali, A. Donald, C. Storry, M. Parkar, J. Suvan, A. D. Hingorani, P. Vallance, and J. Deanfield. 2007. Treatment of periodontitis and endothelial function. N Engl J Med 356:911-20.

152. Triantafilou, K., M. Triantafilou, and R. L. Dedrick. 2001. A CD14independent LPS receptor cluster. Nat Immunol 2:338-45.

153. Trinchieri, G. 2003. Interleukin-12 and the regulation of innate resistance and adaptive immunity. Nat Rev Immunol 3:133-46.

154. Ukai, T., H. Yumoto, F. C. Gibson, 3rd, and C. A. Genco. 2008. Macrophageelicited osteoclastogenesis in response to bacterial stimulation requires Toll-like receptor 2-dependent tumor necrosis factor-alpha production. Infect Immun 76:812-9.

155. Wagner, E., and M. M. Frank. 2010. Therapeutic potential of complement modulation. Nat Rev Drug Discov 9:43-56.

156. Wall, E. A., J. R. Zavzavadjian, M. S. Chang, B. Randhawa, X. Zhu, R. C. Hsueh, J. Liu, A. Driver, X. R. Bao, P. C. Sternweis, M. I. Simon, and I. D. Fraser. 2009. Suppression of LPS-induced TNF-alpha production in macrophages by cAMP is mediated by PKA-AKAP95-p105. Sci Signal 2:ra28.

157. Wang, M., J. L. Krauss, H. Domon, K. B. Hosur, S. Liang, P. Magotti, M. Triantafilou, K. Triantafilou, J. D. Lambris, and G. Hajishengallis. 2010. Microbial hijacking of complement-toll-like receptor crosstalk. Sci Signal 3:ra11. 
158. Wang, M., M. A. Shakhatreh, D. James, S. Liang, S. Nishiyama, F. Yoshimura, D. R. Demuth, and G. Hajishengallis. 2007. Fimbrial proteins of porphyromonas gingivalis mediate in vivo virulence and exploit TLR2 and complement receptor 3 to persist in macrophages. J Immunol 179:2349-58.

159. Wang, P. L., K. Ohura, T. Fujii, M. Oido-Mori, Y. Kowashi, M. Kikuchi, Y. Suetsugu, and J. Tanaka. 2003. DNA microarray analysis of human gingival fibroblasts from healthy and inflammatory gingival tissues. Biochem Biophys Res Commun 305:970-3.

160. Ward, P. A. 2004. The dark side of C5a in sepsis. Nat Rev Immunol 4:133-42.

161. Wingrove, J. A., R. G. DiScipio, Z. Chen, J. Potempa, J. Travis, and T. E. Hugli. 1992. Activation of complement components C3 and C5 by a cysteine proteinase (gingipain-1) from Porphyromonas (Bacteroides) gingivalis. J Biol Chem 267:18902-7.

162. Ximenez-Fyvie, L. A., A. D. Haffajee, and S. S. Socransky. 2000. Microbial composition of supra- and subgingival plaque in subjects with adult periodontitis. J Clin Periodontol 27:722-32.

163. Yilmaz, O. 2008. The chronicles of Porphyromonas gingivalis: the microbium, the human oral epithelium and their interplay. Microbiology 154:2897-903.

164. Yoshimura, A., T. Kaneko, Y. Kato, D. T. Golenbock, and Y. Hara. 2002. Lipopolysaccharides from periodontopathic bacteria Porphyromonas gingivalis and Capnocytophaga ochracea are antagonists for human toll-like receptor 4. Infect Immun 70:218-25.

165. Zhang, X., Y. Kimura, C. Fang, L. Zhou, G. Sfyroera, J. D. Lambris, R. A. Wetsel, T. Miwa, and W. C. Song. 2007. Regulation of Toll-like receptormediated inflammatory response by complement in vivo. Blood 110:228-36. 


\section{CURRICULUM VITAE}

\section{Jennifer Lynn Krauss}

University of Louisville

School of Medicine, Department of Microbiology and Immunology

School of Dentistry, Department of Periodontics, Endodontics, and Oral Hygiene

501 South Preston Street, Room 209

Louisville, KY 40202

\section{Education and training:}

Bachelor of Arts in Biology: University of Louisville, 5/2003

Master of Science: University of Louisville, 8/2006

Ph.D candidate: University of Louisville, 2004-present

\section{Peer-reviewed publications:}

Jennifer L. Krauss, Jan Potempa, John D. Lambris, and George Hajishengallis. Complementary Tolls in the periodontium: how periodontal bacteria modifiy complement and Toll-like receptor responses to prevail in the host. Periodontology 2000, vol.52, 2010, 141-162.

Min Wang, Jennifer L. Krauss, Hisanori Domon, Kavita B. Hosur, Shuang Liang, Paola Magotti, Martha Triantafilou, Kathy Triantafilou, John D. Lambris and George Hajishengallis. Microbial hijacking of complement Toll-like receptor crosstalk. Science Signaling, vol.3, 2010, ra11.

Jennifer L. Krauss, Shuang Liang, Megan L. McIntosh, Mehmet A. Eskan and George Hajishengallis. Mouse models of host-pathogen interactions and 
inflammation.Periodontal Disease: Methods and Protocols, Methods in Molecular Biology Series 2010.

Jennifer L. Krauss, Shuang Liang, Megan L. McIntosh, and George Hajishengallis.. The C5a receptor impairs IL-12-dependent clearance of Porphyromonas gingivalis and is required for induction of periodontal bone loss. Manuscript in revision. Journal of Immunology, 2010.

\section{Presented Abstracts:}

Pre-doctoral Research:

Jennifer L. Krauss, Charla Mutchler, Josh B. Lane, Jason Hudkins, Jessica Miles and Rey A. Carabeo. Identification of two distinct, but functionally redundant pathways of Chlamydial invasion. Presented at Research Louisville, Louisville, KY. 10/2005.

Jennifer L. Krauss and Rey A. Carabeo. Growth characteristics of Chlamydia trachomatis in human monocyte-derived dendritic cells. Presented at the $3^{\text {rd }}$ Bienniel Meeting of the Chlamydia Basic Science Research Society, Louisville, KY. 03/2007.

Jennifer L. Krauss and Rey A. Carabeo. Fate of Chlamydia trachomatis in human phagocytic cells. Presented at the $14^{\text {th }}$ Annual Midwest Microbial Pathogenesis Meeting, Chicago, IL. 09/2007.

Jennifer L. Krauss, Min Wang, Shuang Liang, John D. Lambris and George Hajishengallis. Manipulation of the complement system by Porphyromonas gingivalis. . Presented at the Gordon Research Conference on Periodontal Disease. New Haven, New Hampshire. 08/ 2009.

Jennifer L. Krauss, Kathy Triantafilou, John D. Lambris and George Hajishengallis. 'Complementary' Immnue Evasion Strategies of Porphyromonas gingivalis. Presented at the International Complement Workshop XXIII, New York, NY. 08/ 2010.

Jennifer L. Krauss, Kathy Triantafilou, John D. Lambris and George Hajishengallis. 'Complementary' Immnue Evasion Oral Pathogen Porphyromonas gingivalis. Presented at Research Louisville, Louisville, KY. 10/2010. 


\section{Presented Seminar Lectures:}

Pre-doctoral Research:

The Role of Human Dendritic Cells in Chlamydial Pathogenesis. Presented to the University of Louisville Department of Microbiology and Immunology. 11/2006

P. gingivalis-induced TLR/Complement Receptor Cross-Talk and Innate Immune Function Presented to the University of Louisville Department of Microbiology and Immunology. 08/2008.

Complement-TLR Crosstalk and Microbial Immune Evasion. Presented to the University of Louisville Department of Microbiology and Immunology. 09/2009.

\section{Mentorship:}

Amanda Brinkworth, Ph.D. Candidate (University of Louisville, Dept. of Microbiology and Immunology). 10/2005-12/2007. Role of Chlamydial-derived heat-shock protein in promoting tarp-induced invasion of Chlamydia trachomatis.

Megan McIntosh, Ph.D. Candidate (University of Louisville, Dept. of Microbiology and Immunology). 2/2009-current. Counteracting microbial immune evasion for the treatment of periodontitis.

\section{Teaching Experience:}

Undergraduate Teaching Assistant 1/2003-6/2003

- Principles of Systematics

Graduate Teaching Assistant. 8/2003-6/2004

- Clinical Microbiology

Graduate Teaching Assistant. 1/2010-6/2010

- Medical Microbiology

\section{Awards:}

The Integrated Programs in Biomedical Sciences Fellowship. 08/04.

Scientific Poster Competition for Research Louisville, First Prize. 10/10. 